UNIVERSITÉ DU QUÉBEC

\author{
MÉMOIRE PRÉSENTÉ À \\ L'UNIVERSITÉ DU QUÉBEC À CHICOUTIMI \\ COMME EXIGENCE PARTIELLE \\ DE LA MAITRISE EN ART
}

PAR

ANDRÉE FORGET

VERS LA CONVIVIALITÉ CRÉATRICE :

UN PARCOURS D'ACCOMPAGNEMENT ARTISTIQUE AXÉ SUR L'EXPÉRIENCE ESTHÉTIQUE CONSCIENTISÉE

Janvier 2012 
Ce travail de recherche a été réalisé

à l'Université du Québec à Chicoutimi

dans le cadre du programme

de la Maîtrise en art

CONCENTRATION : ENSEIGNEMENT ET TRANSMISSION

Pour l'obtention du grade : Maître ès arts M.A. 


\section{RÉSUMÉ}

Ce mémoire consiste en une démarche autoréflexive sur mon parcours en art. Ce parcours de sept ans a culminé dans la création d'ateliers d'exploration picturale prenant la forme d'un accompagnement artistique dans la convivialité créatrice. L'optique de cette recherche est d'approfondir ma compréhension en regard de ce processus singulier d'ateliers : d'où il vient, en quoi consiste-t-il et où peut-il mener. L'objectif est d'élucider la teneur et la portée de ma pratique d'artiste accompagnatrice d'adultes néophytes en matière d'expression picturale pour être à même d'en dégager un sens renouvelé. Afin de rencontrer ces objectifs, j'ai créé ma propre méthode pour ce mémoire qui consiste en un itinéraire d'écriture ordonné. Le style narratif et l'essai-récit ont été privilégiés comme genre d'écriture.

Le premier chapitre présente mes ateliers et les différents aspects qui m'amènent à concevoir le phénomène de la convivialité créatrice et de l'expérience esthétique conscientisée comme voie collective de création et de transformation de soi. Ce chapitre comporte également un exposé des concepts clés qui sous-tendent ma pratique d'artiste accompagnatrice.

Le deuxième chapitre traite plus spécifiquement des aspects épistémologiques et méthodologiques. J'y présente le schéma de l'itinéraire que j'ai créé afin d'orienter mon processus d'écriture. Également, y figure la genèse conceptuelle de ce schéma, de même que ses composantes structurelles et fonctionnelles.

Finalement, le troisième chapitre, abordé davantage sous l'angle du récit et de la narration, consiste à approfondir certains aspects de mon parcours artistique et à formuler le sens émergeant de ce travail de recherche.

Ce travail de recherche inaugure un nouvel ordre dans ma conscience. Un ordre que l'art a rendu manifeste. Un ordre qui fait sens. Je peux maintenant m'actualiser à partir d'un registre cognitif et sensible beaucoup plus vaste. À cet égard, l'écriture de ce mémoire m'aura aussi permis de me réapproprier, de façon personnelle et originale, ma propre dimension artistique, ce qui logiquement me rend apte à aider l'autre à faire de même. C'est en cela partie prenante d'un acte de transmission, ce qui par le fait même vient optimiser l'efficience de ma pratique d'artiste accompagnatrice.

MOTS CLÉS :

ACCOMPAGNEMENT ARTISTIQUE - ADULTE - ATELIER -

AUTOACCOMPAGNEMENT- CONVIVIALITÉ - EXPÉRIENCE PICTURALE EXPÉRIENCE ESTHÉTIQUE - PROCESSUS - RÉCIT 


\section{REMERCIEMENTS}

Au cours de ce travail de recherche, il m'est arrivé souvent d'être étonnée du fait que la vie ait mis sur ma route exactement les deux personnes dont $\mathrm{j}$ 'avais besoin pour m'aider à réaliser ce projet de maîtrise. Tout d'abord, Diane Laurier, ma directrice de recherche, que je tiens à remercier du fond du coeur pour sa disponibilité, sa patience, son expertise et sa vision d'artiste pédagogue. Chez elle, l'amour de l'humain et le respect qu'elle porte à sa profession sont remarquables. C'est sûrement ce qui la pousse, alors qu'elle travaille avec des artistes, à impulser tant de douceur à sa rigueur. Diane est une femme attachante, intense et profondément humaine. $\grave{A}$ travers son accompagnement d'artiste pédagogue, $\mathrm{j}$ 'ai senti tout son respect de l'art et de l'artiste sans pour autant qu'elle n'eut à y sacrifier précision et méthode.

Je tiens aussi à remercier Danielle Boutet, ma codirectrice, que j'ai eu la chance de rencontrer à une étape critique. Toutefois, à ce moment-là, je ne savais pas que tout ce que son contact m'apporterait dépasserait, et de loin, ce que moi-même je pouvais en imaginer. Je lui suis infiniment reconnaissante de la confiance qu'elle a eue en moi et en mon travail. Nos rencontres, nos discussions et nos échanges par courriel ont fait en sorte que ma vision de l'art et de l'artiste s'est enrichie et simplifiée tout à la fois. De mon point de vue, Danielle est une artiste visionnaire qui participe, avec d'autres, à l'ouverture d'un champ de conscience artistique dont le début de ce XXIème siècle a grandement besoin.

Mes chaleureux remerciements à Denys Tremblay qui a généreusement accepté d'être membre du jury malgré ses nombreuses occupations. Il n'est pas sans savoir combien sa présence fut significative pour moi. Un grand merci également à Danielle Nolin, sa participation en tant que jury externe a été fort appréciée.

Je veux aussi remercier d'une façon toute particulière Jean Luc D'Aoust, mon compagnon d'âme dont la sensibilité artistique et la générosité de cœur ont su se transposer dans la matière tant de fois, ce sans aucune hésitation et de façon toute naturelle. Pour un artiste, disposer d'un atelier, du matériel nécessaire et d'une tranquillité d'esprit pour créer est ce qu'il y a de plus précieux. Outre sa présence amoureuse, c'est ce qu'il m'a offert, et pour cela je lui en suis immensément reconnaissante.

Merci à Robert D'Aoust pour la relecture de ce document. Son aide a été des plus précieuses. Merci aussi à ma grande amie Sylvie Gagnon, art-thérapeute, pour son écoute, son encouragement et le soutien constant dont elle m'a toujours gratifiée.

Mon appréciation va également à tous ces convives créateurs qui ont touché mon être. En me faisant confiance, ils ont appris à faire confiance en l'art. Un merci tout spécial à Rébecca, Normand, Nadine et Martine, qui m'ont si gentiment fourni leur témoignage sur leur vécu d'atelier. 
À Sélissa, Pierre-Yves, Mickaël et Amélie

À Jean Luc 
En tant qu'accompagnatrice, mon médium est l'art, en tant qu'artiste, mon médium est l'énergie humaine.

A.F. 


\section{TABLE DES MATIÈRES}

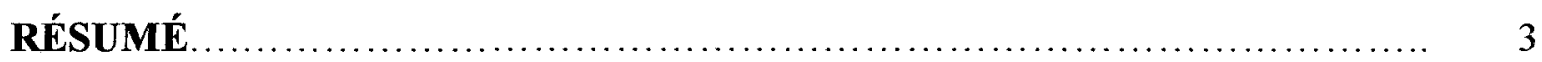

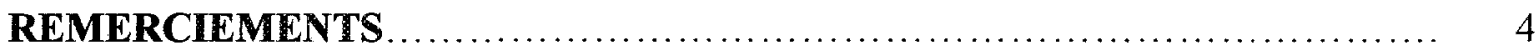

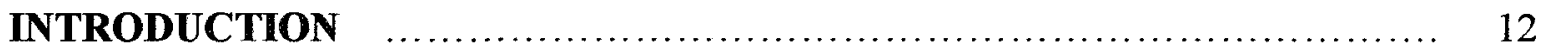

CHAPITRE I

DE L'INSPIRATION À L'EXPLORATION :

DES ATELIERS CONVIVIAUX D'EXPLORATION PICTURALE AXÉS SUR

L'EXPÉRIENCE ESTHÉTIQUE CONSCIENTISÉE............................. 14

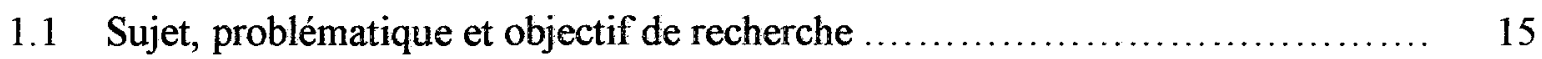

1.1.1 Origine du sujet : Un voyage inspirant .............................. 17

1.1.2 Problématique : Un mouvement propulseur.......................... 18

1.1.3 Objectif de recherche : Une quête de sens............................ 22

1.2 Définitions des concepts clés.......................................... 24

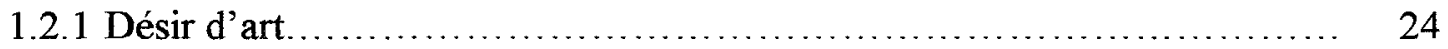

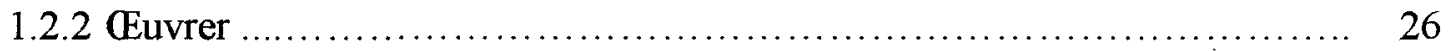

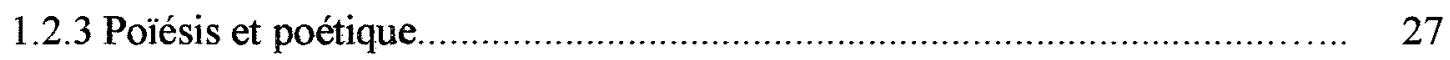

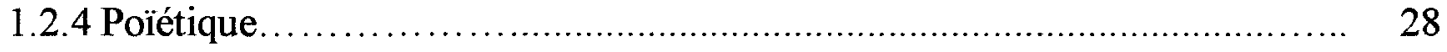

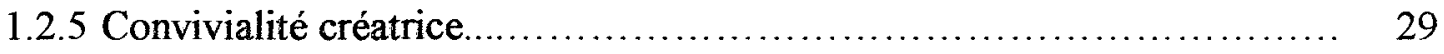

1.2.6 Expérience esthétique.......................................... 31

1.2.7 Accompagnement.............................................. 33

CHAPITRE II

DE L'EXPLORATION À LA MISE EN ORDRE : UN PARCOURS

MÉTHODOLOGIQUE LAANT LA CRÉATION, LA STRUCTURE ET

L'ORDONNANCE DE LA RECHERCHE ................................ 36

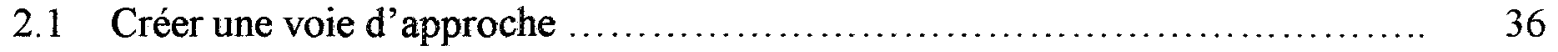

2.1.1 Bâtir une banque de données ..................................... 37

2.1.2 Autoriser l'écriture ................................................. 39

2.1.3 Ordonner le matériel .......................................... 42

2.1.4 Orienter l'ordre .................................................. 43 
2.2 Structurer la compréhension. ............................................... 46

2.2.1 Formaliser ma poétique ............................................. 47

2.2.2 Explorer ma polyphonie personnelle............................... 48

2.2.3 Tracer ma voie................................................... 49

2.2.4 Franchir le passage du sujet écrivant................................. $\quad 50$

2.2.5 Dialoguer avec mes textes............................................. $\quad 52$

2.2.6 Réguler ma réflexion............................................... 53

2.3 Ordonnancer et schématiser l'itinéraire...................................... 55

2.3.1 Ordre caché et origine du sens : écriture descriptive................................. 59

2.3.2 Ordre acté et mouvement : écriture réflexive.............................. 66

2.3.3 Ordre dévoilé et direction : écriture intégrative....................... 72

2.3.4 Ordre communiqué et sens : écriture créative .......................... 73

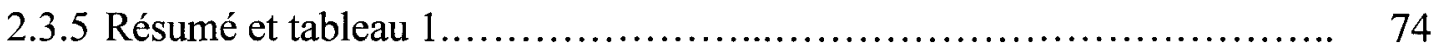

\section{CHAPITRE III}

DE LA MISE EN ORDRE À LA FORMULATION DU SENS.................... 75

3.1 Ordre caché : dire et décrire l'élan inspirant.............................. 75

3.1.1 Surprise par l'art.............................................................................. 75

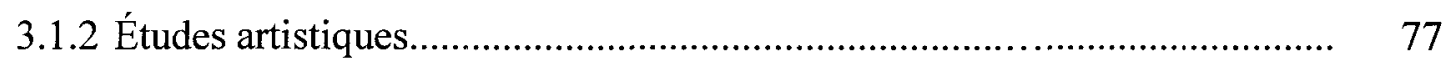

3.1.3 Création des ateliers....................................................................... $\quad 79$

3.2 Ordre acté : explorer et réfléchir le processus d'atelier......................... 90

3.2.1 Base structurelle et fonctionnelle des ateliers............................ 91

3.2.2 Expérience esthétique conscientisée..................................... 106

3.2.3 Mise en œuvre de l'œuvrer de groupe.................................. 113 
3.3 Ordre dévoilé : articuler et conceptualiser le sens du processus d'atelier........... 119

3.3.1 Accompagnement artistique.................................................................... 119

3.3.2 Sens du processus d'atelier pour les convives créateurs................... 123

3.3.3 Sens du processus d'atelier pour moi................................... 124

3.4 Ordre communiqué : synthétiser et formaliser le sens renouvelé de ma démarche d'artiste accompagnatrice................................................. 127

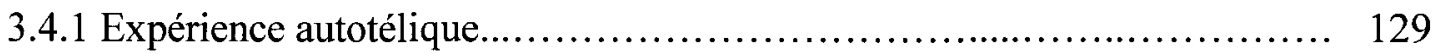

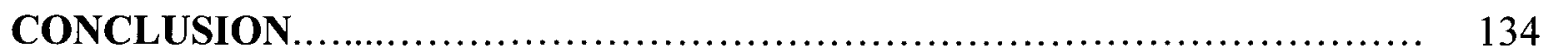

\section{LISTE DES ANNEXES}

Annexe A - État de la situation.......................................................... 139

Annexe B - Retour des participants............................................. 141

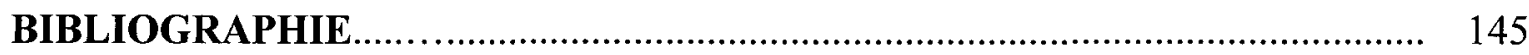




\section{LISTE DES TABLEAUX}

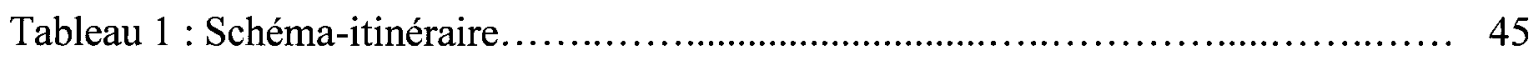

Tableau 2 : Outils d'observation et d'analyse............................................. 74 


\section{LISTE DES FIGURES}

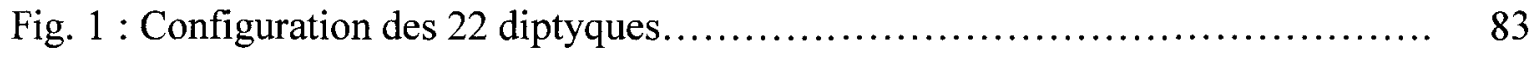

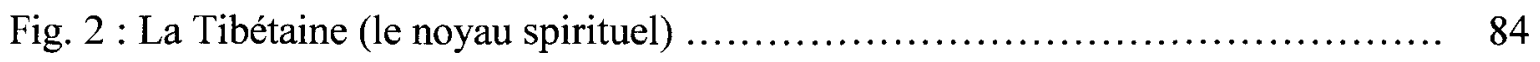

Fig. 3 : Exercice de scription avec collage préalable, Mélanie......................... 95

Fig. 4 : Atelier en action...................................................... 98

Fig. 5 : Synthèse Myriam....................................................... 101

Fig. 6 : Mosaïque Maude........................................................... 103

Fig. 7 : Réalisation Mélanie............................................................. 104

Fig. 8 : Réalisation Nadine......................................................... 104

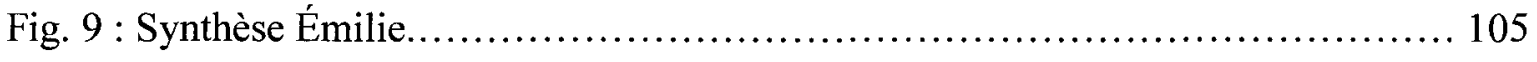

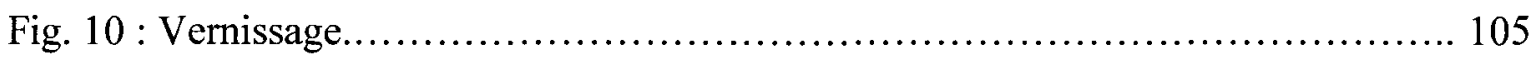




\section{INTRODUCTION}

Ce mémoire fait état d'un parcours artistique d'auto-accompagnement dans l'accompagnement. Par le biais d'ateliers d'exploration picturale s'adressant à des personnes néophytes, non formées dans les arts, j'ai créé un espace poétique convivial où l'expérience de l'art enrichi chacun, et où chacun s'enrichi de l'expérience de l'autre.

Le mémoire se présente dans un style narratif privilégiant l'essai-récit comme genre littéraire. Ma voie épistémologique se déploie dans une logique de sens, non dans une temporalité linéaire. C'est pourquoi la réalité plurielle, mise en sens ici, est passée par une évolution conceptuelle en 4 étapes allant de l'ordre caché à l'ordre communiqué en passant par l'ordre acté et dévoilé. Il s'agit d'un point de vue élaboré en spirale et orienté vers le centre en soi, qui se veut ouvert sur l'altérité. C'est ce qui permet de faire éclore une vérité personnelle féconde, bien enracinée dans un vécu singulier.

Le premier chapitre décrit comment j'en suis venue à concevoir et offrir mes ateliers, découvrant ainsi une de mes facettes, cachée jusqu'alors, mais combien vivace, celle de l'artiste accompagnatrice. En regard de cet accompagnement artistique, quelques concepts clés, expérimentés concrètement au fil des ateliers mais attendant la recherche pour s'articuler théoriquement, viennent dès le début du mémoire éclairer les fondements de ma pratique, tels : le désir d'art; l'œuvrer et l'œuvrer de groupe; la poïétique; la convivialité créatrice; l'expérience esthétique conscientisée et l'accompagnement. Également, en conclusion, mes objectifs y sont présentés en termes de quête de sens. À savoir, qu'il m'importe de définir le sens, la teneur et la portée de mes ateliers afin de doter 
ma pratique intuitive d'artiste accompagnatrice d'assises rationnelles définies, cohérentes et solides.

Le deuxième chapitre se préoccupe essentiellement de ma méthode de recherche. Je rends compte tout d'abord de ces états intérieurs qu'il m'a fallu traverser avant d'en arriver à créer ma propre voie d'approche. Entre autre, je démontre que c'est en bâtissant ma banque de données, en passant par un processus d'autorisation et en ordonnant mon matériel que j'ai pu orienter ma pensée vers un ordre. Ce qui me permettra par la suite d'en arriver à structurer ma compréhension autour du sens et de l'ordre, et de créer mon propre itinéraire d'écriture.

Dans le troisième et dernier chapitre figurent les uns à la suite des autres les 4 ordres mentionnés plus haut. Vient d'abord l'ordre caché où je sonde mes souvenirs, où je dis et décris comment l'art est entré dans ma vie, où il m'a conduite et ce qui en est ressorti. L'ordre acté, qui vient ensuite, explore et réfléchi « ce qui en est ressorti », c'est-à-dire les ateliers et leurs particularités. L'ordre dévoilé suit, qui s'occupe à formuler une direction à suivre en vue de trouver le sens de l'ordre acté. Finalement, l'ordre communiqué synthétise et formalise l'ordre dévoilé dans l'optique de créer du sens et de le communiquer à travers une vision nouvelle de l'advenir ancrée dans ce sens émergeant. 


\section{CHAPITRE I}

\section{DE L'INSPIRATION À L'EXPLORATION : DES ATELIERS CONVIVIAUX D'EXPLORATION PICTURALE AXÉS SUR L'EXPÉRIENCE ESTHÉTIQUE CONSCIENTISÉE}

De l'invitation «Écris-moi », extrait de la lettre 6 : Précieux moments d'humanité. ${ }^{1}$

[...] ces moments d'humanité furent précieux parce que le regard et la volonté de tous semblaient pointer vers l'autre, vers l'humain autour de soi. D'ailleurs, cela est devenu fort éloquent lors de l'atelier sur la cartographie de la pratique en communauté. Là, quelque chose a retenu mon attention. Je me suis dit oui, évidemment, tout commence avec l'artiste et le travailleur communautaire, mais nous, artistes, travailleurs communautaires, on commence où? Et avec quoi au juste? Et comment, pour qui et pourquoi faisons-nous ce que nous faisons? Qui sommesnous en fait? Où se porte donc notre regard et sur quoi se fonde-t-il? Quels sont nos motifs profonds? Avons-nous réellement nommé cette passion de l'autre qui nous habite? Mais aussi, je me demande jusqu'à quel point le ressentons-nous pour soi, cet intérêt prononcé que nous avons envers l'autre? [...]

\footnotetext{
${ }^{1}$ L'invitation « Écris-moi » sera présentée à la section 2.3.1.
} 
Ce chapitre présentera mon sujet de recherche et abordera les motifs et objectifs qui sont à l'origine de mon projet de maîtrise. Suivra ensuite l'exposé des concepts clés qui favoriseront une meilleure compréhension pour la suite du mémoire.

\subsection{Sujet, problématique et objectif de recherche}

Cette section-ci mettra en valeur les fondements de mon projet de maîtrise. J'y présenterai tout d'abord de façon succincte mes ateliers (leur présentation détaillée fait l'objet de la section 3.2.1) et les circonstances qui en sont à l'origine. J'aborderai ensuite ma problématique sous l'angle de certaines observations et constatations. Puis, je conclurai par mes objectifs de recherche, lesquels s'inscrivent de façon signifiante dans une démarche de compréhension personnelle et professionnelle.

\section{Préambule}

Avant de m'inscrire à la maîtrise en art de l'UQAC, j'y avais complété un baccalauréat interdisciplinaire en art. C'est vers la fin de ce premier cycle d'étude que j'ai créé deux séries d'ateliers. L'une, intitulée «Expression de soi - Vibration de l'Être », porte sur l'exploration du langage plastique non figuratif. L'autre, intitulée « Miroir de papier », concerne une démarche artistique exploratoire sur le thème de l'autoportrait. La première série vise principalement à stimuler la sensibilité esthétique. La deuxième série quant à elle consiste en une démarche introspective par le biais de 1'art. Structurellement, 
formellement et fonctionnellement, ces deux séries sont trop différentes pour que je puisse les aborder ensemble dans le cadre de cette recherche. C'est pourquoi le mémoire porte principalement sur l'accompagnement concernant la première série, soit « Expression de soi - Vibration de l'Être ». Pour ma part, c'est une option logique puisque ce sont les premiers ateliers que j'ai créés, et qui m'ont permis d'expérimenter pour une première fois mon rôle d'accompagnatrice.

Mes ateliers s'annoncent donc comme un processus artistique exploratoire s'étalant sur une série de douze rencontres hebdomadaires de trois heures. Ce processus culmine par une exposition collective. Ils sont offerts en contexte populaire et communautaire pour une clientèle adulte provenant de tous les milieux. L'objectif est d'y créer un espace convivial d'exploration artistique dans un contexte d'accompagnement structuré qui stimule la sensibilité esthétique en favorisant les liens entre l'œuvre, l'œuvrant et l'œuvrer (voir section 1.2.2). Plutôt que le développement personnel ou l'art thérapeutique, quoique ces aspects ne soient pas exclus étant donné que, personnellement, je crois que l'art est en soi guérisseur et évolutif, c'est avant tout 1'expérience esthétique conscientisée qui est au cœur de mes ateliers. ${ }^{2}$ En effet, tout ce qui s'y joue s'interprète à partir de l'écoute et de l'accueil de sa propre sensibilité esthétique et de celle de l'autre également : qu'est-ce que j'observe en moi lorsque je crée, que se passe-t-il lorsque je me vois créer, lorsque je vois ce que j'ai créé et également lorsque je vois ce que l'autre a créé? En fait, qu'est-ce que

\footnotetext{
${ }^{2}$ Voir la section 1.2.6 pour une discussion de «l'expérience esthétique » et la section 3.2.2 pour "l'expérience esthétique conscientisée ».
} 
l'art et le faire l'art pour moi et que me procurent-ils? Mon approche est orientée à travers une structure procédurale soutenue qui s'actualise dans la triple articulation de l'écriture, du pictural et de la parole.

\subsubsection{Origine du sujet : Un voyage inspirant}

La source d'inspiration de ces ateliers remonte à un séjour prolongé d'étude en art effectué à l'université Paris 8 en 2005/2006. Toutefois, ma première expérience d'accompagnatrice a eu lieu à mon retour lors d'un projet supervisé dans le cadre de mon baccalauréat interdisciplinaire en art au printemps 2007, alors que j'y ai créé quatre ateliers exploratoires. Cette expérience s'est avérée concluante, c'est ce qui m'a conduite par la suite à concevoir un processus artistique s'étalant sur une série de douze ateliers d'exploration du langage plastique dans le but cette fois de les offrir en contexte populaire. C'est lors de cette deuxième édition, dans laquelle j'ai poussé l'audace exploratoire beaucoup plus loin, que j'ai été à même d'entrevoir les ateliers comme un processus émancipateur d'un genre particulier. 


\subsubsection{Problématique : Un mouvement propulseur}

Effectivement, ce processus d'atelier était émancipateur, même que son apport sensible $^{3}$ était tel que j'ai commencé à l'interroger en tant que voie collective de découverte de soi et d'émergence de sens. À cet égard, je réalisais que le retour personnel que chacun faisait sur son expérience créative offrait, à eux-mêmes, à moi et aux autres participants, de nombreuses ouvertures à la réflexion. C'est notamment cette richesse des rapports intersubjectifs qui me permettait d'appréhender ce processus exploratoire comme un potentiel de connaissance sensible: connaissance de soi, connaissance de l'autre, connaissance du monde.

Fondamentalement, je constatais que le processus exploratoire qui s'actualisait dans les ateliers supportait et était supporté à la fois par l'expérience esthétique individuelle conscientisée et par la richesse des rapports conviviaux générés par l'œuvrer de groupe. C'est cette synergie féconde engendrée par l'acte créatif vécu en réciprocité que j'ai exprimée plus tard sous la notion de convivialité créatrice (voir section 1.2.5). Conséquemment, les ateliers se présentaient autant comme un processus collectif de création artistique que comme une création collective de sens. Ainsi, dans ce contexte de convivialité créatrice, les participants devenaient créateurs, et créateurs d'eux-mêmes, à travers la singularité de leur expérience esthétique conscientisée et partagée.

\footnotetext{
${ }^{3}$ Le sensible se réfère à la fois à la sensation et à l'affectivité. À cet égard, Souriau (2010, p. 1362) nous rappelle que « la sensibilité est la propriété générale de pouvoir être affecté par des objets et de réagir à leur stimulation ».
} 
À cet effet, la teneur des échanges qui s'instauraient lors de la dernière phase d'atelier, le retour parlé, corroborait mes intuitions naissantes sur la force de ce processus d'exploration artistique de groupe que nous vivions. C'est ainsi qu'en moi s'effectuait un glissement de l'attention, laquelle passait inéluctablement de l'objet artistique au sujetartiste. Déjà, je pouvais entrevoir les prémisses fondatrices de ma démarche artistique subséquente, c'est-à-dire qu'au-delà de l'art il y a l'Être, qu'avant l'objet artistique il y a le sujet-artiste, qu'en amont de l'intention il y a la pulsion et qu'au lieu de la performance et de la prouesse technique il peut y avoir lâcher prise, accueil, ouverture et spontanéité. Ainsi, il devenait évident que les ateliers favorisaient un magnifique mouvement de conscience et que je me devais d'explorer cet aspect plus à fond.

\subsubsection{Visée signifiante : l'accompagnement artistique}

C'est ainsi qu'une visée signifiante a commencé à poindre, celle de l'accompagnement artistique. Si, comme le souligne André Malraux dans une citation que je paraphrase ici de mémoire, l'art est le plus court chemin de l'homme à l'homme, j'ai constaté que ces ateliers étaient tout à fait aptes à proposer une petite mais captivante partie du parcours. C'est ainsi que devant la gravité et la délicatesse que requiert une démarche intérieure dans un contexte d'exploration artistique de groupe, inéluctablement, je me suis sentie poussée à démystifier la portée de ces ateliers afin de mieux comprendre ma pratique d'artiste accompagnatrice. 
De mon point de vue, bien accompagner l'autre relève aussi et surtout de l'aptitude à l'autoaccompagnement. Conséquemment, puisque c'est l'art qui m'a amenée à l'accompagnement, et, tenant compte du fait que l'art et l'accompagnement sont inextricablement liés dans mon expérience existentielle ${ }^{4}$, l'écriture de ce mémoire, qui s'inscrit notamment dans un processus d'autoaccompagnement, est à même de me disposer à une compréhension approfondie et renouvelée du sens de l'art dans ma vie. Dans ma pratique, ceci s'impose, car mieux comprendre le sens de l'art dans ma propre vie, c'est aussi mieux comprendre le sens de l'art dans une vie, et ainsi être à même d'aider l'autre à mieux le comprendre dans la sienne propre.

M'appuyant sur ce qui précède, tout en énonçant l'idée de l'écrivain et philosophe Hermann Broch (Rivard, 2010, p. 9) sur le fait que «le premier devoir d'un intellectuel, dans l'exercice de son métier, soit de porter assistance à autrui », je me demande pourquoi n'en serait-il pas de même pour l'artiste? Toutefois, loin de moi l'idée de porter assistance, mais plutôt de mettre en place de façon adéquate les dispositions nécessaires afin que l'art, en tant que dimension profonde de la subjectivité humaine, puisse porter assistance. De fait, afin de m'assurer que ces dispositions soient mises en place de façon adéquate, il m'est essentiel également de conceptualiser et de formaliser mon approche intuitive d'atelier basée sur l'accompagnement artistique convivial.

Substantiellement, voici formulés les enjeux principaux qui ont éveillé en moi une sensibilité nouvelle à l'accompagnement artistique de groupe et, conséquemment, le désir

\footnotetext{
${ }^{4}$ Existentielle au sens où ma façon de relier et d'actualiser l'art et l'accompagnement sourd de mes valeurs profondes.
} 
d'en approfondir le sens par le biais de ce travail de recherche. Avant de poursuivre avec la formulation de mes objectifs, je tiens tout d'abord à situer mes ateliers dans un contexte socioculturel plus élargi. Par le fait même, ce positionnement soulignera leur singularité et leur caractère novateur.

\subsubsection{Concept novateur : la convivialité créatrice}

Suite à mes recherches (voir annexe A), j'ai constaté que parmi la multiplicité des ateliers artistiques offerts au Québec, aucun ne propose une approche conviviale au sens où je l'entends, c'est-à-dire une approche qui soit spécifiquement axée sur l'expérimentation d'un être ensemble créatif où chacun se trouve consciemment enrichi d'une part de l'autre. Mais à mon sens cela s'y passe, nécessairement, comme dans la plupart des ateliers de groupe. Toutefois, ce n'est peut-être pas nommé comme tel, ou l'accent n'y est pas mis spécifiquement, c'est selon. À cet égard, je crois que ce travail de recherche pourrait peutêtre permettre d'éclairer certains processus se produisant dans ces autres ateliers.

En regard de cela, l'art et le faire l'art, vécus dans une optique expressément conviviale, émancipatrice et exploratoire, se présentent comme une approche novatrice et évolutive. Ce genre d'atelier répond, dans un premier temps, à un besoin individuel, à mon sens essentiel, relié à un désir d'art (voir section 1.2.1), mais aussi à un besoin social croissant, et non moins essentiel, qui tendrait vers l'émergence de nouveaux modèles d'échanges conviviaux qui soient créatifs et signifiants. 
Je considère à ce égard que l'artiste humaniste est tout désigné pour créer de nouveaux espaces esthétiques, en favoriser l'exploration et ainsi stimuler l'émergence de connaissances nouvelles et de liens enrichissants. Pour ce faire, des itinéraires de création doivent être élaborés dans le but de restaurer le lien avec sa propre sensibilité esthétique, et celle de l'autre également. Ce retour à soi, par l'art, pour tous, c'est peut-être un peu ce que propose Robillard (Robillard, 1998, p. 9) en soulignant que de plus en plus « l’importance accordée aux artistes va être transférée à la nécessité d'instaurer des ateliers de créativité pour tous, et à leurs animateurs.»

\subsubsection{Objectif de recherche : Une quête de sens}

C'est donc en envisageant tous ces aspects que se profile mon objectif de recherche. Il m'importe effectivement de définir, à travers une démarche réflexive, le sens, la teneur et la portée de mes ateliers d'exploration picturale selon mes propres préoccupations, tant artistiques, qu'humanistes, spirituelles, politiques et sociologiques. J'aspire ainsi à doter ma pratique intuitive d'artiste accompagnatrice dédiée à la rencontre créative conviviale, de fondements personnels qui soient définis, cohérents et affermis. Ainsi, ayant parcouru ce chemin de compréhension et de réappropriation de ma propre dimension artistique, il y a de fortes chances que je puisse aider l'autre, le convive créateur participant à mes ateliers, à faire de même dans sa propre vie. De plus, je suis convaincue que cette compréhension plus pointue de l'impact que l'art peut avoir dans une vie orientera 
et stimulera certaines visées sociales et communautaires quant à la conception de nouveaux dispositifs de création dans la convivialité créatrice.

Ayant présenté mon sujet, l'origine de mon questionnement et mes objectifs de recherche, j'aborderai maintenant la définition des concepts clés qui sous-tendent ma recherche. 


\subsection{Définitions des concepts clés}

Dans le but de favoriser une meilleure compréhension de mon approche d'artiste accompagnatrice, je définirai dans cette section, quelques concepts clés et certaines théories qui s'y réfèrent.

\subsubsection{Désir d'art}

L'art ne demande qu'à être fait, il tend à se manifester à travers un véhicule : la personne.

Vicki Noble in Cameron, 2004

Extrait de la trame narrative 1 : Une si petite trace de graphite $^{5}$

[...] ainsi, confronter l'aventure artistique est déjà énorme. Oui, il faut du courage pour assumer ses désirs d'art et y croire jusqu'à créer. En ce sens, moi et les participants sommes avant tout des explorateurs. Et qu'est-ce que l'exploration sinon que l'acte de chercher avec l'intention de trouver quelque chose d'inconnu? Car, même insaisissable, indicible, parce que tapie au fond de soi, il y a intention. Intention rendue manifeste justement par ce désir d'art. C'est ce quelque chose d'inconnu qui est le trésor en soi et vers lequel, semaine après semaine, nous nous engagions dans une joyeuse et fébrile expectative. [...]

\footnotetext{
${ }^{5}$ Afin de ne pas surcharger la lecture de ce mémoire, j'ai choisi de n'y inclure que des extraits pertinents à ma recherche. Tous ces extraits sont tirés de ma banque de données scripturales, soit: l'écriture parallèle; l'invitation «Écris-moi»; les trames narratives; le récit autobiographique; le récit d'artiste et le journal de recherche. Cette banque de données fait l'objet d'une présentation détaillée à la section 2.1.1.
} 


\subsubsection{Besoin d'expression et désir d'art}

Afin de mieux exprimer ce que j'entends par « désir d'art », il importe de préciser la distinction entre désir et besoin. Ces deux termes peuvent parfois se confondre, à cette différence près toutefois que le besoin semble davantage relié à une instance vitale et même organique, comme le besoin de manger par exemple. Quant au désir, selon le Larousse en ligne (http://www.larousse.fr), c'est «l'action de désirer, d'aspirer à avoir, à obtenir, à faire quelque chose, envie, souhait », alors que le besoin s'associerait davantage à « un sentiment de privation qui porte à désirer ce dont on croit manquer; nécessité impérieuse. » Ainsi, le désir d'art tel que je l'entends souligne aussi un besoin d'art, comme une nécessité impérieuse. En fait, ce qui semble vouloir s'exprimer par le désir d'art serait avant tout profondément stimulé par un besoin essentiel et fondamental de créer.

Notamment, chez beaucoup de gens qui ne se considèrent absolument « pas doués pour les arts $»^{6}$, un intense désir de créer artistiquement est pourtant très présent en eux, et parfois même pressant. J'entends en cela un besoin de communiquer quelque chose de soi, de l'exprimer concrètement bien sûr, mais aussi et surtout, poétiquement. De plus, je constate chez la plupart des participants qu'il y a ce désir de s'exprimer et de créer également dans une optique de partage et de communication, un désir de s'exprimer avec et vers l'autre, de dire de soi et d'en avoir une résonance. Ce besoin d'expression, dans son fondement même, concerne l'intégralité de l'être. Il y a là un besoin intuitif d'unification de

${ }^{6} \mathrm{~J}$ 'entends cette phrase, formulée plus ou moins ainsi, chez beaucoup de gens qui me téléphonent pour s'inscrire à mes ateliers ou demander des informations. 
son être au monde par la voie naturelle de l'art. C'est ce besoin pressant, entier, apparemment irrationnel, difficilement identifiable, que j'ai nommé « désir d'art ».

\subsubsection{Espace d'accueil et désir d'art}

Considérant ce désir d'art sous plusieurs angles, physique, psychique, émotionnel, affectif et spirituel, c'est pour moi une question d'écologie personnelle qu'il soit canalisé adéquatement en respectant l'intégralité de l'être. Pour ce faire, il est indispensable de créer un espace émergeant qui puisse en tenir compte. Un espace que l'on parcourt en suivant un itinéraire adapté. Un espace qui soit créé spécifiquement pour accueillir, stimuler et soutenir le désir d'art à tous les niveaux de l'être. Il importe également que cet espace soit à la fois réceptif et émissif, et qu'il nous permette de nous y aventurer aussi loin que possible tout en créant au plus près de soi. En atelier, dans une démarche procédurale, cet espace du désir d'art se crée en donnant la primauté à la sensibilité esthétique de chacun dans un contexte créatif et relationnel accueillant, stimulant, supportant et respectueux. Cet espace totalement dédié à l'être en création, c'est celui de la poïésis, qui sera abordé plus bas.

\subsubsection{Euvrer}

«Pour Valéry la dimension de l'œuvrer est celle qui se rapporte primordialement à l'esprit œuvrant, c'est-à-dire à l'esprit en activité réfléchissant sur les transactions 
multidimensionnelles qui s'échangent entre lui, le corps et le monde. ${ }^{7}$ Dans mes ateliers, c'est par le biais d'un accompagnement artistique adéquat que cette dimension de l'œuvrer se trouve stimulée, favorisée et soutenue.

\subsubsection{Cuvrer de groupe}

Pour les besoins de la cause, je reformulerai ici, au pluriel cette fois, la définition de l'œuvrer pour l'appliquer à la dimension de l'œuvrer de groupe, ce qui donne ceci : la dimension de l'œuvrer de groupe est celle qui se rapporte primordialement à l'ensemble des esprits œuvrant, c'est-à-dire à l'ensemble des esprits en activité dans un contexte de convivialité créatrice, esprits réfléchissant sur les transactions multidimensionnelles qui s'échangent entre eux, leurs corps et le monde.

\subsubsection{Poïésis et poétique}

Les ateliers sont envisagés dans un contexte poétique au sens où l'entend Heidegger (in Levine, 1992, p. 37), qui considère que l'existence authentique en est une poétique. Selon lui, la poïésis, c'est-à-dire l'activité transformatrice, est la voie essentielle de la vérité de l'être. La poïésis est aussi l'acte par lequel la vérité est mise en action, où de

\footnotetext{
${ }^{7}$ Thérien C., Valéry et le statut " poïétique » des sollicitations formelles de la sensibilité, Les études philosophiques 2002/3, n 62, p. 353-369. , p.355
} 
nouvelles possibilités d'être sont soutenues et contenues dans l'œuvre même. ${ }^{8}$ Je dirais que c'est ce dont il est question dans mes ateliers: il s'agit de l'exploration de soi et de l'affirmation de sa singularité par le biais de l'activité créatrice conviviale. Mes ateliers proposent cet espace particulier de la poïésis où l'œuvrer et l'œuvrer de groupe peuvent se déployer librement.

\subsubsection{Poïétique}

Sous ce terme, Valéry rassemble

tout ce qui concerne la production des œuvres; et une idée générale de l'action humaine complète, depuis ses racines psychiques et physiologiques, jusqu'à ses entreprises sur la matière ou sur les individus [...]. D'une part, l'étude de l'invention et de la composition, le rôle du hasard, celui de la réflexion, celui de l'imitation, celui de la culture et du milieu; d'autre part, l'examen et l'analyse des techniques, procédés, instruments, matériaux, moyens et suppôts d'action. ${ }^{9}$

La poïétique concerne donc, entre autres, le faire et la réflexion. Dans mes ateliers, le retour parlé sur l'œuvrer est de nature poḯtique. Ce retour parlé est un moment fondamental car il contribue à dynamiser le rapport qui unit le convive créateur non seulement à son œuvre et à son œuvrer, mais aussi à tout le groupe.

\footnotetext{
${ }^{8}$ Traduction libre de Levine, S.K., (1992) Poiesis : the language of psychology and the speech of the soul, London and Philadelphia, Jessica Kingsley, p. 37

${ }^{9}$ Thérien C., Valéry et le statut " poïétique » des sollicitations formelles de la sensibilité, Les études philosophiques 2002/3, n 62, p. 353-369. , p.355
} 


\subsubsection{Convivialité créatrice}

Je définirai ici le concept de convivialité créatrice, lequel a fait l'objet de ma part de nombreuses réflexions, reformulations et ajustements tout au long des quelques séries d'ateliers offertes.

\subsubsection{Phénomène synergique}

La convivialité est «l'ensemble des rapports positifs qu'entretiennent les personnes et les groupes qui composent une société » (http://www.granddictionnaire.com). Quant au terme de créatrice, je me réfère dans un premier temps à la définition que Souriau (2010, p. 549) donne d'une création, à savoir que c'est « l'acte par la vertu duquel une chose, un être commence à exister ». Ce qui m'amène au terme de créatrice qui selon le Larousse en ligne se rapporte à ce «qui crée, tire du néant» (http://www.larousse.fr). Ainsi, dans les ateliers, la convivialité est effectivement créatrice puisque c'est son avènement même qui permet l'acte de créer tel qu'il s'y manifeste.

J'ai choisis de lier ces deux mots' en un énoncé signifiant pour rendre compte, dans un premier temps, de la qualité des rapports qui s'actualisent dans les ateliers, c'est-à-dire des rapports qui sont à la fois conviviaux et créatifs. Et, dans un deuxième temps, ce terme veut aussi souligner les potentialités réciproques qui émergent de ces rapports. C'est-à-dire que la convivialité supporte l'œuvrer, et que c'est à partir des échanges et du partage autour de cet cuvrer que se manifeste un rapport de convivialité supportant et stimulant. Ces deux 
aspects, convivialité et création, interagissent réciproquement à travers le processus exploratoire pour créer la dynamique propre aux ateliers. De fait, l'expérience esthétique, l'aspect formel, de même que les rapports intersubjectifs qui y ont cours sont intrinsèquement liés à cette dynamique d'atelier concomitante au phénomène synergique de la convivialité créatrice.

\subsubsection{Convives créateurs}

Le fondement créatif et convivial des ateliers étant défini, je présenterai maintenant ceux par qui tout arrive, les convives créateurs. Les convives créateurs sont ceux qui participent à mes ateliers, qui viennent vivre une aventure artistique guidée, orientée et structurée, aventure dans laquelle leur liberté créative peut prendre forme et envol. Ils s'engagent ainsi dans un processus créatif émancipateur, qui, de l'exécution à l'exposition, en passant par l'exploration, l'expression et la communication verbale et écrite, les amènera à vivre des expériences esthétiques conscientisées. C'est par l'intégration du sens de ces expériences qu'ils se disposent à une transformation intérieure par le biais de l'exploration artistique conviviale. 
1.2.6 Expérience esthétique

Je tiens à donner ici une idée générale de ce qu'est, selon certains auteurs, une expérience et une expérience esthétique. Plus loin, j'élaborerai un point de vue original sur les particularités unificatrices et transformatrices de l'expérience esthétique telle qu'elle est vécue dans mes ateliers.

Des emplois multiples du mot expérience, Souriau (2010, p. 745) retiendra «faire l'expérience de », dont l'anglais offre un équivalent avec le verbe to experience.

L'expérience réfère alors au vécu, elle désigne le fait même de vivre une présence; et, par exemple, un certain mode du percevoir qui rend justice au perçu pour l'accomplir. Ainsi, dirions-nous que l'expérience esthétique est requise pour l'esthétisation de l'esthétisable. Peut-être aussi pour la production de l'esthétisable, quand cet esthétisable est une œuvre d'art.

De son coté, Dewey prône l'expérience de l'art afin de « rétablir la continuité entre l'expérience esthétique et les processus normaux de l'existence ». (Dewey, 2010, p. 41) Suivant cela, Shusterman (Shusterman, in Dewey, 2010, p. 19-20) souligne que 
dans toute son ampleur, la notion d'expérience semble aussi assurer l'unité d'un grand nombre de dualismes qui nous égarent sitôt que nous pensons à l'art et à la vie. L'expérience peut être de nature cognitive ou non cognitive; elle inclut à la fois le sujet et l'objet, en enveloppant aussi bien le contenu de l'expérience que la manière dont elle est expérienciée. L'expérience est en même temps le flux général de la vie consciente, que nous avons tant de mal à saisir, et ces moments distincts, aigus, qui surgissent de ce flux et constituent « une expérience ». Parce qu'elle embrasse à la fois le passé, le présent et le futur, elle renferme la sagesse accumulée de la tradition, célébrée par la pensée conservatrice, et elle symbolise l'ouverture au changement et à l'expérimentation que défend la pensée progressiste. L'expérience humaine est constituée, de part en part, de contextes historiques, sociaux et politiques. En définissant l'art comme expérience, on se donne les moyens d'accorder à ces contextes l'attention qu'ils méritent, au lieu d'enfermer l'esthétique dans un formalisme étroit. En anglais, comme nom et comme verbe, l'expérience désigne à la fois un événement accompli et un processus; elle enveloppe à la fois l'instant immédiat et la durée. Elle appartient à la vie et à l'art, et elle est essentielle à l'artiste autant qu'au public. On peut l'interpréter comme une chose qu'une personne engendre par son action, mais aussi comme une chose qu'elle subit ou qui la submerge, comme on peut l'être par le saisissement esthétique.

À la lumière de ces propos, il semble entre autre que l'expérience esthétique réfère tant au vécu créatif qu'au rapport contemplatif qui peut en émerger. De plus, si l'art est envisagé comme expérience, outre le fait que cette expérience de l'art permettrait de se situer historiquement, sociologiquement et politiquement, elle est aussi, dans une optique phénoménologique, un événement immédiat, émergeant en grande partie du déjà connu, mais offrant aussi la possibilité de s'inventer un avenir. 


\subsubsection{Accompagnement}

Pour le concept d'accompagnement, je me référerai plus spécifiquement à Chaîné, (Chaîné in Cifali, Théberge et Bourassa, 2010, p. 63) qui, en regard de son accompagnement dans la recherche création en art visuel, considère la création comme une « médiation » entre l'accompagnant et l'accompagné. De son travail d'accompagnement elle dégage trois fonctions : soutenir le travail créateur de l'étudiant, l'amener à voir et à dire sa pratique et développer une distance critique. Concernant le soutien au travail créateur, si je mets ses propos en parallèle à mon travail d'artiste accompagnatrice, le «zoom avant » qu'elle propose sur le travail en cours, je le propose de mon coté, non sur le travail (l'œuvre) en cours, mais sur l'être en train de faire l'œuvre en cours, et sur les liens l'unissant à son œuvrer. Donc, plutôt sur son élan même à poser des actes de création que sur le contexte ou le résultat de ces mêmes actes (la pratique, la recherche création ou l'œuvre esthétique par exemple). Mes questions sont : que se passe t-il intérieurement chez le convive créateur ${ }^{10}$ en rapport avec la dynamique créative en cours? Qu'est-ce qu'il reconnait de lui dans ce faire inusité? Mais aussi, que découvre t-il de nouveau? Et, pour rejoindre mes préoccupations de convivialité créatrice, que peut-il identifier et nommer de lui (sensations, sentiments, idées, etc.) à travers les productions et le vécu créatif des autres participants? Il s'agit d'accompagner l'être dans sa propre expérience esthétique, mais aussi de le soutenir dans une expérience conviviale de création. Ce sont ces différents niveaux d'expériences qui se doivent d'être conscientisés pour être à même d'acquérir un statut évolutif, favorisant ainsi une meilleure intégration de l'être.

${ }^{10}$ Afin de ne pas alourdir la lecture de ce document, le genre masculin a été privilégié. 
Toutefois, cette intégration ne se fait pas sans heurt, sans remise en question, sans découragement, sans retrait également. Cela se passe aussi dans mes ateliers bien sûr, alors que certains se trouvent momentanément désorientés par le reflet d'eux-mêmes que l'exploration conviviale leur propose. Cet aspect concerne aussi l'accompagnement en tant que tel. Ainsi, en regard d'une posture éthique et professionnelle, André et Cifali (André et Cifali, 2007, p.45), dans leurs propos sur l'accompagnement, parlent d'un « aller avec » qui

évoque un professionnel qui se déporte vers le chemin de l'autre. Il est là, présent, permettant qu'un autre traverse l'épreuve, le moment, l'évènement [...]. Accompagner signifierait que l'on a intégré le fait que l'on ne peut pas agir et décider à la place de quelqu'un : que, sur certains registres de la vie, on ne peut contraindre, qu'il faut « aller avec», dans le mouvement imprimé par un autre. On propose, on accueille, on renonce à l'injonction. Avec accompagner, on s'éloignerait, aussi, de la prise de pouvoir sur autrui.

J'ai présenté ici quelques idées générales sur l'accompagnement. Dans une prochaine section, j'aborderai plus en détail ma conception personnelle de l'accompagnement artistique.

En résumé, ce premier chapitre, outre la définition de mes concepts clés, portait également sur les motifs, les objectifs et le questionnement à l'origine de ce travail de recherche. Je conclurai donc en faisant ressortir à quel point ce processus d'atelier a soulevé des interrogations personnelles, face à moi, face à l'art, face à l'autre et à la vie en général. Comment se fait-il, effectivement, que le faire l'art ensemble soit de cette manière si transformateur et évolutif? Que se passe t-il de particulier dans ces ateliers? Quel est mon rôle? Quelle est la fonction de l'accompagnement dans un tel processus? Comment faire le 
lien entre mon intimité profonde et ma vision d'artiste accompagnatrice? À quoi je carbure en fait? Et l'art, ce merveilleux mystère, est-il possible de me le rendre plus palpable? Comment puis-je améliorer la transmission de ma passion pour l'Humain par le vecteur de l'art? Et vice et versa? Et jusqu'à quel point la convivialité créatrice et l'expérience esthétique conscientisée sont-elles parties prenantes de cette transmission ? Est-il possible de faire davantage la lumière sur l'intuition que j'ai de l'art en tant que dimension profonde de la subjectivité humaine? En tant que vecteur et révélateur de soi? Ce sont là les principales questions qui m'habitent depuis longtemps. Étant donné que ce projet d'écriture me permet d'aller à la rencontre de l'artiste réflexive en moi, j'ose espérer que de nombreuses questions trouveront réponses, et que des inspirations nouvelles porteront à leur tour le germe de nouvelles questions.

Au regard de tout cela, le prochain chapitre abordera les aspects épistémologiques et méthodologiques qui m'ont conduite à élaborer un itinéraire d'écriture adapté à ma démarche réflexive. 


\title{
CHAPITRE II
}

\section{DE L'EXPLORATION À LA MISE EN ORDRE : UN PARCOURS MÉTHODOLOGIQUE LIANT LA CRÉATION, LA STRUCTURE ET L'ORDONNANCE DE LA RECHECHE}

\begin{abstract}
La recherche créatrice procède donc par paliers et par étapes; chacun d'eux représente un résultat provisoire qu'il est encore impossible de relier à la solution finale. Même si la solution visée est donnée, comme c'est le cas quand on cherche à prouver une proposition hypothétique, la voie à suivre est inconnue.
\end{abstract}

Ehrenzweig, 2005

Cette section traitera des aspects épistémologiques et méthodologiques. J'exposerai au préalable ma voie d'approche. Ensuite, je présenterai la genèse conceptuelle de mon itinéraire, puis l'organisation ordonnée sur lequel s'articule mon processus d'écriture.

\subsection{Créer une voie d'approche}

Créer, c'est l'action « de tirer du néant [...] d'imaginer, de réaliser ou d'organiser quelque chose qui n'existait pas encore. $»$ (http://www.granddictionnaire.com). Créer, c'est s'avancer dans l'inconnu. À cet effet, tel que mentionné en exergue, Ehrenzweig nous rappelle que dans « la recherche créatrice [...] la voie à suivre est inconnue ». (Ehrenzweig, 2005, p.83) Ainsi, cette voie à suivre, encore inconnue, participe-t-elle du processus de création: comme un explorateur trace graphiquement le chemin parcouru, 
appréciant les distances à vue, jaugeant instinctivement la route à venir, soupesant les écueils et percevant les attraits bien au-delà de l'horizon, j'aurai ainsi à élaborer progressivement les moyens à partir desquels s'articulera mon processus de recherche.

\subsubsection{Bâtir une banque de données}

Lorsque j'ouvre mon dossier maîtrise dans mon ordinateur, je vois apparaître trois sous-dossiers : recherche prise 1; prise 2; prise 3. Dénomination personnelle et quelque peu théâtrale j'en conviens, mais qui démontre bien les différentes étapes de rédaction. En ce qui concerne mon processus de recherche, ces reprises auront été non seulement nécessaires mais essentielles. Je souligne cet aspect pour introduire l'idée d'une banque de données scripturales. Ce sont entre autres ces données, présentées plus bas, qui seront traitées dans le troisième moment de la recherche.

Mais tout d'abord le premier moment, ou sous-dossier, recherche prise 1. Ce fut celui des premiers «tâtonnements et brouillonnements » (Delamotte et al, 2000, p. 127), alors que sans direction pour raison institutionnelle, remplie de bonne volonté, je tentais d'avancer par moi-même. C'est ainsi que tout en terminant ma scolarité, j'offrais mes ateliers, j'expérimentais, j'explorais, je notais tout, je lisais et j'écrivais beaucoup, tout cela en attendant d'être dirigée. 
Ce premier sous-dossier date de la période s'étendant de l'automne 2008 à juin 2010, c'est-à-dire jusqu'à ce que la direction de recherche devienne officielle. Il contient entre autres une bibliographie enrichie au fil des semaines; de nombreux documents virtuels dont quelques thèses téléchargées; des extraits manuscrits de certains livres accompagnés de notes de lecture; beaucoup d'écriture: journal d'atelier, journal de création, journal personnel, carnet de notes, etc. L'élaboration de ma problématique et de quelques questions de recherches est contenue dans ce premier dossier.

Puis, est venu le deuxième moment, soit recherche prise2, qui s'étend de juin 2010 jusqu'à décembre 2010. C'est alors que j'ai commencé à travailler officiellement avec mes directrice et codirectrice de recherche. Encore là, beaucoup d'écriture, plus de 250 pages assurément. Ce dossier comporte des écrits sur mes assises théoriques en plus de l'élaboration de nombreuses questions de recherche, de plusieurs plans de travail, de pistes méthodologiques, de schémas, etc.

Y figurent également :

- Récits autobiographiques (avril 2010):

$1^{\text {ière }}$ intériorisation (4 avril 2010): l'arbre aux lumières (4 pages)

$2^{\text {ième }}$ intériorisation ( 7 avril 2010) : La musique d'Oscar (2 pages)

$3^{\text {ième }}$ intériorisation ( 9 avril 2010): Les routes ( 3 pages)

$4^{\text {ième }}$ intériorisation (12 avril 2010): Un si petit dessin (2 pages)

$5^{\text {ième }}$ intériorisation (17 avril 2010): Le cadeau (1 page)

$6^{\text {ième }}$ intériorisation (25 avril 2010): Le jeûne (2 pages)

- Récit fondateur (septembre 2010): Je suis une enfant (1 page) 
- Journal de recherche du 6 juillet 2010 au 28 septembre 2010 (17 pages).

- Trames narratives et textes de l'invitation « Écris-moi » (automne 2010):

1. Une petite trace de graphite : 9 pages

2. En marche vers l'autre : 7 pages

3. Un artiste est-il un être singulier : 2 pages

4. Réunir les fragments : 10 pages

5. Le noyau spirituel : 5 pages

6. Précieux moments d'humanité : 6 pages

7. Ouvrir le noyau : 13 pages

- Écriture parallèle du 1 juillet 2010 au 21 janvier 2011 : 47 pages

Ce que je tiens surtout à souligner en abordant ces deux moments de la recherche est le fait de leur richesse de données. Données qui dans un certain sens ont été détournées de leur contexte originel de recherche puisque j'ai réorienté ma recherche à trois reprises, tant en regard de la question de recherche que des objectifs. Mais, alors même que j'ai cru parfois avoir fait fausse route, un ordre caché sous-tendait le processus de recherche à venir, c'est-à-dire le troisième moment, décisif celui-là, qui ne viendra que plusieurs mois après le début officiel de la recherche.

\subsubsection{Autoriser l'écriture}

Ainsi, ce troisième moment aura commencé lors d'une rencontre avec ma directrice en janvier 2011. Pendant notre entretien, elle m'a redonné, classé et annoté, un corpus de 
textes issus des moments un et deux de la recherche, textes que je lui avais remis au cours des mois précédents, et autour desquels nous avions eu des rencontres, des discussions et des échanges virtuels. Ces textes en question, problématique, questions et objectifs de recherche, assises théoriques, plan de travail, etc., étaient le fruit des multiples tentatives précédentes en vue de formaliser ma poétique et de l'assimiler en quelque sorte à une démarche rationnelle de recherche. C'est dire que certains des écrits mentionnés plus haut (récits autobiographiques, récit fondateur, journal de recherche, trames narratives, «Écrismoi » et écriture parallèle) n'y figuraient pas puisqu'il s'agissait d'une écriture intime. Même si ma directrice connaissait ce travail d'écriture, je tenais à le garder personnel. De toute manière, je ne savais pas l'importance qu'il prendrait au fil de la recherche et de la création de mon schéma-itinéraire. Toujours est-il que lors de cette rencontre, elle m'a rassurée sur le fait que toutes les données de ma recherche, "et plus », étaient dans ce corpus qu'elle me remettait. À présent, elle m'invitait à y faire œuvre de sens. Ainsi, tout en m'assurant de sa confiance et de son soutien, elle me proposait de créer, par moi-même, ma propre structure de compréhension afin de rendre le tout cohérent, signifiant et communicable.

Le fait que ma directrice confirme la pertinence de mon travail déjà accompli et qu'elle me confronte habilement à écrire, à créer, m'aura permis d'entrer de plein pied dans le troisième moment de la recherche. Cette rencontre aura enclenché « une libération de la parole sous-tendue par des processus identitaires tels que mise en confiance, assurance " (Delamotte et al, 2000, p.126). Notamment, cette « libération de la parole », intime celle-là, avait déjà commencé à s'actualiser par le biais de l'invitation «Écris-moi » dont je parlerai 
plus loin. À ce moment-là, cette reconnaissance de moi en formation, mais aussi en tant que « sujet concepteur », inaugurait le «processus d'autorisation » dont parlent Gippet et Jorro (Delamotte et al, 2000, p. 126).

Cette reconnaissance du projet d'écriture dans ses tâtonnements et brouillonnements s'inscrit délibérément dans une perspective phénoménologique rendant compte de l'expérience vive des scripteurs sans laquelle l'activité d'écriture devient une opération de mise en mots détachée des valeurs et de l'affect. (Delamotte et al, 2000, p. 127)

Ici, le formateur se place en marge et laisse «l'apprenant prendre l'initiative, s'autoriser à penser par lui-même. » (Delamotte et al, 2000, p.126) C'est exactement ce que ma directrice a fait.

Cette forme de relation semble particulièrement adaptée pour permettre à tout sujet en formation de partir de ce qu'il est, sait et met en œuvre (connaissance en acte) pour tisser des liens avec des savoirs de référence et pour prolonger ces liens dans une perspective praxéologique. (Delamotte et al, 2000, p.126)

Il s'agissait bien de plonger dans «l'expérience vive », ce qui de toute évidence n'avait pas eu lieu aux deux premiers moments. Dans la visée heuristique de la recherche, cela me convenait parfaitement. J'entrais ainsi en possession de mes moyens propres, habitée cette fois d'une assurance lucide et posée. 


\subsubsection{Ordonner le matériel}

Ainsi, de retour chez-moi, mon premier réflexe fut de visualiser en bloc tout ce matériel, puis de le relire intégralement. Ensuite, j'ai procédé à une division et à un reclassement. J'ai inséré chacun de mes textes sous l'un ou l'autre des thèmes suivants, soit l'inspiration, l'exploration ou l'expiration, rappelant en cela les grandes étapes du processus de création. En classant mes textes ainsi, j'ai été à même de réaliser à quel point j'avais été propulsée par un puissant souffle créateur et qu'un bon bout de chemin avait déjà été parcouru.

Mais quand même, j'étais devant un chantier sémantique pour le moins chaotique. Toutefois, après cette rencontre avec ma directrice, je savais maintenant, et le constatais visiblement, que le matériel pertinent à ma recherche était à ma portée. Il y avait là un sens à découvrir: un ordre caché gisait dans ces «tâtonnements et brouillonnements 》. Il s'agissait d'en faire un usage créateur et signifiant. Je concevais dès lors ce corpus comme étant ma propre contrainte de création et je me devais donc d'en élucider le sens caché. Ainsi, il me fallait accueillir mes textes à nouveau et, dans une optique renouvelée, les revisiter, les questionner, les soupeser, les mettre en dialogue entre eux, mais aussi avec mon écriture personnelle, ainsi, les réagencer, les enrichir, les articuler, les synthétiser et finalement les formaliser selon un ordre de sens. Il me revenait donc de les raviver à la lumière d'un sens émergeant, d'en dévoiler l'ordre caché en fait. Le projet de maîtrise se présentait maintenant comme un véritable acte de création, une œuvre de sens. 


\subsubsection{Orienter l'ordre}

J'étais prête à m'engager dans le troisième et dernier moment de la recherche. Mais avant tout, puisqu'il était question d'ordre et de sens, je devais me positionner stratégiquement dans une zone où je pourrais porter mon regard loin, et dans plusieurs directions à la fois, tout en demeurant au plus près de moi. Aussi, puisque le matériel était considérable et les voies à suivre multiples, il était nécessaire que je puisse me prémunir d'un moindre risque d'égarement. Ainsi, dans ma démarche compréhensive et autoréflexive, créer ma propre voie d'approche, c'était me donner les moyens de m'explorer et de me rencontrer au plus près. C'était aussi m'offrir la possibilité de parcourir un territoire neuf de moi, regorgeant de ressources intuitivement palpables, mais pour la plupart encore innommées. Et justement, je devais les nommer, car c'est cette nomination même qui en viendrait à valider l'accomplissement de ma démarche heuristique. D'autant plus que c'est cet accomplissement, humain avant tout, qui était à même de poser de solides jalons pour la suite de mon parcours artistique ouvert sur l'altérité.

Toutefois, cette ouverture sur l'altérité ne pouvait s'opérer réellement qu'à partir d'une singularité affirmée. Et avant de l'affirmer, encore fallait-il me donner les moyens d'y accéder et ensuite de l'exprimer. De là l'importance de créer ma propre voie d'approche orientée vers le sens et qui participerait pleinement du processus créatif inhérent à ma recherche. Cette voie d'approche me donnerait aussi l'assurance de parcourir mes propres sentiers. C'est donc dans cet état d'esprit que j'en suis arrivée à définir ce dont j'avais 
besoin pour amorcer mon processus d'écriture, soit une structure de compréhension ordonnée qui comporte tout à la fois une marche à suivre. Mais aussi, il fallait que je puisse accéder, de façon très personnelle, à une perspective privilégiée qui me permettrait de voir à la fois loin et près, dans le passé, le présent et le futur. Perspective qui me permettrait également de synthétiser le sens encore caché contenu dans mon écriture personnelle (trames narratives, récits, Écris-moi, écriture parallèle, journal, etc.). C'est alors que m'est venue l'idée d'élaborer un schéma sur la base d'un itinéraire ordonné pour guider ma réflexion et mon processus d'écriture. (voir p. 45)

Conséquemment, dans la prochaine section, j'aborderai la genèse conceptuelle de ce schéma-itinéraire à travers la notion de l'ordre qui en instaure les fondements. 


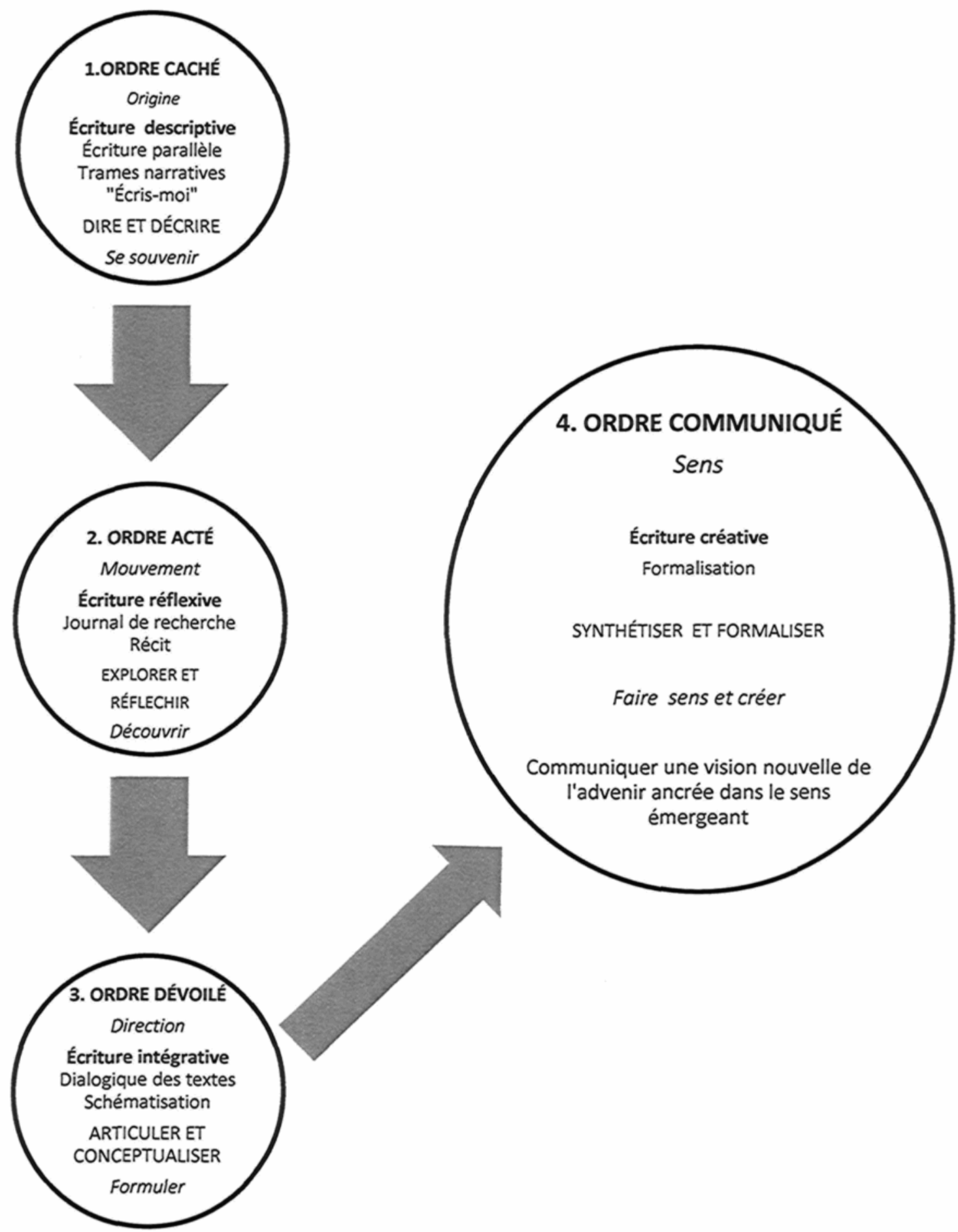

Tableau 1

Schéma-itinéraire : structure de compréhension pour amorcer le processus d'écriture 


\subsection{Structurer ma compréhension}

Car l'ordre n'est pas un phénomène évident; si on peut dire qu'il existe, ce n'est pas simplement pour être regardé. On ne peut pas le pointer du doigt ou le saisir avec une caméra; l'ordre doit être découvert et en un sens extrême, il doit être créé.

Bronowski, in Craig (1978)

Souriau (2010, p. 1160) souligne que l'ordre relève d'une «disposition selon un principe d'organisation et de rapports évidents. Se dit en particulier de la façon dont les éléments se placent l'un après l'autre dans le temps. [Il] fait naître [...] une unité dans un ensemble complexe, une intelligibilité.» Par contre, poursuit-il, «ce qui n'a pour soi que d'être en ordre risque d'apparaître monotone, voire ennuyeux. »

Dans le cadre de cette recherche, l'ordre, loin de n'être « là que pour soi », prend toute sa teneur, son « intelligibilité », spécifiquement en lien avec le sens même qu'il est apte à déployer. À cet égard, le principe d'organisation et de rapports qu'il sous-tend est mis en évidence dans mon schéma itinéraire. De plus, tel que souligné plus haut, sur le fait qu'un ensemble ordonné soit aussi composé d'éléments qui «se placent l'un après l'autre dans le temps », on pourra constater que, quoique les étapes qui le composent peuvent se chevaucher et s'interpénétrer, cet itinéraire se déploie par étape, de l'ordre caché à l'ordre communiqué, en passant respectivement par l'ordre acté et dévoilé, ceci dans un parcours discursif orienté vers la production de sens. 


\subsubsection{Formaliser ma poétique}

Cet itinéraire méthodologique pour le moins existentiel et personnel (puisqu'il m'a fourni les outils pour accéder, entre autre, à une part de mon intimité oubliée) me rappelle à quel point l'art puise dans nos racines humaines profondes. En ce qui me concerne, parler d'art c'est aussi parler de moi. Dans mon existence, ces aspects ne sont séparés l'un de l'autre d'aucune façon. Mais encore, de prime abord et à plusieurs égards, pour moi, l'acte créateur artistique n'est originellement que pulsion, intuition, émotion, sensibilité et réceptivité. Dès lors, comment pouvais-je en arriver à rationaliser et formaliser cette poétique qui m'habite, qui me fait vibrer et créer, alors même que, dans une optique inquisitrice et interprétative, tenter de mettre mes propres phénomènes existentiels à distance relèverait apparemment d'un contresens? Alors, la question était de savoir comment, dans une démarche d'écriture autoréflexive, prendre de la distance tout en restant au plus près de moi? En d'autres termes, était-il possible de faire en sorte d'instaurer un contact original, profond et unificateur avec ce merveilleux fouillis qui m'habite, avec mes propres trames expérientielles, passées, présentes et futures, et ceci tout en me prévalant du recul nécessaire pour les questionner respectueusement dans le but d'en faire émerger le sens caché? De fait, selon Houle (in Bruneau et Villeneuve, 2007, p. 154), la tâche qui est alors confiée à l'artiste chercheur est celle « [...] d'assurer une passerelle entre l'expérience du praticien, les savoirs qui animent et gouvernent intuitivement cette expérience et les savoirs explicites, formalisés dans un discours structuré et structurant. » Ainsi, il devenait évident qu'il me fallait trouver ma manière propre d'instrumentaliser mon écriture afin que 
ma connaissance intuitive puisse émerger, se rationaliser et se formaliser. Mais pour l'heure, c'était encore chaotique.

\subsubsection{Explorer ma polyphonie personnelle}

À ce sujet, Delamotte et Penloup (Delamotte et al, 2000, p.129) soulignent que

Dans l'expérience de l'écriture, le scripteur passe par une épreuve identitaire indissociable d'une tension cognitive. Si un ensemble de valeurs circulent dans son imaginaire, il sait qu'il lui incombe de ramasser sa pensée pour la traduire en un langage écrit. Une intense activité le mobilise: sa vision du monde, sa mythologie personnelle, ses idéaux s'entrechoquent avec les mots qui lui viennent et pour lesquels il oscille, tant leurs valeurs hétérogènes l'emportent dans une valse hésitation langagière et interprétative.

Voilà exactement la situation dans laquelle je me trouvais avant d'envisager ma voie d'approche et d'élaborer mon itinéraire. Mais encore, à cela s'ajoutait aussi la nécessité épistémologique d'un processus d'introspection rétroactif. Je devais effectivement convoquer et revisiter différentes trames existentielles dans une optique dialogique, analytique et interprétative. Ici se précise

[U]ne fonction identitaire de l'écriture avec l'idée d'un «continuum » entre identité personnelle et identité scolaire ou professionnelle, vers une maîtrise de la polyphonie énonciative autour de sa propre voix; une fonction heuristique, comme lieu de travail conceptuel; une fonction de mise à distance, qui peut favoriser l'identification et l'articulation des référents en jeu (expériences/observations, cours, lecture...); une fonction communicationnelle spécifique :c'est-à-dire autocommunicationnelle et/ou réservée aux pairs dans le cadre d'interactions gérées par le formateur. (Delamotte et al, 2000, p. 139) 
Ainsi, avant même de prendre connaissance de la pensée de ces auteurs, j'avais déjà amorcé l'articulation de ce continuum schématisé sous forme d'itinéraire. De fait, l'ordre caché était à l'œuvre ici aussi, annonçant déjà l'avènement du « sujet écrivant » qui me permettrait de sortir des entrechoquements et oscillations.

Comme le souligne Ehrenzweig (2005, p. 28)

Toute structure artistique est essentiellement « polyphonique »; elle ne se développe pas selon une ligne unique de pensée, mais en plusieurs courants superposés à la fois. Aussi la créativité exige-t-elle un type d'attention diffus, éparpillé, en contradiction avec nos habitudes logiques de pensée.

C'est cette même créativité, pouvant permettre en quelque sorte ce même « type d'attention, diffus, éparpillé, en contradiction avec les habitudes logiques de pensée "), qui se devait d'être à l'œuvre dans mon travail d'écriture, à la différence près toutefois que ce travail serait chapeauté par une instance rationnelle préstructurante, en l'occurrence mon schéma-itinéraire.

\subsubsection{Tracer ma voie}

Partant, pour répondre à cette exigence de formalisation dans « un discours structuré et structurant», et pour tenter de mettre à jour ma propre structure artistique intériorisée, celle qui a donné naissance à l'accompagnement artistique dans la convivialité créatrice, il me fallait «établir un appareillage 
méthodologique qui pourrait servir la formation et les pratiques en art. » Pour y parvenir, comme le soulignent Bruneau et Burns (Bruneau, Villeneuve, 2007, p. 155), il me fallait adapter mon approche d'investigation aux particularités contextuelles et épistémologiques de ma recherche.

De fait, alors que je me questionnais, que j’écrivais et réécrivais, déjà, une approche investigatrice, qui se voulait adaptée à ces particularités contextuelles, émergeait à travers l'idée de l'ordre caché, acté, dévoilé et communiqué. Succinctement, car ces aspects seront abordés plus en détails au troisième chapitre, l'ordre caché concerne l'origine des actes posés, le souvenir et la description. L'ordre acté est le fait du mouvement, de l'action et de l'exploration. Puis, l'ordre dévoilé me dirige vers le dévoilement du sens, sa conceptualisation et sa formulation. Finalement, l'ordre communiqué concerne le sens émergeant et sa formalisation créative qui se veut ouverte sur l'altérité.

\subsubsection{Franchir le passage du sujet écrivant}

C'est ainsi que cette approche investigatrice ordonnée émergera progressivement sous la forme d'un itinéraire d'écriture. Cet itinéraire à caractère interstructurant permettait l'avènement du scripteur qui «convoque et met à l'épreuve sa pensée, son histoire de scripteur, la symbolique de l'écrit, la charge émotionnelle et affective qui adhèrent à une telle expression, qui habitent telle pratique langagière (Delamotte et al, 2000, p.131). 
Cet itinéraire devait être élaboré et orienté de sorte que, comme le soulignent encore Gippet et Jorro (Delamotte et al, 2000, p. 131), il ne puisse y avoir « d'arraisonnement de la pensée du scripteur par l'écriture et de l'écriture par la pensée, mais une interstructuration [...]. » Dans l'optique d'un travail sur le sens immanent, mais encore caché, cette dynamique scripturale semblait ouvrir sur des voies épistémologiques fiables. Aussi, cette démarche d'écriture m'offrait la possibilité d'éprouver ma pensée dans mes conduites langagières, « [...] qui par leur propre tournure, la modifient en retour» (Ricœur in Delamotte et al, 2000, p. 131). C'est dire que ce type de projet d'écriture, «en tant qu'inscription de soi dans un discours, en tant que prise en charge énonciative, marque une forme d'émergence d'un sujet dans la production discursive » (Delamotte et al, 2000, p. 56). En créant cet itinéraire, fait important, j'avais franchi ce passage dont parle Gippet et Jorro qui résultait « de l'avènement du sujet écrivant » (Delamotte et al, 2000, p. 129). Effectivement, je me découvrais en tant « qu'auteur-interprète ${ }^{11}$ d'une parole, en tant qu'opérateur cognitif ${ }^{12}$ et en tant qu'acteur situé ${ }^{13} \gg$ (Delamotte et al, 2000, p. 129).

Dès lors, je pressentais que cet itinéraire était apte à me conduire à la conquête de mon autonomie d'artiste réflexive, dans des espaces et des lieux qui me sont propres, que je pourrais explorer intentionnellement et dont je pourrais revenir chargée d'un sens neuf, sans m'être égarée pour autant. Cet itinéraire ordonné me proposait également un

${ }^{11}$ Où la «conscience du scripteur est élargie aux résonances affectives et émotionnelles qu'il dépose dans l'écrit et qu'il questionne. " (Delamotte et al, 2000, 129)

${ }^{12}$ Où la « relation à l'écrit est nourrie d'une nouvelle exigence, ce que nous désignons avec l'expression «tension cognitive » dès qu'il mobilise sa pensée. » (Delamotte et al, 2000, 130)

13 «En tant qu'acteur situé, il parle (sic) son positionnement du sujet écrivant par rapport aux autres voies qu'il convoque. » (Delamotte et al, 2000, 130) 
espace où organiser et construire un discours cohérent en vue de l'éprouver et de l'améliorer.

\subsubsection{Dialoguer avec mes textes}

Dès ce «passage du sujet écrivant» franchi, je prenais possession de mes moyens cognitifs et scripturaux. Par l'écriture, la lecture, la réécriture, la relecture, ma pensée et mes textes s'interstructuraient à travers ce rapport dialogique rétroactif que j'avais instauré. Ainsi, l'écriture descriptive de l'ordre caché, première étape de l'itinéraire, me fournissait une base référentielle ${ }^{14}$ que l'écriture réflexive m'amenait ensuite à explorer « scripturalement ». Ce qui me conduisait à l'écriture intégrative de l'ordre dévoilé, dans laquelle le rapport dialogique des textes m'offrait la distance nécessaire pour articuler un discours rationnel et amorcer ainsi un travail conceptuel. Puis, l'écriture créative de l'ordre communiqué, qui s'effectuait en surimposition aux textes de l'écriture intégrative, rendait possible une formalisation discursive cohérente de mon rapport à l'art et à l'autre par le biais de l'accompagnement artistique.

Cette instrumentalisation des différents registres du discours scriptural m'amenait graduellement à réaliser le potentiel médiateur de l'écrit. C'est véritablement à partir de cette perspective médiatrice et dialogique que j'ai pu considérer l'écriture comme un outil cognitif et ainsi bénéficier de sa fonction de mise à distance. J'étais

${ }^{14}$ Base référentielle qui je le rappelle est constituée en grande partie des écrits des prises 1 et 2 de la recherche, voir section 2.1.1 
maintenant apte à explorer ma polyphonie personnelle et, par le fait même, à me « constituer un lieu où objectiver des savoirs en construction, un lieu de (re) travail conceptuel. » (Delamotte et al, 2000, p. 13)

\subsubsection{Réguler ma réflexion}

Ainsi, dans le cadre de ma recherche, l'écriture, dans son application fonctionnelle, est partie prenante de cette passerelle entre mon expérience artistique, mes savoirs intuitifs et les savoirs explicites. C'est cette passerelle, qui schématisée sous forme d'itinéraire d'écriture, fait figure d'appareillage méthodologique autour de la fonction médiatrice de l'écrit et sert non pas la «transmission/réception de concepts (ou représentation mentale) conçus indépendamment, mais un lieu où ils se construisent. » (Delamotte et al, p. 137)

En conclusion, Gippet et Jorro notent que «l'écriture peut constituer en formation professionnelle un lieu réflexif pour la régulation de l'action » (Delamotte et $a l, 2000$, p. 138). À cet égard, je tiens à souligner que l'écriture peut aussi constituer un acte favorisant la régulation de la réflexion. C'est du moins ce vers quoi tendait ma volonté lorsque j'ai élaboré mon schéma itinéraire. Car, réguler sa réflexion nécessite d'être guidé à travers une structure souple, ordonnée et orientée, d'autant plus lorsqu'on accède à des données de base qui procèdent de l'intimité la plus profonde, comme ce fut le cas pour moi. 
Dans cette section, j'ai mis en relief mes notions personnelles de l'ordre et du sens à partir desquelles s'est construit mon schéma-itinéraire. Suivra maintenant la présentation détaillée des composantes de ce schéma. 


\subsection{Ordonnancer et schématiser mon itinéraire}

Une pensée créatrice est capable d'osciller entre ses modes différenciés et indifférenciés, et de les atteler ensemble pour leur confier des tâches bien précises

Ehrenzweig (2005)

Je présenterai ici d'une façon détaillée ma méthodologie de recherche par le biais du schéma-itinéraire que j'ai créé ${ }^{15}$. Je passerai en revue les éléments qui y figurent car chacun d'eux représente une composante à partir de laquelle s'est articulée ma démarche scripturale. Toutefois, pour bien mettre ce schéma en valeur, je dois préalablement aborder la manière dont je me suis approprié la notion de l'ordre. Pour ce faire, il est nécessaire que je présente succinctement, et de manière tout à fait personnelle, ma conception du Soi inspirée de la pensée jungienne.

Jung, le soi et l'ordre

Ce que je retiendrai ici de la pensée jungienne est que le Soi y est considéré comme un aspect de l'homme qui le dépasse infiniment. Selon Vézina (Vézina, 2001, p.145), psychologue et spécialiste de la pensée jungienne, notre « besoin de sens et de cohérence dans notre mythe personnel proviendrait du Soi. » Il cite Jung qui stipule que «le soi est non seulement le centre, mais aussi le périmètre qui inclut conscient et

${ }^{15}$ Afin de mieux appréhender cette section, il importe de le faire en se référant simultanément au tableau 1, Schéma-itinéraire : Structure de compréhension pour amorcer le processus d'écriture. (voir p. 45) 
inconscient; il est le centre de cette totalité comme le moi est le centre de la conscience. » (Jung in Vézina, 2001, p.145) Contrairement au Moi qui appartient à la dimension consciente, le Soi aurait sa source dans les profondeurs de l'inconscient et engloberait aussi le conscient. J'en déduis que les phénomènes reliés au Moi conscient se déroulent donc dans l'espace et le temps, là où les événements nous apparaissent de façon chronologique. En regard de mon schéma, cet aspect correspond à l'ordre acté, au mouvement. Par contre, les phénomènes reliés au Soi prennent leur source en deçà de la trame spatio-temporelle habituelle, c'est-à-dire hors du Moi conscient, c'est l'ordre caché, l'origine, là où gît la potentialité du sens. À cet égard, le Soi représente une totalité englobante et, selon la pensée jungienne, le Soi tendrait sans cesse à s'actualiser dans la conscience par le processus d'individuation, puisque « le soi est aussi le but de la vie, car il est l'expression la plus complète de ces combinaisons du destin que l'on appelle un individu. ». (Jung, in Vézina, 2001, p. 145) C'est l'ordre dévoilé de mon schéma itinéraire, alors qu'un rapport signifiant s'établit et qu'une formulation émerge. Chez Jung, le concept du Soi suggère que chaque être humain serait porteur d'un réservoir de potentialités existentielles à réaliser, ainsi, toujours en référence à mon schéma, c'est l'ordre communiqué, l'acte de création, c'est-à-dire le sens formalisé ouvert sur l'altérité. 


\section{L'ordre caché de mon cheminement artistique}

C'est autour de cette tendance ontologique qu'aurait le Soi à actualiser ses potentialités que s'est profilée en moi l'idée d'un ordre caché, bien avant celles de l'ordre acté, dévoilé et communiqué, qui s'y sont greffées par la suite. Le fait que l'art soit arrivé tardivement dans ma vie est un facteur très important dans mon cheminement artistique. Ceci précisé, lorsque, dans un rapport chronologique orienté vers le sens, j'observe les différents aspects de mon expérience artistique, que ce soit la création picturale, les études ou les ateliers, il m'apparait évident qu'au delà de ma volonté propre et éclairée j'ai actualisé là, de façon spontanée, un potentiel artistique qui m'a toujours habitée, mais dont j'avais à peu près ignoré l'existence ma vie durant, puisqu'il participait d'un ordre caché. Pourtant, pendant toutes ces années, alors que ma nature créatrice s'exprimait dans différents domaines, autres que l'art toutefois, ce potentiel se dépliait quand même, exaltant une instance implicite dont les échos m'arrivaient sous forme d'intuitions ou d'expériences intenses. Irrésistiblement, je me devais de répondre à ces intuitions, et je le faisais en posant des actes spontanés en accord avec celles-ci. Il en a été ainsi entre autre pour le choix d'entreprendre des études supérieures en art, alors qu'il ne s'est écoulé à peine que quelques jours entre ma décision et mon inscription effective. Et puis, pour moi, cette spontanéité était essentielle, car d'emblée elle excluait toute réflexion trop analytique, qui je crois m'aurait éloignée de ma (la) nature humaine profondément créatrice. C'est ainsi qu'à l'aube de cette recherche, portant mon regard en arrière, je comprenais qu'il me fallait donner un sens et un fondement solide à ma 
démarche artistique qui s'était construite avant tout à partir de l'écoute spontanée de mes intuitions, c'est-à-dire, à partir d'un ordre caché, d'un sens immanent.

L'ordre acté de mon projet de maîtrise

À travers mon projet de maîtrise, je devais donc cheminer, intentionnellement cette fois et en pleine conscience, vers un but créatif signifiant. Il me fallait faire œuvre de sens, et ceci tant au regard de mes études en art que de mes ateliers. Conséquemment, le style réflexif de ma recherche me donnait à envisager mes expériences artistiques à partir d'une modalité et d'une perspective nouvelle.

Pour mieux comprendre la portée singulière de l'art et de l'accompagnement dans ma vie, je devais tenir compte du fait que ma démarche d'accompagnement artistique s'était inaugurée avant tout à travers mon parcours d'atelier. C'est pourquoi ce parcours fait l'objet du troisième chapitre du mémoire. Pour cause, car c'est ce parcours qui m'a portée, d'un même souffle, tout à la fois vers la convivialité créatrice à travers l'accompagnement artistique; vers l'autoformation à travers la conception et l'animation d'ateliers artistiques; et vers l'autoaccompagnement par le biais de cette recherche.

Comme le soulignent Delamotte et Penloup (Delamotte et al, 2000, p. 60), « étudier le processus créateur consiste à retrouver le chemin parcouru et à repérer l'organisation du travail artistique des premiers instants jusqu'à la présentation 
publique "), ou, dans mon cas, jusqu'au dévoilement du sens et à sa formalisation dans un mémoire de maîtrise.

Conséquemment, après avoir abordé les notions du Soi et de l'ordre, intrinsèquement liées dans mon schéma-itinéraire, la prochaine section traitera de chacune des composantes de ce schéma.

\subsubsection{Ordre caché et origine du sens : écriture descriptive}

Première étape, l'écriture descriptive qui, constituée de l'écriture parallèle, de l'invitation «Écris-moi » et des trames narratives, textes qui pour la plupart ont été rédigés dans les deux premiers moments de la recherche, figure en quelque sorte l'entrée en matière de ma démarche réflexive ${ }^{16}$. Cette première étape se distingue par des moments d'introspection synchronique et diachronique que je tente de décrire avec le moins possible de surimpositions psychologisantes, analytiques ou interprétatives. Cette manière d'écrire favorise une posture scripturale qui rend possible une certaine distanciation face à mes états d'être les plus intimes.

L'écriture descriptive s'accole à l'ordre caché parce qu'elle consiste en du matériel et une stratégie ${ }^{17}$ d'écriture apte à me rapprocher du sens caché qui a guidé mes

\footnotetext{
${ }^{16}$ L'intégralité de ces textes ne font pas partie de ce mémoire, y figurent seulement quelques extraits pertinents.

${ }^{17}$ « La stratégie suppose un investissement dans le temps, elle ne peut construire une action que dans la durée en la pensant à long terme. La tactique, elle, se meut dans l'instant : elle joue avec les événements, pour en faire, comme le dit Certeau, des "occasions». Elle est une réponse temporaire à un besoin du moment. Dans l'invention des moyens de passage à l'écriture, on a affaire à nombre de ruses et d'astuces, de trouvailles et de détournement des savoir-faire de
} 
actes. À cet égard, elle constitue aussi une banque de données regorgeant d'éléments signifiants, souvent profondément enfouis, qu'il me reviendra de mettre à jour aux étapes subséquentes, en l'occurrence par l'écriture réflexive et intégrative.

En résumé, l'écriture descriptive tend à déplier volontairement les situations, états ou évènements à partir d'un regard sensoriel, sensible, mais sans émotivité : ce que j'ai vu, dit, senti, goûté, touché, entendu, ressenti, pensé, etc. À cette étape, ce sont deux trames temporelles qui m'intéressent plus particulièrement, soit le passé et le présent.

1) Écriture parallèle : avancer avec tout de soi

S'engager dans une recherche basée sur un processus autoréflexif nous amène assurément dans nos zones intimes et profondes. Ainsi, on se questionne, on se remet en question, on cherche à comprendre davantage sur soi. C'est ici que l'écriture parallèle s'est avéré un outil précieux. Lorsque je l'ai utilisée, c'est que mon écriture de recherche stagnait ou semblait contrainte pour des motifs indistincts. En cela, l'écriture parallèle permet d'éclairer quelques zones d'ombre.

Cette forme d'écriture se dit parallèle parce qu'elle s'effectue en parallèle avec l'écriture principale de la recherche. Mais contrairement à cette dernière, elle n'est pas

l'autre à son profit, qui prennent de biais et non de front la mise en œuvre du texte. Ces inventions sont et restent tactiques si elles ne sont pas l'objet d'une activité réflexive, d'un retour sur les raisons de leur fabrication et leurs modes de fonctionnement. [Ainsi, la phase de réflexion], de distanciation et de théorisation de l'action [...] opère le passage de la tactique à la stratégie, du bricolage au savoir. » (Delamotte et al, 2000, p. 55) 
dédiée aux instances institutionnelles. C'est une écriture de l'intime, une écriture de la sensibilité, de l'accueil et de l'ouverture. Elle me permet de me situer « scripturalement» dans mes états d'être, sans excès d'analyse ou de rationalisation. Elle donne lieu et espace à ce « tout de soi », personnel, intime, réservé, qui se trouve remué de quelque manière par l'amorce d'un projet créatif. Ne serait-ce le fait qu'elle s'amarre directement à mon projet de recherche, l'écriture parallèle ne diffèrerait que très peu de l'écriture d'un journal intime en termes d'autoréflexivité et de fonction exutoire. Il s'agit effectivement d'une description libératrice de mes états d'âme. Conséquemment, l'écriture parallèle fluidifie le courant créatif, libère les digues qui isolent certaines zones d'ombre, redirige dans le flux créatif des éléments jusque-là stagnants, enrichissant ainsi d'un limon fertile l'écriture principale de la recherche. Fonctionnellement, il s'agit aussi de garder l'écriture en mouvement, de ne rien laisser se figer, de reconnaître et d'accueillir tout ce qui en soi gravite autour de l'écriture principale, celle du mémoire en l'occurrence, mais qui ne peut en faire explicitement partie : liens de synchronicités, opinions personnelles, prises de conscience, impressions, états d'âme, projections, émotions, souvenirs, etc. L'écriture parallèle peut aussi être une expression parallèle, car parfois ce sont des dessins, des schémas et souvent même des dialogues qui ont émergé. 
Écriture parallèle, 1 juillet 2010, Kamouraska

[...]mais, si j'étais sans barrières et sans limites, c'était qu'on me les avait prises, on avait forcé mes limites les plus intimes. Ce que j'avais de plus précieux, tout est parti en éclats, en "fragments" oui, en même temps, dans une violence extrême [...] mais mon expression bafouée, je l'ai quand même trouvée par des voies détournées, celles des participants de mes ateliers. Je les ai fait créer, car moi je ne pouvais pas créer, je ne pouvais me permettre, moi, de créer, mais il fallait que je crée puisque tel était mon destin, alors le destin s'est accompli au mieux. On exerce le métier de son plus grand conflit, apparemment, on donne ce dont on a le plus besoin [...]. Dénouer les conflits pour oxygéner mon vivre, cela m'est nécessaire afin de m'accomplir à travers une action consciente plutôt qu'à travers une réaction (aussi louable soit-elle) motivée par des motifs inconscients [...].

2) «Écris-moi »: s'explorer, s'exprimer, être reçue

Dans le deuxième moment de ma recherche, ma question de recherche et mes objectifs me posaient un problème qui me confinait dans une position duelle et paradoxale: je me voyais aborder de l'extérieur un sujet qui en réalité m'était profondément intime. Je ne savais comment procéder, mon écriture était trop théorique, pensant en cela répondre aux exigences institutionnelles. Ainsi, j'étais en décalage, me plaçant en inquisitrice devant un objet, alors même que je savais intimement qu'il n'y avait pas d'objet, donc, de prime abord, pas d'objectivation possible non plus. Il n'y avait effectivement que sujet, que subjectivité en fait, laquelle se devait, j'en prendrai conscience plus tard, d'être avant tout assumée. Ainsi, mon expérience d'atelier et d'accompagnement artistique n'était pas un objet à investiguer, ni par ailleurs un sujet à analyser, mais bien une expérience à part entière qui m'avait été donnée de vivre de tout 
mon être, et qui plus est esthétique, dans tous les sens du terme. Et cette expérience me dépassait. Pour mieux la comprendre, je devais donc adapter ma perspective et ma voie d'approche.

Mais comment faire? Comment m'assurer d'aller toujours vers ma singularité afin d'honorer ma quête de sens? C'est ici que la pertinence de l'invitation « Écris-moi » entre en jeu. Ces exercices d'écriture intime de libération de la parole, contrairement à l'écriture parallèle ou au journal personnel, trouvaient un exutoire dans le phénomène de la réception. Car effectivement, je répondais là à une invitation de ma codirectrice à lui écrire pour délier mes pensées et mon écriture. C'est le fait de savoir que ma parole serait accueillie qui a fait en sorte que je puisse partir allègrement à ma propre rencontre, aux sources mêmes de ma singularité. C'est ainsi que, destinés au partage pur et simple, des mots jusque-là cachés émergeaient, des sentiments et des impressions se formulaient, des sentis, des ressentis et même des ressentiments étaient mis à jour, certains pour une première fois. Voilà d'ailleurs pourquoi cette tactique ${ }^{18}$ d'écriture figure sous le thème de l'ordre caché. C'était bien là une voie de passage qui, à travers le phénomène de l'affirmation, de la confirmation et de la réception, a donné lieu, sans que je ne m'y attende, à une prise de parole écrite ancrée profondément dans ma réalité personnelle. Ici aussi, comme ce fut le cas avec ma directrice pour l'amorce du troisième moment de la recherche, il s'agit d'un processus d'autorisation de l'écriture, mais intime celle-là.

\footnotetext{
${ }^{18}$ Pour la définition de tactique, voir note 17.
} 
Écris-moi, lettre 7, automne 2010: Ouvrir le noyau

[...]La démarche exploratoire, artistique et spirituelle, fait que nous devenons plus sensibles à l'irrationnel. En fait, la démarche artistique nous propose de voir autrement. Ainsi, dans mes ateliers, une déstructuration-restructuration s'opère presque simultanément, à la source même, libérant de ce fait nos manières d'être et de penser trop figées. Nous sommes ainsi propulsés dans des zones toujours plus profondes et fertiles de la psyché. Cela se répercute au niveau métaphysique, subtil et holistique. De plus, cela est enrichissant non seulement pour la conscience individuelle, mais aussi pour la conscience collective, par résonance. C'est comme si le faire l'art est inducteur d'un mouvement organique et multidimensionnel à même de générer des énergies subtiles, évolutives, vitales et puissantes. Faire l'art et surtout faire l'art ensemble fluidifie les mouvements d'être, ce qui engendre une vision nouvelle qui se répercute de manière signifiante dans la famille, la communauté, la collectivité, etc. En gros, voilà pourquoi selon moi le faire l'art est un acte politique. Entre autre, il nous déconditionne d'un automatisme grégaire, nous met en contact avec notre singularité créative, stimule et valide notre sensibilité à l'irrationnel, ajoutant en cela à l'aventure du vivre. [...]

3) Récit autobiographique et trames narratives: plonger dans son intimité profonde

À la fin de ma scolarité, j'ai participé à un séminaire sur le récit autobiographique à l'Université du Québec à Rimouski avec Jeanne Marie Rugira. J'y ai été sensibilisée à des techniques d'intériorisation qui ont favorisé l'émergence de contenus psychiques profondément enfouis en moi, dont certains mêmes étaient tout simplement tombés dans l'oubli le plus total, demeurant ainsi cachés. J'ai utilisé ces techniques afin d'explorer mon intériorité. J'ai ainsi eu accès à une connaissance et des données de première main en ce qui concerne des thèmes qui me tiennent à cœur, tels l'accompagnement, le désir d'art et la convivialité créatrice, entre autres. Pour les 
besoins de la recherche, plusieurs de ces textes ont été revisités à la lumière de l'écriture réflexive, intégrative et créative.

Récit autobiographique, hiver 2010 : Un si petit dessin

[...] Ce petit dessin est arrivé comme une pluie fine sur un après-midi collant et assommant de chaleur.[...]Dans mon intériorisation j'ai revécu pleinement l'intensité de ce dessin. Alors, en contact avec mon ressenti mémoriel, je me revois tournant une page du livre, arrivant sur ce dessin et continuant, tournant la page suivante, mais réalisant soudain que quelque chose de moi était resté dans la page précédente. Avec ce petit dessin me dis-je? Étrange. Je me vois faire demi-tour pour revenir à cette page, revoir et observer ce petit dessin, sachant que je ne pourrai continuer sans cette part de moi qui y était restée. Et vlan! J'avais raison! Quelque chose se passe. Je vois! Mais voilà, je pense que je vois mais je ne vois pas. C'est mon ventre qui voit, c'est ma peau, c'est quelque chose derrière mon cerveau qui voit, c'est mon énergie, mais ce n'est pas mes yeux. Je ne vois pas, je ressens. C'est bien ça, l'art est dans le corps, dans toute la vitalité du corps sensible, pas dans la tête, pas dans le concept! Ah! Moi blasée? Jamais! Impossible, car l'art c'est organique, toujours vivant, mouvant, évoluant. Ce n'est pas une histoire de concept c'est une histoire de vie brut qui colle à la peau, ce n'est pas une histoire de couleur c'est une histoire d'ondes et de vibrations, pas une histoire de technique mais de mouvement d'être, pas de volonté mais de spontanéité. L'art ça ne s'étudie pas, ça nous enseigne. Ça ne se cherche pas, ça nous trouve. L'art ce n'est pas quelque chose qu'on donne, c'est quelque chose qu'on abandonne. Et c'est cet abandon qui s'offre d'abord à soi, puis à l'autre, qui nous apprend à recevoir à même ce don précieux. L'art c'est une question de vérité personnelle, et ce qui provient de la vérité de l'artiste a de bonnes chances de nous livrer aussi une vérité sur nous, ce que ce petit dessin a fait. L'art ça nous ouvre au sens en soi.C'est le lien entre la conscience humaine et l'infini inconnaissable. L'art, c'est tout ce que nous avons pour transformer le réel en réalité vive et évolutive. [...] 


\subsubsection{Ordre acté et mouvement : écriture réflexive}

La deuxième étape de mon itinéraire est l'ordre acté, là où le matériel descriptif de l'étape précédente est abordé sous l'angle exploratoire et réflexif. Cette forme d'écriture réflexive s'apparente à l'ordre acté parce qu'à travers elle je suis dans un mouvement simultané d'exploration et de réflexion. Je suis également réceptive, me disposant à ressentir du sens. L'écriture réflexive, comme son nom l'indique, me permet tout à la fois de réfléchir et de me réfléchir à travers un processus exploratoire de lecture, de relecture et de réécriture de mes textes. De fait, je suis entièrement tournée vers ma subjectivité tout en bénéficiant d'une certaine distance grâce à cette stratégie scripturale. Ce qui m'intéresse n'est pas tant moi comme sujet pensant, mais plutôt moi en tant que sujet se pensant. J'interroge mes propres textes, me sensibilisant au sens qu'ils véhiculent, les laissant résonner. Je tente par le fait même d'en détecter les similarités, d'en isoler les mots clés, les énoncés récurrents, etc. Le journal de recherche et le récit de pratique que je présente ici font partie de l'ordre acté.

\section{1) Le journal de recherche : garder le fil}

Le journal de recherche s'apparente à l'écriture réflexive parce qu'il participe à ma réflexion, mais aussi, parce qu'il me fournit un reflet de l'avancement de la recherche et des points de repères importants. J'ai commencé le journal de recherche par souci d'archivage et de traces. Souci d'auto-poïétique aussi. Mais encore, ce journal 
m'aide à garder le fil et me sert d'ancrage. Y sont notés mes lectures, mes commentaires de lecture, ce que je ne dois pas oublier, les échanges avec la codirection, un compte rendu quotidien du travail accompli ou à faire, les liens signifiants entre textes et auteurs, mes projections, mes repositionnements, mes reculs, etc. À la différence de l'écriture parallèle, le journal de recherche, envisagé exclusivement en regard de l'avancement de la recherche, contient très peu d'éléments personnels, lesquels le cas échéant y font l'objet de renvois, soit dans l'écriture parallèle ou mon journal personnel.

Journal de recherche, 7 juillet 2010

$12 h 25$

Reçu ce matin le livre de Danielle Nolin ${ }^{19}$. Ai cru bon d'en faire des commentaires personnels dans l'écriture parallèle. Rejointe par les propos intelligents de cette auteure artiste.

\section{$16 h 25$}

Problématique révisée à la lumière de ma grille. Beaucoup de choses encore aujourd'hui. Lecture du premier chapitre de Nolin qui m'aide à comprendre encore davantage le fait que je dois partir de ma problématique pour envisager ma recherche. Je comprends qu'il ne me sert à rien d'avancer davantage car je ne sais pas vraiment où je vais. Je dois partir de ma problématique. Je l'ai donc reprise, avec la grille que j'ai visualisée avant-hier avant de m'endormir.

2) Récit de pratique et récit d'artiste : un geste heuristique

Pineau et Legrand (2007, p. 3) parlent du récit, de ces «écritures du moi », en tant que « prise humaine de savoir et de pouvoir sur la vie ». Ils en parlent aussi comme

${ }^{19}$ Nolin, D. (2008), L'art comme processus de formation de soi. L'Harmattan, Paris 
de ces pratiques de prise en main de cette vie qui «émergent aux frontières de l'existentiel et du professionnel, du privé et du public, du dicible et du visible ». Ils soulignent également que ces écritures du moi, engageant un processus d'expression de l'expérience, se définiraient « comme recherche et construction de sens à partir de faits temporels personnels $[\ldots] »$. J'inclus en cela le récit de pratique et le récit d'artiste, lesquels toutefois sont rédigés dans le but d'être communiqués.

Le récit de pratique, qui figure dans ma banque de données scripturales de l'écriture descriptive, et dont je présente un extrait plus bas, consistait à revivre dans un ordre chronologique le déroulement d'un atelier type. Je l'ai fait en revisitant intérieurement de nombreuses trames temporelles issues des expériences d'ateliers. Ces trames sont différentes dans leur contenu, mais identiques dans leur forme. Ce sont ces formes, la structure procédurale des ateliers en fait, que le récit de pratique m'aura aidé à synthétiser. Cet exercice m'aura aussi permis d'esquisser une configuration mentale du fondement structurel et fonctionnel de mes ateliers. Et puis, maintenant, par la double perspective que ce récit de pratique m'a proposée, l'expérience d'atelier se trouve enrichie de façon significative, et par l'intervention de l'auteure, alors que j'ai dû rédiger un texte explicite, et par l'intermédiaire de la lectrice, alors que j'ai pu lire ce récit, avec une certaine distanciation. 
Extrait d'un récit de pratique : Les ateliers, comment ça se passe?

[...]Mon atelier est dans un local sans fenêtres. C'est donc un endroit fermé, ce qui au départ n'était pas nécessairement voulu, mais qui n'est pas sans me rappeler le lieu clos d'Arno Stern. J'ai fini par beaucoup apprécier. Ainsi, nous y entrons comme dans un endroit hors du temps. Après que la porte se soit refermée, les bruits et sons que nous y entendons sont les nôtres: le glissement des mines sur le papier, le frottement fébrile des brosses et des craies sur les supports, ma voix qui clame la poésie, récite et narre, donne les consignes, les contraintes, les inducteurs. Puis, bien sûr, il y a aussi les échanges verbaux qui font suite à la création. Et, en cours de création, les quelques onomatopées des participants à l'œuvre, qui surpris devant le tracé de leur geste, qui déçu ou soudainement encouragé. Et parfois, pour accompagner un exercice, une musique soigneusement choisie en fonction du rythme, des sonorités particulières, d'une harmonie inusitée ou encore, du silence entre les notes. Par cette atmosphère, déjà, une coupure se crée d'avec l'énergie souvent survoltée du quotidien. Cette délimitation spatiotemporelle est fort importante dans mes ateliers. C'est une invitation à la présence, lancée à l'organisme entier, à toute la sensibilité corporelle. Ces dispositions participent d'un déconditionnement ponctuel. C'est voulu, stratégiquement favorisé afin de brouiller un peu les références habituelles. C'est ce qui aide à faire la transition vers sa propre énergie créative et vers celle du groupe également. [...].

Quant au récit d'artiste, à caractère phénoménologique ${ }^{20}$, il a ravivé de façon particulière l'expérience ponctuelle que j'ai vécue en créant les ateliers. Comme le souligne Danielle Boutet sur son site, «le récit d'artiste ne rend pas exprimable ce qui ne l'est pas. Il cherche plutôt à connaître et à rendre compte de cette expérience de l'inexprimable ${ }^{21}$. Et cette expérience fût tellement inexprimable que je n'en avais pour ainsi dire parlé à personne, sinon que sur le vif à mon conjoint. Ce n'est que par la suite

\footnotetext{
${ }^{20}$ «Comme philosophie, la phénoménologie s'intéresse au phénomène de la conscience ainsi qu'à tous les objets qui peuvent s'y révéler » (Bruneau et Villeneuve, 2007, p. 356)

${ }^{21}$ Le texte dont cette citation est tiré s'intitule «L'expérience artistique : réfléchir, communiquer », la date est 2010, et l'adresse URL est: http://www.recitsdartistes.org/textes-theoriques/2 ii-lexperience-artistique-reflechir-communiquer
} 
que le récit, dont Thyrion propose qu'il serait « la face verbale de la conceptualisation inventive » et «geste heuristique par excellence » (in Delamotte et al, 2007, p. 50) m'aura donné à voir davantage, et sous un angle inusité, mon rapport personnel aux enjeux de la force créatrice. C'est à partir de ma singularité qu'il m'aura permis de reconnaître l'avènement de cette force créatrice, de la nommer, de lui faire place rétrospectivement et de manière plus rationnelle je dirais. L'exercice du récit m'aura aussi facilité la communication de cette expérience intuitive, intense et organique. Pour tous ces aspects, le récit d'artiste est un outil puissant puisque ces expériences de création, profondément personnelles, singulières, à la limite mystiques, sont difficilement communicables. Malheureusement, elles le resteraient peut-être sans l'appui des mots qu'offre cette forme d'écriture qu'est le récit d'artiste. Et ces mots, intimes, métaphoriques souvent, non censurés surtout, agissent comme une interface entre le vif de créer et le désir, sinon l'urgence, d'en garder des traces et d'en communiquer l'expérience. À cet égard, Boutet souligne encore que «chaque fois que nous travaillons sur une œuvre, nous faisons l'expérience de régions du sensible et de la conscience que nous sommes en train d'ouvrir. Nous vivons un surcroît d'être, une augmentation de notre sentiment d'exister, une familiarité accrue avec nos sujets, un « éveil des sens » et un « enrichissement intellectuel », comme dit Sontag. C'est cette expérience que nous tentons d'abord de raconter. " ${ }^{22}$ Ce récit, par le phénomène de la remémoration, de l'écriture et de la lecture, a restauré le contact avec mes racines créatrices et a participé pleinement à l'affirmation identitaire engendrée simultanément par le fait même de cette recherche.

${ }^{22}$ Ibid. 
L'extrait de récit qui suit fait référence à la vision de départ qui a mené à conception des ateliers.

Extrait d'un récit d'artiste : Ouvrir le noyau ${ }^{23}$

[...] Aussi, la façon dont tout cela s'était déroulé m'impressionnait beaucoup, surtout parce que, justement, je ne l'avais pas calculé, pensé, cogité, projeté, etc. En fait, j'avais juste ressenti et agi de façon spontanée en fonction de ce ressenti, sans désir ou volonté précise. Alors, même si je sais en quelque partie de moi que la création sourd des profondeurs de l'être, j'étais tout de même fortement impressionnée du sens révélateur que prenait tout ceci à travers la symbolique des nombres, de la forme, de la configuration, mais aussi à travers l'acte spontané, précis, essentiel, et à travers l'imbrication simultanée du temps passé, présent et futur, les synchronicités, etc. C'est pourquoi, alors que j'entrevoyais cette profusion de "données ", j'ai senti l'urgence de verbaliser devant un témoin tous les éléments de synchronicité que je pouvais identifier dans ce défilement incessant. Ces éléments s'instauraient trop rapidement dans une logique rétrospective pour que je puisse les écrire convenablement, les transcrire fidèlement. J'avais peur d'oublier des choses bien sûr, mais le plus important je crois, c'était de les inscrire dans la parole et de les partager. [...]

${ }^{23}$ Le récit d'artiste, dont cet extrait est tiré, porte le même titre que la lettre 7 dans le cadre de l'invitation «Écris-moi ». Ceci s'explique par le fait que le contenu de cette lettre s'inscrivait sous la rubrique de l'ordre caché. Il a suivi les étapes du schéma-itinéraire pour en arriver à l'écriture créative, au récit en tant que tel. 
2.3.3 Ordre dévoilé et direction : écriture intégrative

Suit l'étape de l'écriture intégrative. Là, je révise mes textes déjà annotés dans l'écriture réflexive, j'écris, réécris et écris encore, tout en jaugeant ma pensée à l'aune de celles d'auteurs et de chercheurs confirmés. Je confronte ainsi mes écrits et me réapproprie de façon personnelle certaines notions pertinentes à une compréhension plus pointue de mon « objet de recherche ». Également, à cette étape, je fouille beaucoup dans l'ensemble de mes nombreux écrits personnels afin de dénicher des textes pertinents. À travers le filtre d'une attention sélective, je me rassemble en fait, de façon cohérente, dans mes écrits et ma pensée. Cette forme d'écriture relève de l'articulation et de la conceptualisation, elle m'ouvre à l'ordre dévoilé et à sa formulation. C'est l'étape de l'intégration du sens qui a été pressenti à travers l'écriture réflexive de l'étape précédente.

1) Dialogique des textes : construire du sens

À cette étape, mes textes se rencontrent. Je rassemble, épure, harmonise. Je réponds à certaines questions. J'analyse, je coupe et rajoute, écrème et peaufine, synthétise et articule. C'est ainsi que je formule et reformule, encore et encore, à la lumière d'une pensée renouvelée.

\section{2) Schématisation : visualiser ma méthode}

Dès le départ, il m'aura fallu trouver un moyen visuel qui m'aiderait à ordonner ma pensée. À cet égard, j’ai conçu de nombreux schémas dans le but de m'aider à 
visualiser une voie épistémologique adéquate. Je tenais à bien préciser les limites de l'attention que je consacrerais à mon « objet de recherche », de même que "les outils d'observation et d'analyse qui rendront compte de la complexité de cette réalité et des savoirs qu'elle révèle » (Bruneau et Villeneuve, 2007, p. 155). C'est le schéma-itinéraire de la page 45 qui a été retenu.

\subsubsection{Ordre communiqué et sens : écriture créative}

Suite à tout ce travail de sens, pour que l'acte créatif devienne création à part entière, le sens pressenti qui a été formulé dans l'écriture intégrative sera en quelque sorte formalisé dans la dernière et quatrième étape de l'itinéraire qui est celle de l'écriture créative. Cette formalisation peut se présenter autant sous une forme littéraire, le mémoire par exemple, qu'esthétique, une œuvre, une exposition, etc. Cette étape finale est celle qui porte une vision de l'advenir ancrée dans le sens émergeant.

Pour conclure ce chapitre, suivront un résumé de mon itinéraire d'écriture sur lequel se fonde ma méthode de recherche et un tableau des outils d'observation et d'analyse. Quant au chapitre suivant, il s'impose comme le cœur du mémoire alors qu'y sera abordé, dans un premier temps, le cheminement qui m'a conduite vers l'accompagnement artistique dans la convivialité créatrice et, dans un deuxième temps, le sens émergeant de cette démarche d'accompagnement. 


\subsubsection{Résumé et Tableau 2}

En résumé, c'est d'abord l'écriture descriptive qui m'amène à entrer en contact avec différents registres expérientiels de ma vie et à les transcrire dans un mode descriptif. C'est ma banque de données scripturales de départ. C'est aussi là où je suis en contact avec l'ordre caché. Puis, la deuxième étape est celle de l'écriture réflexive qui concerne l'ordre acté. Cette écriture m'amène à porter un regard inquisitif sur certains textes de l'écriture descriptive. Puis, le matériel de cette deuxième étape fera l'objet de l'étape suivante, celle de l'écriture intégrative où tous les liens pertinents recueillis dans l'écriture réflexive m'aideront à cheminer vers une formulation signifiante, concluant ainsi cette troisième étape. Finalement, la quatrième et dernière étape est celle de l'ordre communiqué. Ici, c'est l'écriture créative qui, à partir des textes de l'écriture réflexive, fera en sorte que je puisse exprimer une vision nouvelle de l'advenir ancrée dans le sens émergeant.

\subsubsection{Tableau 2 : Outils d'observation et d'analyse}

\begin{tabular}{|c|}
\hline ORDRE CACHÉ \\
ÉCRITURE DESCRIPTIVE \\
Cueillette de données : écriture parallèle; « Écris-moi »; \\
trames narratives \\
ORDRE ACTÉ \\
ÉCRITURE RÉFLEXIVE \\
Outils d'observation : journal de recherche; récit \\
ORDRE DÉVOILÉ \\
ÉCRITURE INTÉGRATIVE \\
Outil d'analyse : dialogique des textes; schématisation \\
ORDRE COMMUNIQUÉ \\
ÉCRITURE CRÉATIVE \\
Étape finale de création de sens
\end{tabular}




\section{CHAPITRE III}

\section{DE LA MISE EN ORDRE À LA FORMULATION DU SENS}

\subsection{Ordre caché : dire et décrire l'élan inspirant}

Ce troisième chapitre est placé sous l'angle réflexif et exploratoire. Il consiste en un approfondissement de mon parcours artistique. Cette étape-ci du mémoire veut rendre compte de la portée de l'art dans ma vie à travers mes études, à travers la création des ateliers et à travers l'accompagnement artistique.

\subsubsection{Surprise par l'art}

J'ai eu deux rencontres avec l'art dans ma vie. La première alors que j'étais jeune adolescente, période au cours de laquelle j'ai dessiné de l'âge de 12 ans à 16 ans. Ensuite, des circonstances particulières, hors de ma volonté, m’ont éloignée du dessin. En ce qui concerne la deuxième rencontre, elle s'est effectuée relativement tard, dans des circonstances encore là assez particulières. Ainsi, à l'âge de 42 ans, je vivais depuis quelques années une période difficile et je croyais ma situation sans issue. Je vivais isolée, dans un état de profonde solitude. Puis, quelque temps après la naissance de mon petit-fils Mickaël, voulant faire un cadeau personnel à ma fille, j'ai pensé lui offrir un portrait que j'aurais moi-même réalisé. Finalement, ce portrait de mon petit-fils était non seulement 
réussi, mais sa réalisation m'avait apporté une grande joie et un sentiment d'accomplissement surprenant. J'ai alors découvert que j'avais une habileté pour le portrait. Toutefois, je n'ai pas vraiment redessiné jusqu'à ce qu'une dame, deux ans plus tard, voie la reproduction du portrait de Mickaël et me demande alors de réaliser un portrait pour elle. Ensuite, d'autres demandes sont venues. C'est ainsi que, mine de rien, tout doucement, je me suis mise à dessiner et à peindre, tous les jours, plusieurs heures par jour, ce pendant plus d'un an. Je me couchais tard afin de dessiner le plus longtemps possible. Finalement le sommeil me gagnait. Toutefois, avant de m'endormir, je plaçais mon chevalet sur une table près de mon lit avec, dessus, le portrait en cours. Je voulais que ce soit la première chose que je voie en ouvrant mes yeux. C'était en quelque sorte un rappel à la vie. Ces dessins, pareils aux cailloux du Petit Poucet, me ramenaient à la maison. Ainsi, l'art a fait son chemin en moi, graduellement, illuminant ma vie de l'intérieur, éveillant une passion nouvelle et un désir de renouer avec ma dimension spirituelle, dont je m'étais éloignée pendant sept longues années.

Je me souviens de mon premier portrait à l'huile, c'était comme si tout mon corps savait ce qu'il devait faire, je peignais naturellement. J'étais étonnée de tout cela. Ainsi, moi qui vivais isolée, sans plus de visions d'avenir, et pour ainsi dire sans espoir, en l'espace de quelques mois seulement, je me suis sentie revivre à travers l'art et les contacts sociaux renouvelés que cela a engendré. Car effectivement, j'offrais aux gens les portraits que je réalisais d'eux ou de leurs proches à partir de photographies qu'ils me donnaient. J'ai fait de cette manière plus d'une centaine de portraits au cours des deux années qui ont suivi. J'en ai vendus très peu, et seulement sur commande. Je crois que je ne voulais pas 
vraiment vendre ces portraits. En fait, je préférais les offrir, car au fond de moi je me considérais beaucoup plus redevable envers ces gens qu'eux ne pouvaient l'être envers moi : ils me permettaient d'exprimer et de partager mon amour du vivant. Amour qui, j'étais à même de le constater, était toujours vivace malgré ces années d'isolement. C'est ainsi que je me suis progressivement réintégrée à moi-même et à la société. Ce mouvement artistique vers l'autre me redonnait vie, espoir, confiance et estime. Peut-être que cette disposition artistique ne me permettait pas de gagner ma vie, mais assurément elle me permettait de gagner de la vie, et à vrai dire c'est réellement tout ce qui comptait.

\subsection{2 Études artistiques}

Cette passion nouvelle a occasionné de grands bouleversements: séparation catastrophique, changement de milieu, de mode de vie, déménagement, etc. C'était en tout et pour tout une vie définitivement nouvelle qui s'annonçait. Avec l'art comme perspective, je revivais, je me sentais guidée, protégée et à nouveau libre. J'étais heureuse et profondément reconnaissante. Je savais que mon chemin de vie prenait un autre tournant, inconnu mais incontournable, et que je devais m'y engager.

La vie m'a ainsi conduite à Chicoutimi où je me suis inscrite au baccalauréat interdisciplinaire en art sans savoir ce que tout cela signifiait vraiment. Outre le fait que la démarche universitaire rencontrait mes espoirs d'approfondir mes connaissances artistiques à plusieurs niveaux (historique, théorique, technique, anthropologique), elle répondait aussi à un besoin de me situer face à l'art. Lors de mon admission, tout s'est déroulé très vite. Le 
fait est que j'étais en retard car la session commençait la journée même où j'étais venue rencontrer le directeur du programme. Selon sa secrétaire, mon admission était plus qu'improbable puisque la limite d'étudiants admis était déjà dépassée. De plus, je n'avais ni études artistiques précédentes à mon actif, ni portfolio en règle pour appuyer ma demande. Toutefois, à la dernière minute, le directeur du programme a quand même demandé à voir ce que je produisais. Je lui ai montré mes portraits, que j'avais apportés au cas où. Aujourd'hui, je sais bien que ce que je produisais n'avait aucun rapport avec l'art conceptuel contemporain, et encore moins avec l'interdisciplinarité mise en valeur dans cette université. Cependant, ce professeur artiste, alors directeur du baccalauréat interdisciplinaire en art, m'a tout de même dit qu'il y avait une place pour moi en art et qu'il m'acceptait dans son programme. Il a même insisté auprès de sa secrétaire pour qu'elle m'inscrive alors qu'elle était très réticente pour la raison évoquée plus haut. C'est ainsi que j'assistais à mon premier cours l'après-midi même. Dans les années qui ont suivi, ce professeur a encouragé ma démarche académique et artistique, me ramenant parfois sur mon propre chemin. C'est d'ailleurs lors d'une courte conversation encourageante avec lui que j'ai pris la décision d'entreprendre une année d'étude à Paris. Séjour qui s'est avéré essentiel à ma maturation artistique. 


\subsubsection{Création des ateliers}

J'ai donc commencé mes études en septembre 2004. L'automne suivant je partais pour Paris afin d'y effectuer une année d'étude en art à l'université Paris 8. Septembre 2006, de retour à Chicoutimi, j'entreprenais ma troisième année et, à l'automne 2007, je commençais ma scolarité de maîtrise tout en finalisant mon baccalauréat. C'est au printemps 2007, dans le cadre d'un projet supervisé, que j'ai conçu et offert 4 ateliers artistiques inspirés de mes apprentissages parisiens. C'est ici que se trouve l'élément déclencheur de ma démarche d'accompagnatrice, alors que, stimulée par l'appui encourageant de mon enseignante, $\mathrm{j}$ 'ai fait mes premiers pas en conception et animation d'ateliers artistiques exploratoires. Toutefois, ces premiers ateliers seront très différents de ceux offerts par la suite en contexte populaire et qui m'ont conduite à l'écriture de ce mémoire. Ces ateliers, quant à eux, ont été conçus au printemps 2008 et quelques semaines plus tard je commençais déjà à les offrir. La section de la problématique au début du mémoire a mis à jour les points essentiels qui ont nourri mon questionnement en regard de ces ateliers (ordre caché). Ici, ce sera plutôt par le biais d'un récit d'artiste ${ }^{24}$ (ordre acté)que je rendrai compte de cette expérience de création.

\section{Préambule au récit}

Ma démarche existentielle m'amène à faire régulièrement des prises de conscience transformatrices. En ce qui me concerne, ces prises de conscience, pour être réellement

\footnotetext{
${ }^{24}$ Ce récit d'artiste s'est élaboré à la suite d'une lettre dans le cadre de l'invitation «Écris-moi ».
} 
transformatrices, doivent participer d'une expérience globale. De fait, l'expérience de création dont je ferai le récit plus bas en est une transformatrice et globale. Elle est spirituelle au sens où elle dépasse la sphère matérielle pour rejoindre les domaines de l'esprit, de l'immatériel et de l'insondable. Elle est aussi organique puisque je l'ai ressentie intensément dans mon corps par des courants d'énergie très forts, entre autre. Elle est émotionnelle également pour tout ce qu'elle a soulevé d'amour, d'émoi et de reconnaissance. Et c'est aussi une expérience psychique car elle m'a donné l'occasion de faire des liens entre les images intérieures, les souvenirs, certains événements, etc.

\subsubsection{Récit d'artiste : Ouvrir le noyau}

Tout commence un matin que j'étais plongée dans l'écriture de mon journal personnel. Des idées me sont alors venues sur la structure d'éventuels ateliers artistiques auxquels je songeais depuis quelque temps déjà. Bien sûr, j'ai commencé à écrire ces idées selon l'inspiration qui me venait, et il en venait beaucoup. Finalement, les idées arrivaient si rapidement que j'ai dû écrire de plus en plus vite, étant pour le moins surprise de cette soudaine inspiration et voulant en bénéficier pleinement. Plus j'avançais, plus je devais abréger mes mots afin de m'assurer que je puisse en écrire au maximum. J'encerclais des mots clés, je reliais par des flèches, j'encadrais des thématiques, etc. Je craignais d'être incapable de me relire, mais je ne pouvais m'arrêter ne serait-ce que quelques minutes pour faire de l'ordre. Car évidemment, j'avais peur de perdre ce fil conducteur qui s'était présenté si soudainement à moi et que l'inspiration ne se tarisse aussi subitement qu'elle ne 
m'était venue. C'est ainsi qu'en peu de temps je me suis retrouvée avec un amas de feuilles éparses autour de moi. J'y avais écrit les idées qui me venaient au sujet de l'art, de la communication, du partage que je pouvais en faire, surtout. Mais tout à la fois il me venait aussi des images, des souvenirs et des ressentis. Cet aspect est difficilement explicable, c'est comme si je ressentais et écrivais en fragments. Donc, outre les ressentis, que je ne pouvais ni écrire ni décrire, de nombreuses images se présentaient: des moments particuliers de ma vie, de mes études, de mon voyage à Paris, d'une période de ma jeunesse, de certains choix que j'avais faits, d'expériences inusitées que j'avais eues, etc. C'est pour toutes ces raisons que mon écriture n'était pas fluide et continue, mais au contraire, fragmentée et dispersée. Toutefois, même si cela parait étrange à dire, cette forme d'écriture débordait de sens, pour moi seule évidemment, parce que collée sur mon vécu.

J'écrivais ainsi depuis plus d'une heure avant qu'une pulsion ne me pousse à partir à la recherche des études picturales que j'avais réalisées à Paris en 2005. J'avais effectivement l'intuition qu'elles portaient le sens même des ateliers que j'étais en train de créer. Je me suis mise à chercher fébrilement ces études que j'avais rangées jadis, je ne me souvenais plus trop où, dans quelque pièce de la maison. Finalement, après les avoir trouvées somme toute assez facilement, je les ai installées au mur à l'aide de gommettes, sans même réfléchir à la façon dont cela se présenterait. Soudain, quelques minutes plus tard, je me suis retrouvée devant une configuration non préméditée de forme ovoïdale. Même si cette forme était parfaite et aurait pu rester ainsi, j'avais encore six diptyques dans les mains. Il était impératif que je les dispose eux aussi. C'est ce que spontanément je fis 
en séparant la configuration horizontalement avec 4 diptyques et, verticalement, avec les 2 diptyques restant. Contrairement à mon écriture, mes actes étaient fluides, rapides et précis. J'étais absorbée. Je me sentais propulsée par une étrange force de même qu'une certitude que tout était dans l'ordre des choses. Aussi, je sentais que la réflexion brusquerait le processus et j'essayais de ne pas commenter ni analyser. Je tenais à rester en contact avec mon senti, mes impulsions, ma vision intérieure. Finalement, avec l'ajout de mes 6 diptyques, la forme ovoïdale était maintenant remplie. Elle contenait les reproductions, en format $27 \mathrm{~cm} \times 21 \mathrm{~cm}$ de 22 diptyques. Chacune de ces 22 propositions présentait les diptyques côte à côte, donnant ainsi à voir la représentation de quarante-quatre études. (voir fig. 1) 


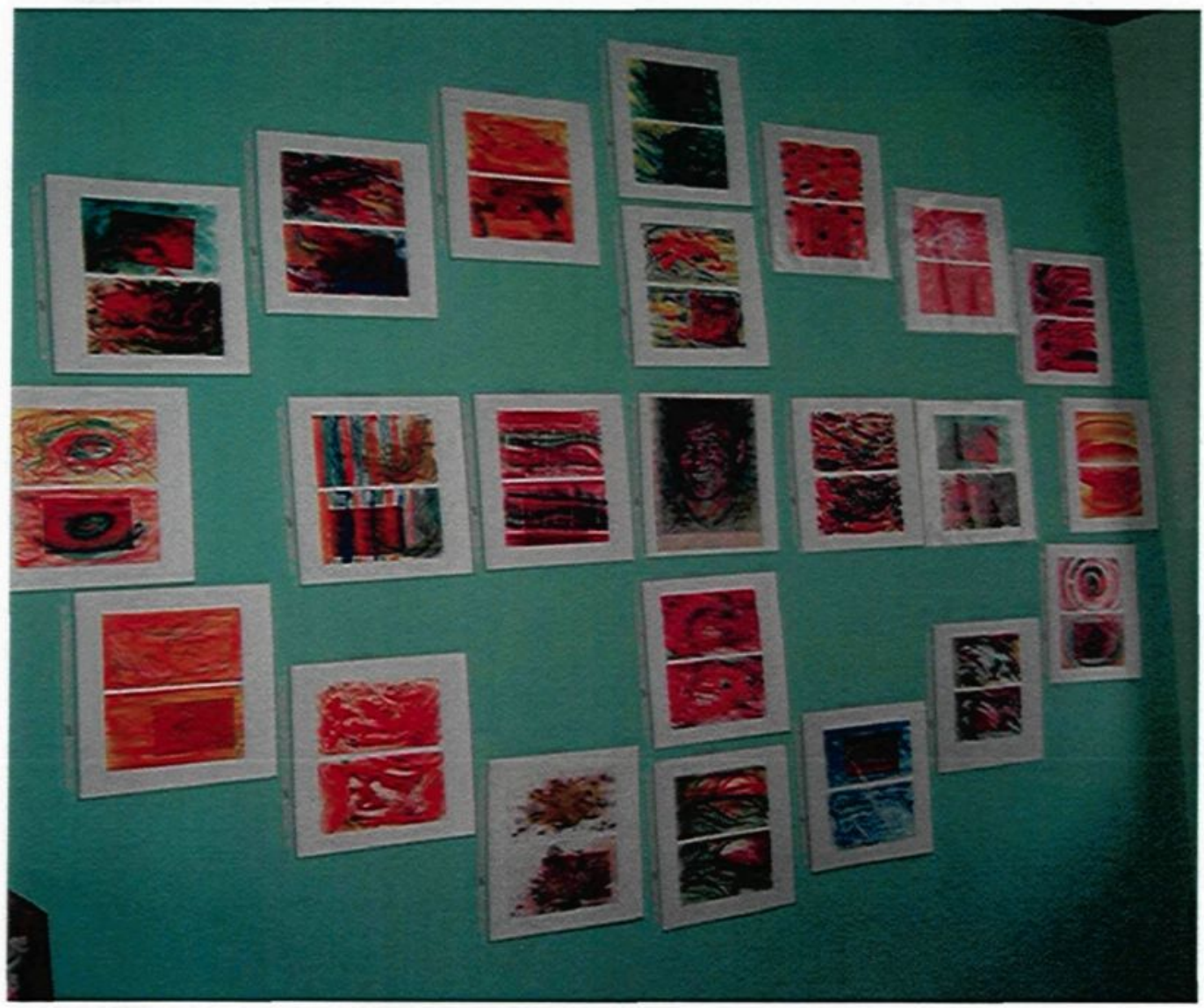

Fig. 1 : Configuration de 22 diptyques

Oui, tout était au mieux n'eût été de la place laissée vacante au centre, à l'entrecroisement de l'horizontal et de la verticale. Que faire, me demandai-je alors, car j'avais placé tous mes diptyques. Immédiatement, me vient à l'esprit ce portrait d'une sage Tibétaine réalisé aussi à Paris dans le souffle inspirant de ces mêmes études, dans le même langage pictural. Voilà que je dispose la représentation de ce portrait en plein milieu de mon œuf, comme un noyau spirituel. (voir fig. 2) 


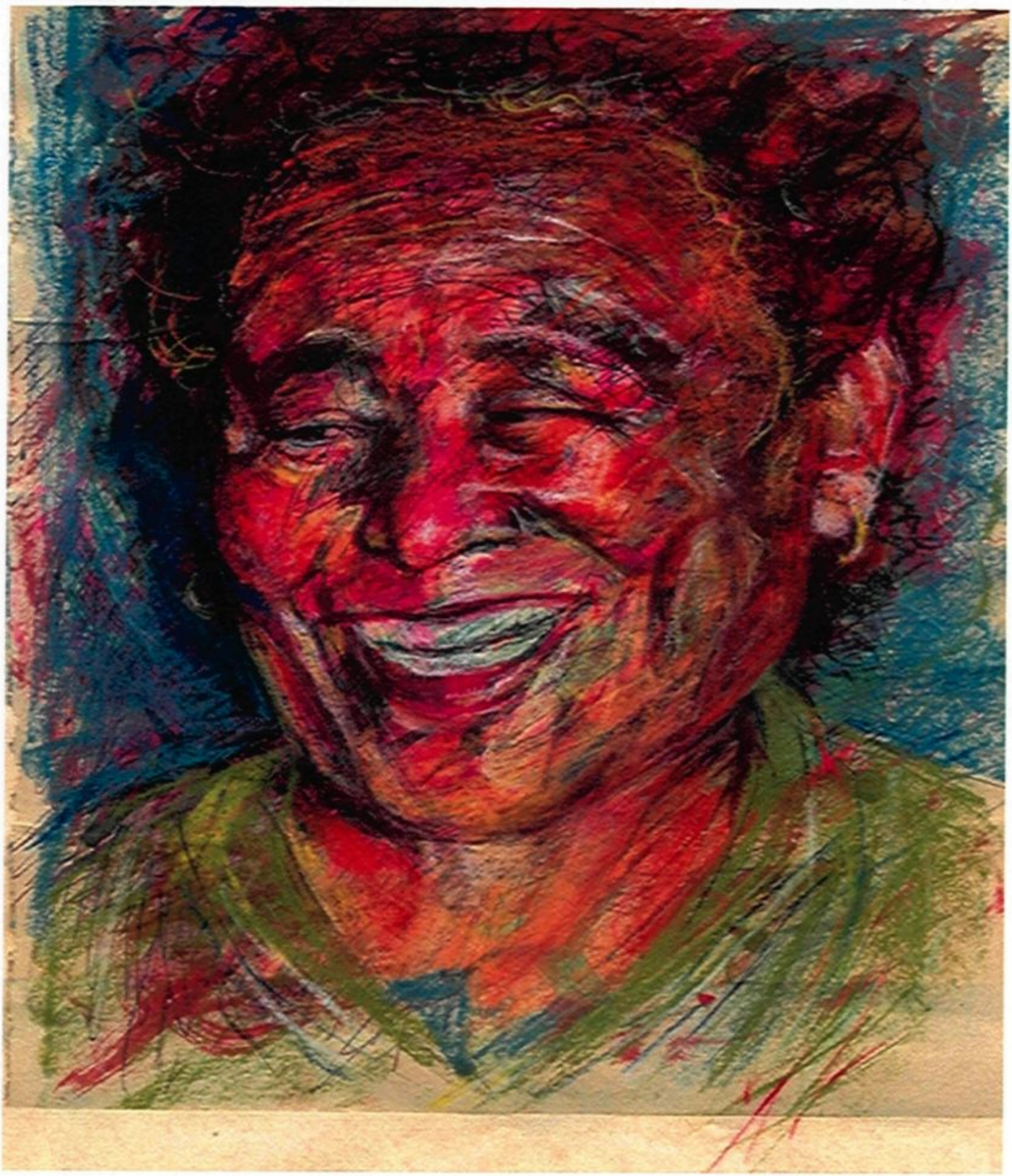

Fig 2 : La Tibétaine (le noyau spirituel) 
Je suis estomaquée en réalisant à quel point ce processus est porteur de sens. Toutefois, ce sens est en grande partie incommunicable, non rationalisable, à moins d'avoir vécu dans ma peau et d'avoir marché avec mes souliers. C'était comme si je comprenais en bloc tout ce que, à certains moments, je n'avais pu m'expliquer rationnellement, surtout au sujet des choix spontanés et apparemment insensés que j'avais pu faire dans certaines périodes de ma vie. Je ne peux entrer dans ces détails, là n'est pas le sujet de ce mémoire, plutôt, je tente de présenter au mieux cette expérience et l'impact révélateur qu'elle a eu pour la suite des choses. Donc, je sentais que j'avais devant moi quelque chose de parfait et d'extrêmement personnel dans son essence, sans toutefois être capable d'expliquer précisément pourquoi. Je vivais cet événement de manière organique et intense. Par ailleurs, je me retrouvais aussi dans un état paradoxal : j'avais peur de briser la magie en réfléchissant trop, alors que, tout à la fois, mon ressenti et les liens de synchronicité étaient tellement forts que je devais vraiment en accuser réception, les dire, les crier même, que sais-je. Ce que m’a donné cette expérience est le sens de mon vécu, et même de ma vie, à ce moment-là, ni plus ni moins. Alors, pour garder le maximum de traces sur le phénomène que j'étais en train de vivre, je sentais que le mieux était d'essayer de raconter ce que je vivais.

C'est alors que j'ai demandé à mon conjoint d'être le témoin silencieux du récit spontané qui s'amorçait. Si je voulais rendre compte le plus exhaustivement possible de cette abondance d'information, l'écriture n'était pas le meilleur moyen à cause de sa relative lenteur d'exécution. La parole était donc requise. Je tenais à partager mon ressenti, mais surtout, il fallait que je puisse me déposer poétiquement dans une écoute sensible. 
Pourquoi inscrire cette expérience dans la parole? D’une part, comme je l'ai déjà mentionnée, je savais que je ne pourrais écrire tous les liens que je faisais concernant cette expérience car le débit d'entrée dans ma conscience, si je puis dire, était beaucoup trop rapide pour l'écriture, et, d'autre part, je tenais également à laisser des traces verbales, que quelqu'un d'autre soit témoin de cet étrange processus que je venais de vivre, et de tout ce qui en découlait de logique rétrospective. J'ai ainsi parlé pendant plus d'une heure portée par l'écoute attentive de mon conjoint, qui heureusement m'a très bien accueillie. Sa présence silencieuse et réceptive se présentait comme un ancrage. Il recevait ma parole, acquiesçait et me rassurait du regard. Cette attitude ouverte de sa part a été fondamentale pour assurer la complétude du processus que j'étais en train de vivre.

Au cours de cette expérience, je réalisais que le chemin artistique sur lequel j'étais engagée depuis quatre ans, et qui malgré ma confiance en l'art avait quand même fait l'objet de quelques questionnements, prenait dès lors un sens beaucoup plus concret. Des réponses m'étaient maintenant proposées à travers la symbolique de ce processus de création. Ainsi, la forme ovoïdale configurée par les diptyques me parlait de quelque chose prêt à éclore, mais qui s'était préparé dans le silence des profondeurs. Tel un œuf porteur de potentiel vital se forme dans la profondeur et le mystère de l'organisme animal, le sens, qui jusque-là s'était préparé en silence dans l'ombre couveuse, se frayait finalement un chemin vers ma conscience par le vecteur de l'art. De fait, ce sens s'avançait vers moi en provenance de multiples trames temporelles signifiantes qui se reliaient à une vitesse folle dans mon esprit. Je ne cessais de faire des liens. En moi se bousculaient des images « sensibles » d'évènements particuliers, certains remontant à très loin, à partir desquels je 
constatais de stupéfiantes synchronicités. Tout faisait sens. Je reliais certains événements de mon enfance, de mon adolescence, de ma vie de jeune femme et d'adulte, etc. Cette expérience a donné un sens ponctuel à mes études artistiques, et un sens rétrospectif à mes choix de vie. Cette expérience créatrice m'a effectivement apporté l'intime conviction d'être guidée et protégée par la vie. De plus, parce que j'avais devant moi 22 diptyques, et que dans la numérologie hébraïque mon chemin de vie est gouverné par le nombre 22, j'ai compris que l'art participait de ce chemin de vie. Aussi, ces 22 diptyques configuraient une croix. Les axes de cette croix, représentaient la verticalité (l'esprit) et l'horizontalité (le corps), tous deux alignés dans un équilibre parfait sur le portrait de la sage Tibétaine. Ce portrait comptait pour beaucoup dans l'enrichissement du sens, je le considérais comme mon noyau spirituel. D'autant plus, comme je l'ai mentionné plus haut, qu'il avait été réalisé dans le même langage pictural que ces études parisiennes. Tout se tenait. Plus tard, alors que j'avais déjà offert quelques ateliers et que j'étais à même d'en apprécier le potentiel évolutif et transformateur, j'ai compris davantage sur la symbolique de la verticalité. Comme par exemple qu'elle m'annonçait la démarche spirituelle que le processus d'atelier artistique était à même d'engendrer, d'appuyer, de stimuler et de soutenir. L'axe horizontal quant à lui représentait la cristallisation des ateliers dans la matière et dans le corps. Je comprenais dès lors que je pouvais me mettre à l'œuvre, créer mes ateliers, et que tout irait bien.

L'intégralité du processus semblait répondre à un ordre préétabli, mais pas encore connu : un ordre caché. Je me sentais poussée par tout mon corps à m'activer, et je le faisais de façon ordonnée, dans le lâcher prise, sans savoir le moins du monde où tout ça 
pouvait me conduire. Au cours de ce phénomène créatif, qui s'est étendu sur plus de trois heures, j'étais dans un état fécond de fébrilité intelligente, ou d'intelligence fébrile, je ne sais trop. En quelque partie de moi je sentais bien que ce que je faisais était porteur de sens et, paradoxalement, malgré la fébrilité, je peux dire que je me sentais étrangement posée. C'est un peu comme si j'avais été guidée à faire ces gestes. Toutefois, alors qu'une partie de moi les accomplissait en confiance, une autre partie était exaltée, surprise, et tout de même un peu inquiète. Un processus duel en quelque sorte, mais chapeauté par une sensibilité accrue et une conscience élargie, car effectivement, j'étais aussi observatrice de ces états. C'est un sentiment étrange que de faire des choses apparemment insensées en sachant profondément qu'elles ont un sens. De faire des gestes très précis sans savoir pourquoi ni où ils mènent, mais de ressentir une confiance particulière, plus, savoir que c'est cette forme particulière de confiance qui est requise pour mener l'expérience à terme. Toutefois, je sentais que ce que je vivais, et qui semblait couler de source, était quand même très délicat. En sourdine m'habitait la peur de faire du sabotage en cherchant, par réflexe plus que par volonté, à rationaliser. J'avais la curieuse impression de penser sur deux niveaux. C'est-à-dire l'un, en arrière-plan, qui me portait à juger ce que je faisais, et l'autre, à l'avant-plan, qui me disait que tout était parfait ainsi. Dans cet état particulier où rien de moi n'oubliait rien de moi, j'étais en mouvement continuel, soit pour écrire, soit pour fouiller dans la maison à la recherche de mes études, soit pour les placer au mur, soit pour partager sur le vif avec mon conjoint, etc. Je constatais que je pensais en double: d'un coté une pensée inhibitrice, comme par exemple: c'est stupide, personne ne comprendra ce que tu fais, tu fabules, c'est ridicule et insignifiant, etc., et, d'un autre coté, 
une pensée accueillante et encourageante qui me disait que c'était super, que je touchais à quelque chose, qui me disait de rester branchée sur mon ressenti, de ne pas trop penser, de ne pas juger, de continuer, etc. Ainsi, je devais absolument poursuivre sur ma lancée inspirante en faisant confiance. On verra après, me disais-je.

Bref, je vivais là un phénomène duel et paradoxal : la pensée constructive et la pensée destructrice cohabitant, la volonté de faire et la pensée inhibitrice cohabitant, le jugement et la suspension de jugement cohabitant. Mais c'est spécifiquement l'acte de poursuivre le faire créateur malgré le doute qui me propulsait vers l'avant de la création : faire, faire et faire, en ayant confiance au processus en cours.

\section{L'art avec l'Autre}

Ce qui me réjouissait tout particulièrement dans cette expérience était surtout l'idée que je pourrais partager l'art avec l'Autre. J'avais l'intuition qu'une proposition m'était ainsi présentée, comme si une connaissance en moi cherchait par différents moyens à communiquer à ma conscience par le biais de l'art, de la matière, du geste et de la symbolique. C'était bien le cas, cette expérience créatrice me proposait une manière de faire l'art avec l'Autre par le vecteur d'ateliers artistiques basés très spécifiquement sur l'exploration du langage plastique non figuratif. Cette expérience me présentait tout à la fois une idée de la procédure, de la structure, de même de la forme et du bien-fondé de ces ateliers. 
Cette expérience m'est apparue fort concluante. Je me disais : finalement, ça aboutit à quelque chose ces études artistiques! C'était bien une ouverture au sens, car à quelques reprises au cours des années précédentes, et ce malgré ma confiance en l'art, je m'étais occasionnellement questionnée sur la pertinence de poursuivre mes études. Alors, le fait de vivre cette expérience intense était un peu comme si, finalement, j'avais là une sorte de confirmation que mon engagement envers l'art porterait fruit, que j'étais sur mon chemin et en quelque sorte guidée vers un accomplissement singulier.

Jusqu'ici ce troisième chapitre s'est attardé sur trois aspects importants de mon cheminement artistique, à savoir, la façon dont l'art est entré dans ma vie, le choix de mes études artistiques et le récit de création des ateliers. Le point suivant abordera le processus d'atelier à travers l'écriture réflexive.

\subsection{Ordre acté : explorer et réfléchir le processus d'atelier}

Pour faire suite à ce regard descriptif porté sur l'émergence de l'art dans ma vie, je tenterai maintenant de réfléchir sur les actes concrets qui en ont découlé, c'est-à-dire principalement la conception et l'animation d'ateliers d'exploration picturale axés sur l'expérience esthétique conscientisée. 
3.2.1 Bases structurelles et fonctionnelles des ateliers

Tel que mentionné au début de ce document, mes ateliers se présentent comme un processus artistique exploratoire vécu au travers d'une série de douze rencontres hebdomadaires de trois heures. Chaque atelier est subdivisé en cinq moments bien distincts, mais chronologiquement liés dans un rapport progressif structurant, c'est-à-dire que chacun d'eux conduit à l'étape suivante, permettant une plongée toujours plus profonde dans l'intériorité. Comme je l'ai déjà souligné, ces rencontres se veulent un espace dédié à l'expérience esthétique conscientisée (voir section 3.2.2). À cet égard, Dewey stipule que

[L]a compréhension esthétique (en tant que distincte du pur plaisir) doit tout d'abord s'intéresser au sol, à l'air et à la lumière qui sont à l'origine même des choses esthétiquement admirables. Et ce sont ces conditions et ces facteurs qui font de l'expérience ordinaire quelque chose d'achevé. (Dewey, 2010, p. 44)

C'est dire que la compréhension esthétique ne relève pas seulement et uniquement d'un fait formel, conceptuel ou théorique, mais aussi et avant tout d'un phénomène fondamentalement organique dont les phases, à mon sens, peuvent être reliées dans la conscience du sujet artiste. Je suis d'avis que c'est la reliance des phases créatives organiques (ce qui se passe en moi, dans mon corps, lorsque je crée) avec les émotions, les idées, etc. qui donne à l'expérience son caractère évolutif. C'est aussi mon rôle d'accompagnatrice que de favoriser cette reliance. À cet égard, les phénomènes de conscientisation, de continuité, de complétude et de reliance priment dans l'intégralité du processus d'atelier. C'est-à-dire que tant dans les différents moments qui structurent mes 
ateliers (lesquels seront présentés plus loin), que dans les exercices qui constituent ces mêmes moments (écriture pulsionnelle, scription, picturalité, etc.), je porte une attention particulière à la cohérence et la fluidité de l'expérience exploratoire. Je tiens effectivement à ce que chaque atelier, même s'il fait partie d'un cycle plus vaste, soit en lui-même complet. C'est-à-dire, par exemple, que des œuvres picturales y soient achevées, que des prises de conscience y soient faites, que des ressentis y soient verbalisés et que des expériences concluantes et enrichissantes y soient conscientisées.

En rapport avec ce qui précède, et afin de bien mettre en évidence mon rôle d'accompagnatrice, je présente ici la praxis créative que j'ai intuitivement conçue. Cette praxis s'est affinée tout au long des ateliers pour en arriver au phénomène de la convivialité créatrice et de l'expérience esthétique conscientisée. Je souligne par ailleurs que j'ai créé la plupart des exercices que je propose dans mes ateliers, lorsque ce n'est pas le cas, je précise mes sources.

Partons donc du début de chaque atelier, alors que je propose une visualisation guidée dans le but de favoriser une transition vers l'espace de la convivialité créatrice. C'est ainsi qu'on se dépose physiquement, émotionnellement, spirituellement et énergétiquement dans cet espace particulier que nous sommes à ouvrir ensemble. Ici, on se dispose à l'acte créatif, on prend conscience de son état d'être et de l'énergie du groupe. Ensuite, les moments-clés se succèdent harmonieusement, dans le silence et le respect de la bulle créative de chacun. 


\subsubsection{Moments-clés}

\section{Moment 1}

Suite à la visualisation du début d'atelier, je propose un exercice d'écriture expressive de 5 minutes dans lequel se projettent les ressentis du moment. Les mots inducteurs sont toujours : «j'arrive avec... ». C'est à partir de ces mots que chacun a la possibilité d'exprimer ce qui l'habite avant que l'atelier ne commence. Suite à cet exercice, j'offre un espace de parole à ceux qui le désirent. C'est souvent l'occasion de reconnaître et de verbaliser certains états d'âme, qui autrement auraient peut-être entravé le processus de création.

\section{Moment 2}

Le deuxième moment est un exercice d'une dizaine de minutes sous écoute flottante. L'écoute flottante consiste en la lecture, parfois en boucle, d'un texte choisi. Je demande de ne pas écouter ce que je dis, de laisser flotter les mots, de les laisser résonner sans essayer de les retenir ou de les comprendre. Parfois, tout dépendant de l'exercice, je peux aussi demander d'en capter quelques-uns pour s'en laisser inspirer. La plupart de mes textes sont des écrits poétiques autour de l'art. Je privilégie les auteurs tels Henri Michaux pour sa vision éclatée, Éric Baret pour son approche radicale de l'humain et de l'art, Pascale Quiviger pour sa verve et sa lucidité artistique, de même Fabienne Verdier, Christian Bobin, Pierre Bertrand et Yves Bonnefoy, entre autres, pour leur expression 
poétique propre. Tous ces textes, la manière de les lire, de les écouter, disposent l'organisme à s'actualiser à partir du cerveau droit (Edwards, 1979). Donc, l'exercice du moment 2 est celui de l'écriture inspirée et pulsionnelle. Il annonce les couleurs de l'atelier en donnant le coup d'envoi à l'avènement poétique. Le retour sur ces écrits se fait à la fin, lors du moment 5.

\section{Moment 3}

On passe ensuite au troisième moment axé sur le graphisme et la scription ${ }^{25}$. Comme le moment 2, c'est aussi un exercice d'échauffement qui peut se faire sous écoute flottante, c'est selon. Il consiste en une intervention scripturale de quelques minutes sur petits supports $(15 \times 10 \mathrm{~cm})$, l'un noir, l'autre blanc, avec crayon noir et crayon blanc, en alternant main gauche, main droite, yeux fermés, yeux ouverts, etc. Ces consignes et suggestions sont différentes à chaque atelier. Cet exercice a pour effet d'initier l'activité alternée des deux cerveaux. La scription est cette pulsion essentiellement scripturale qui fait en sorte de nous délester d'une appréhension trop linéaire, conventionnelle et attendue du réel pour nous orienter vers une exploration éclectique, ludique et inusitée. Cet exercice permet de plonger plus profondément dans l'intériorité. Aussi, il sert à dévier une éventuelle tendance à la représentation figurative, laquelle est à éviter dans ces ateliers. (voir fig. 3)

${ }^{25}$ Scription : n.f. écriture en tant que suite de gestes (re:http://dictionnaire.reverso.net/francaisdefinition/scription) 


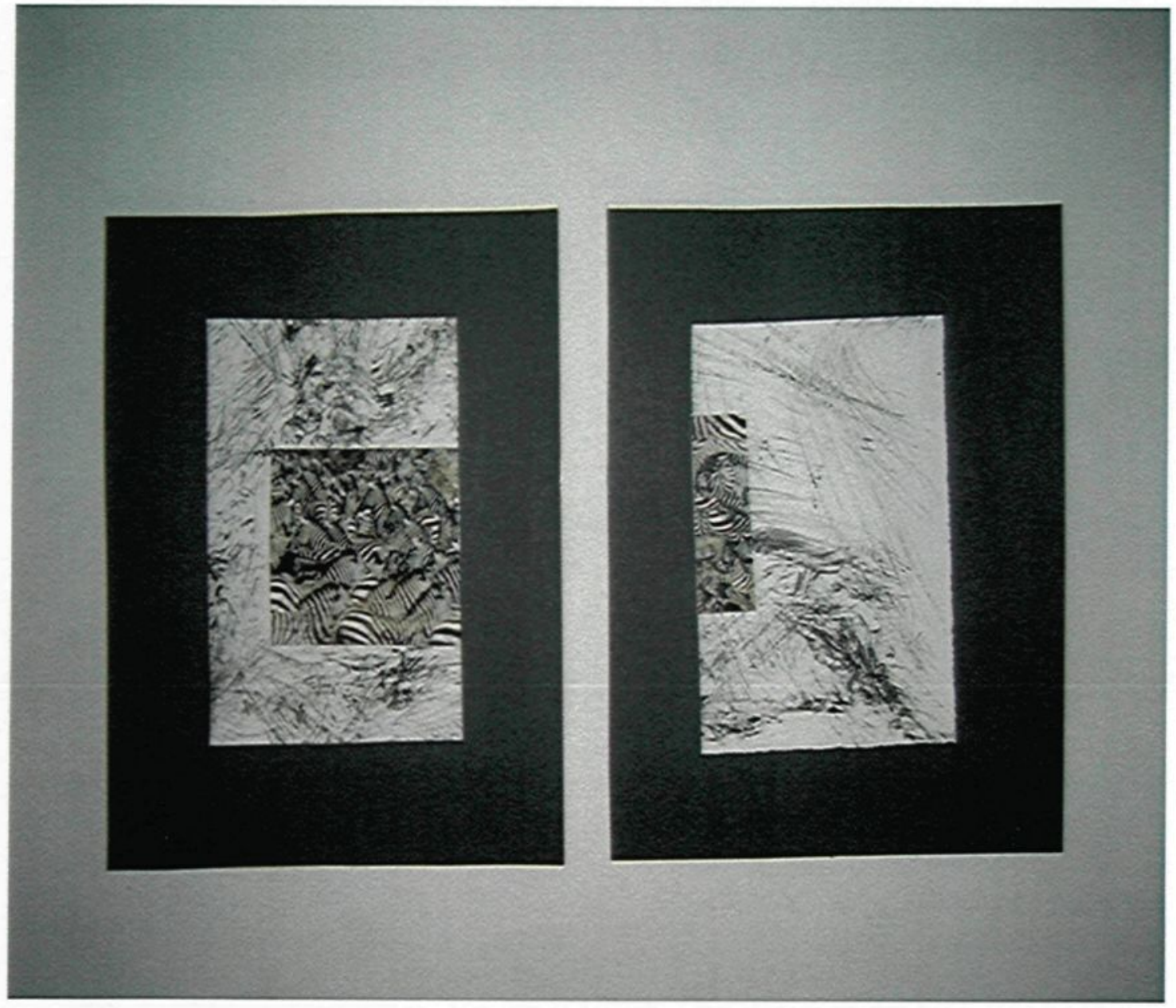

Fig. 3 Exercice de scription avec collage préalable. Émilie 


\section{Moment 4}

Ce moment est celui de la picturalité. Exercice principal d'une heure sous écoute flottante, avec consignes et contraintes intempestives (dont je parlerai plus bas). Il consiste essentiellement en une exploration picturale du langage plastique non figuratif. C'est le cœur des ateliers. Ici, les participants interviennent sur plusieurs supports à la fois, entre quatre et douze. Les supports sont en carton. D'un atelier à un autre, ils sont disposés différemment suivant l'exercice et leur format varie de $15 \mathrm{~cm} \times 20 \mathrm{~cm}$ à $60 \mathrm{~cm} \times 80 \mathrm{~cm}$. L'intervention picturale se fait avec certains outils (pinceaux, spatule, brosse, chiffon, etc.) et plusieurs médiums (acrylique, peinture à l'eau, aquarelle, pastel sec, pastel gras, crayon de couleur, de feutre, de plomb, de cire, fusain, sanguine, etc.), lesquels en l'occurrence doivent tous être utilisés en alternance. Ainsi, tout au long de cet exercice, les particpants sont invités soit à changer de support, soit à changer de médium, soit à utiliser tel ou tel médium, tel ou tel outil, à faire tel ou tel geste, etc. Ce sont là en fait les consignes et contraintes intempestives. À cet effet, il y a une entente préalable entre moi et les participants : lorsque je leur demande de changer de support ou de médium par exemple, il est préférable de le faire de suite. Ils doivent jouer le jeu pour se retrouver momentanément déstabilisés et ainsi expérimenter un déphasage. Ce phénomène du déphasage est un point crucial de l'expérience esthétique telle que nous la vivons. C'est en fait le moment précis et déterminant où le rapport à l'expérience peut devenir soit évolutif, soit stagnant, soit inexistant. Ce sont ces déphasages qui sans cesse surmontés participent, dans le cadre des ateliers, d'une expérience esthétique concluante. Ainsi, de façon générale, là est la fonction 
principale des contraintes et consignes intempestives, qui s'expérimentent surtout dans le moment 4, la picturalité.

Une quinzaine de minutes avant la fin de cet exercice, je propose aux artistes convives de «sortir » tranquillement de leur réalisation et d'y apporter les dernières touches. C'est alors que l'aspect esthétique formel s'exprime davantage, que des choix conscients sont faits en fonction d'un équilibre, d'une harmonie, d'une force, etc. Je cesse l'écoute flottante et parfois je mets de la musique jusqu'à la fin de l'exercice, ou encore c'est le silence, ça dépend de l'ambiance déjà installée. La lumière est rallumée, ce qui, phénomène toujours surprenant, permet de voir le travail pictural sous un jour neuf. En effet, nous travaillons toujours sous une lumière tamisée, et ce jusqu'au dernier quart d'heure de l'exercice de la picturalité. Ce dernier quart d'heure (illuminé!) est particulièrement important car c'est là où s'actualisent des choix esthétiques réfléchis, en opposition aux choix spontanés qui se sont effectués dans une certaine pénombre, sous écoute flottante avec consignes et contraintes intempestives tout au long de l'exercice. 


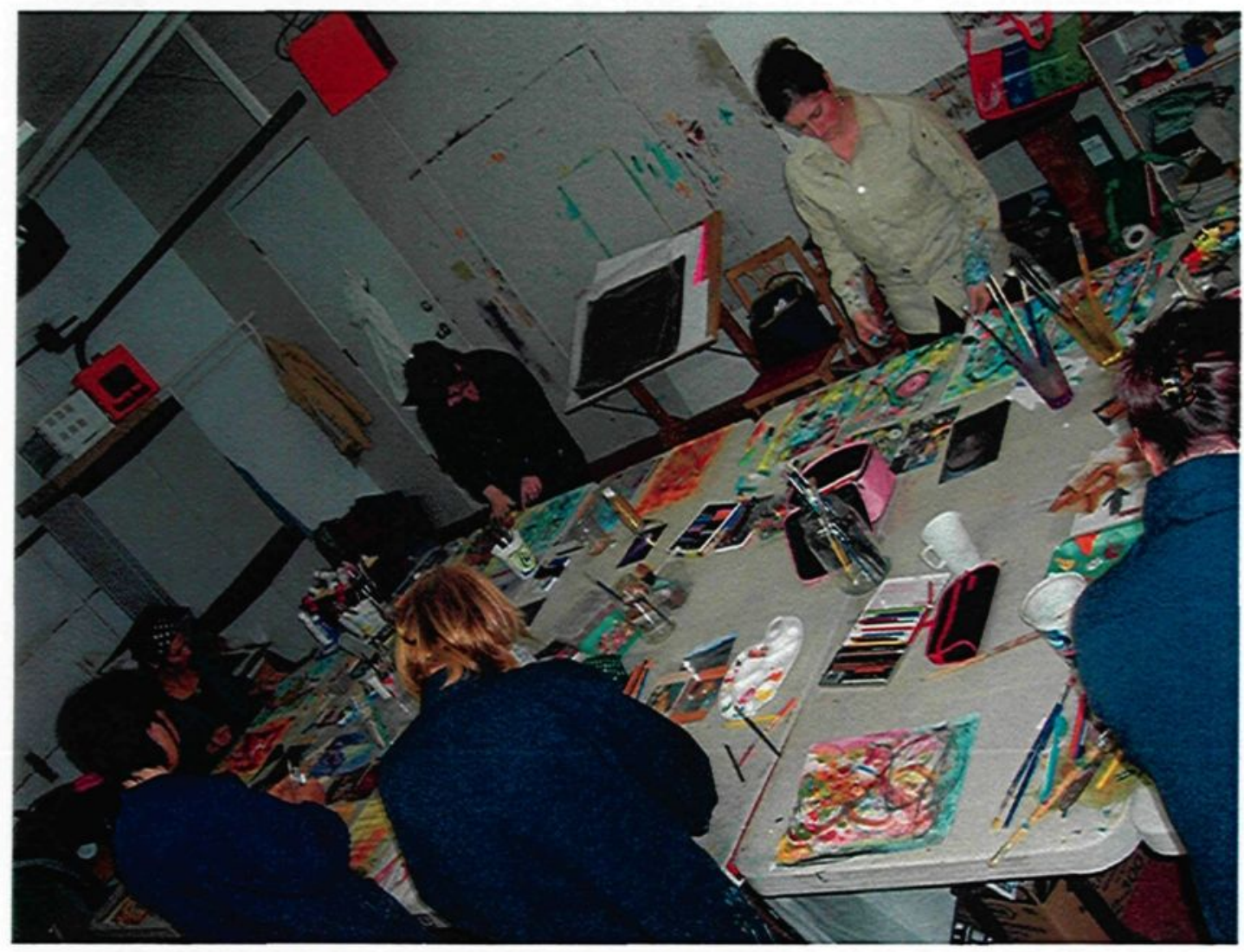

Fig. 4 : Atelier en action

\section{Moment 5}

Ensuite, nous abordons le cinquième et dernier moment de l'atelier, le retour parler. Mais auparavant je prends des photos des productions de chaque convive pour leur faire parvenir par courriel après l'atelier. ${ }^{26}$ Puis, les réalisations sont installées au mur. Ensuite, de façon aléatoire chacun est invité à parler de son processus d'atelier pendant une dizaine de minutes. Toutefois, avant que le convive ne commence à parler, $\mathrm{j}$ 'invite tout le monde à laisser vibrer les œuvres, à les ressentir sans nécessairement mettre des mots dessus. C'est avant tout un signe de respect envers ce processus créateur que nous venons de vivre.

\footnotetext{
${ }^{26}$ Faire parvenir par courriel les œuvres numérisées après chaque atelier fait partie de mon rituel d'accompagnement.
} 
Ce moment est particulièrement émouvant. Ensuite, à tour de rôle, les participants parlent de leur rapport au vécu de l'atelier, comment ils voient leurs œuvres, comment ils se sentent, ce qui ressort de cette rencontre créative, etc. Par moment, on discute aussi tout le monde ensemble. Une dizaine de minutes est accordée à chacun, parfois plus, ça dépend des besoins et du nombre de convives. On passe en revue l'ensemble des productions de l'atelier, c'est-à-dire le texte du début «j'arrive avec... »; l'exercice d'écriture pulsionnelle sous écoute flottante; l'exercice graphique, la scription et la picturalité. Certains lisent leur texte à voix haute. C'est aussi à cette étape que nous envisageons formellement et esthétiquement les réalisations. À cet effet, j'ai un passe-partout que je promène sur les réalisations installées au mur de manière à isoler les parties picturalement intéressantes. On propose alors de possibles parentés picturales, on suggère leur réunion en diptyques, polyptiques, etc. C'est l'occasion de se sensibiliser au langage plastique comme tel. À cette étape, j'aide à voir les rapports formels, l'équilibre, la composition, la force, le mouvement, le rythme, etc. Ainsi, en regard des productions, plutôt que d'y imaginer des formes connues, je tente de ramener l'attention sur le non figuratif, car je considère que cette forme d'expression, qui passe par d'autres canaux que ceux de la représentation imagée ou symbolique habituelle, favorise un renouvellement de la vision artistique.

L'atelier se termine sur une conclusion collective, c'est-à-dire qu'on passe rapidement en revue les moments d'ateliers et ceux qui le désirent peuvent s'exprimer sur ce qu'ils ont vécu de particulier. Puis, je propose que l'on se recentre un peu avant de partir, histoire de refermer la boucle. J'essaie de faire en sorte que chacun puisse se réapproprier en conscience la richesse des moments vécus afin d'en favoriser l'intégration au quotidien. 
Ainsi, les participants réalisent que ce qu'ils viennent de vivre relève d'une expérience évolutive et transformatrice. L'accueil conscient de ce vécu expérientiel est important. C'est ce qui amène graduellement à vivre le quotidien avec une qualité d'écoute différente, une vision rafraîchie et une sensibilité toujours plus en éveil.

\subsubsection{Synthèse esthétique}

Un mot ici sur le dernier atelier, la douzième rencontre en fait, qui consiste en ce que j'appelle une synthèse esthétique. À cette occasion, je rencontre chaque participant individuellement pour effectuer un retour complet sur les ateliers, ce qui peut facilement s'étendre sur deux heures. Cette rencontre individuelle fait aussi partie de mon rituel d'accompagnement artistique. Lors de cette synthèse, toutes les productions réalisées dans le cadre des ateliers sont déposées en même temps sur la grande surface de travail. (voir figure.5) Je prends des photos, puis on fait tranquillement le tour ensemble, on échange. Je tiens à faire un survol du vécu des ateliers de manière à donner l'occasion au convive créateur de se réapproprier ce cycle d'expériences créatrices. Parfois, je suggère des lignes de force afin de vitaliser certaines productions. Nous apposons des passe-partout sur les œuvres et déterminons les parentés picturales. J'invite le participant à affirmer ses préférences, à dire comment il aimerait agencer ses œuvres et pourquoi. On cherche aussi les titres des œuvres à même les écrits poétiques des ateliers et on choisit quelles œuvres feront partie de l'exposition collective qui a lieu à la fin des ateliers. Parfois, un échange a 
lieu, plus intime, plus émotif. Ainsi, cette rencontre de synthèse, vivifiée du souffle poétique des œuvres et des écrits, est l'occasion de rapports interpersonnels enrichissants.

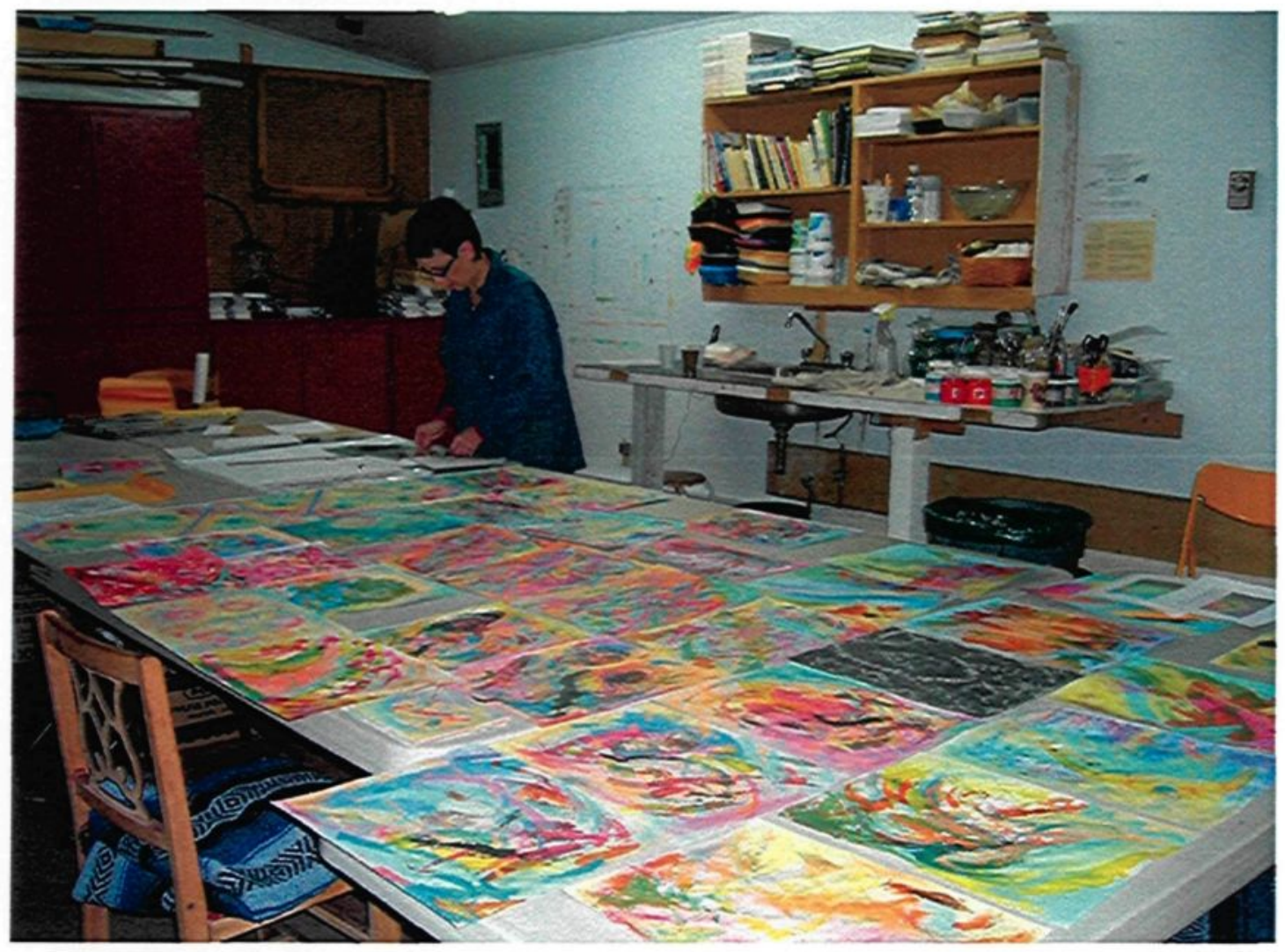

Fig. 5 : Synthèse, Myriam

Le processus d'atelier s'étale donc sur douze rencontres dont l'une se vit en individuel. Au cours des onze premières rencontres sont réalisés entre 12 et 20 petits tableaux non figuratifs, lesquels sont réunis le plus souvent en polyptiques. (voir fig. $6,7,8$ et 9). Ainsi, le cycle d'atelier culmine approximativement en 120 réalisations picturales et de multiples écrits. Une exposition collective couronne ce processus créatif (voir fig. 10). 
De plus, de nombreuses traces gardent vivant ce processus exploratoire, soit à travers le journal d'atelier, lequel accueille les exercices d'écriture, soit au travers le carnet de traces qui contient des collages, écrits, idées, dessins, fragments d'œuvres, etc. Aussi, la plupart des participants encadrent à peu de frais plusieurs de leurs tableaux. Certains les offrent en cadeau ou en font des cartes sans textes, etc. Je suis à même de constater qu'ils sont fiers de leurs réalisations et, selon leurs dires, ils se sentent intérieurement transformés par ce processus artistique vécu dans la convivialité.(sur le retour des participants, voir l'annexe B) 


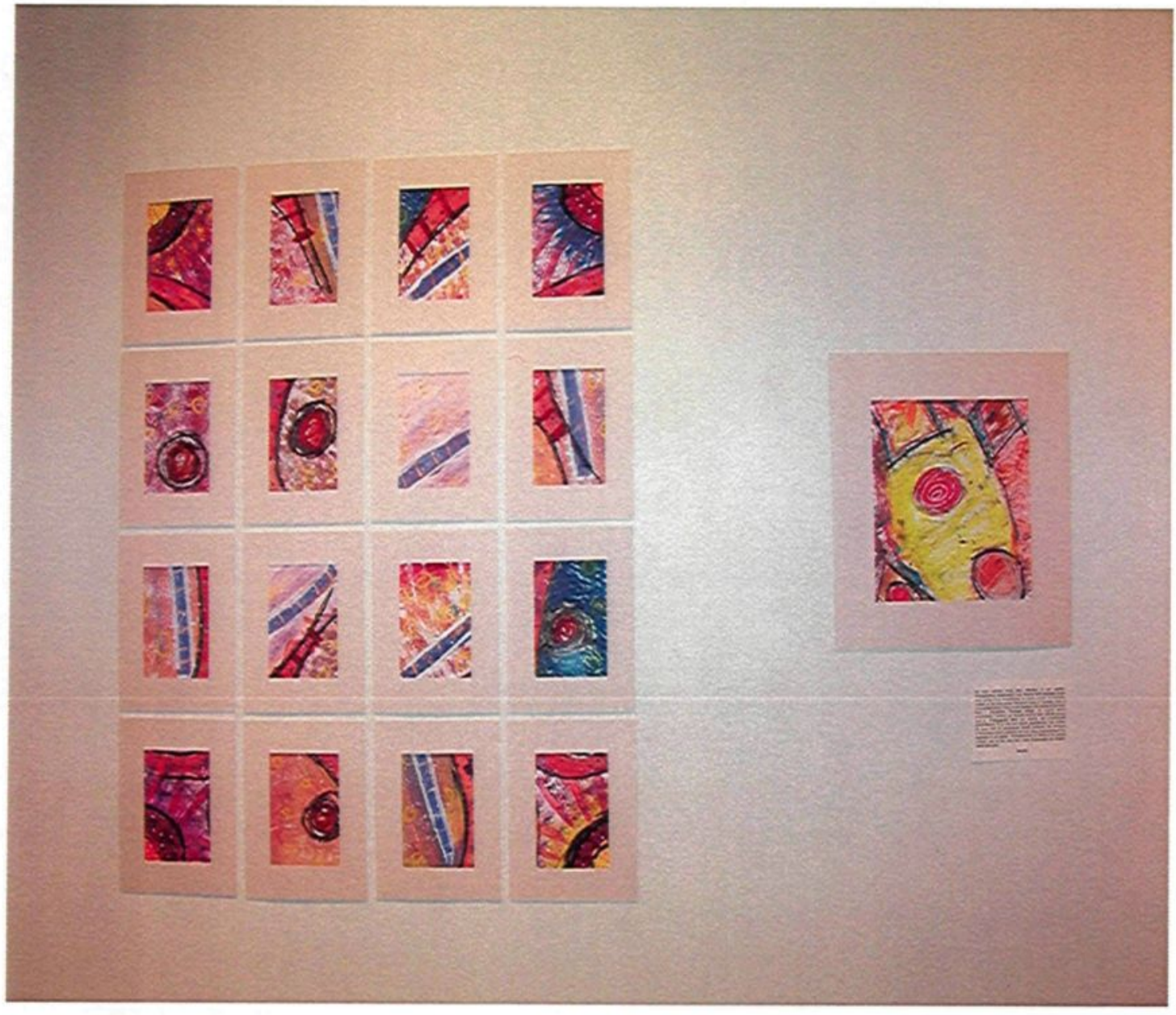

Fig. 6 : Mosaïque, Maude 


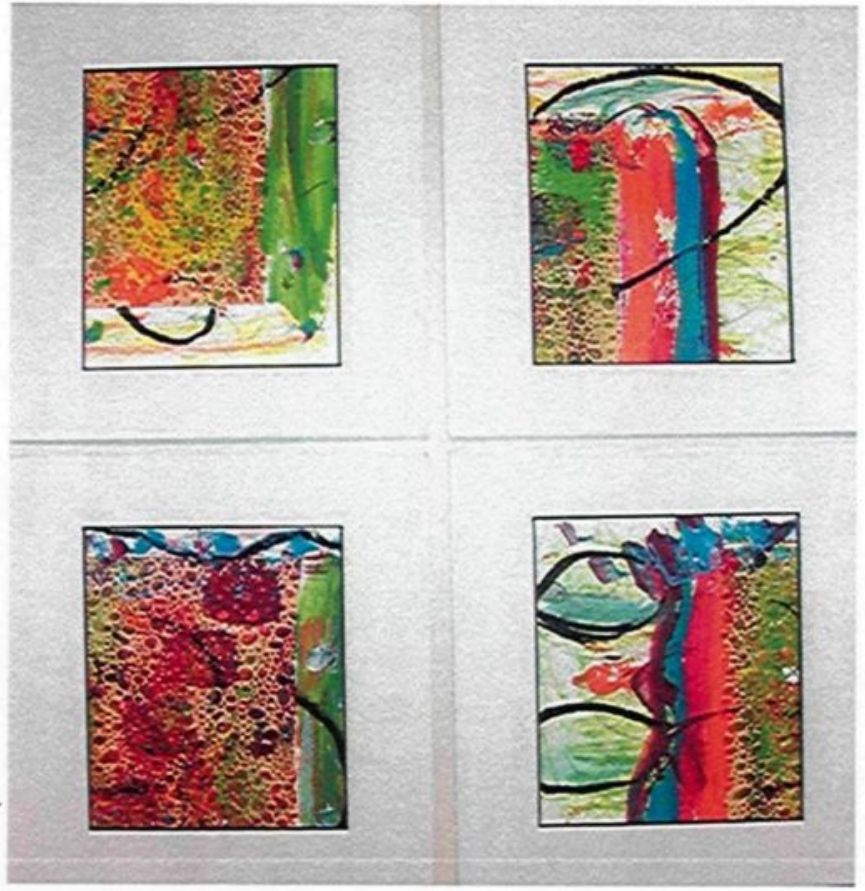

Fig. 7 Réalisation, Mélanie

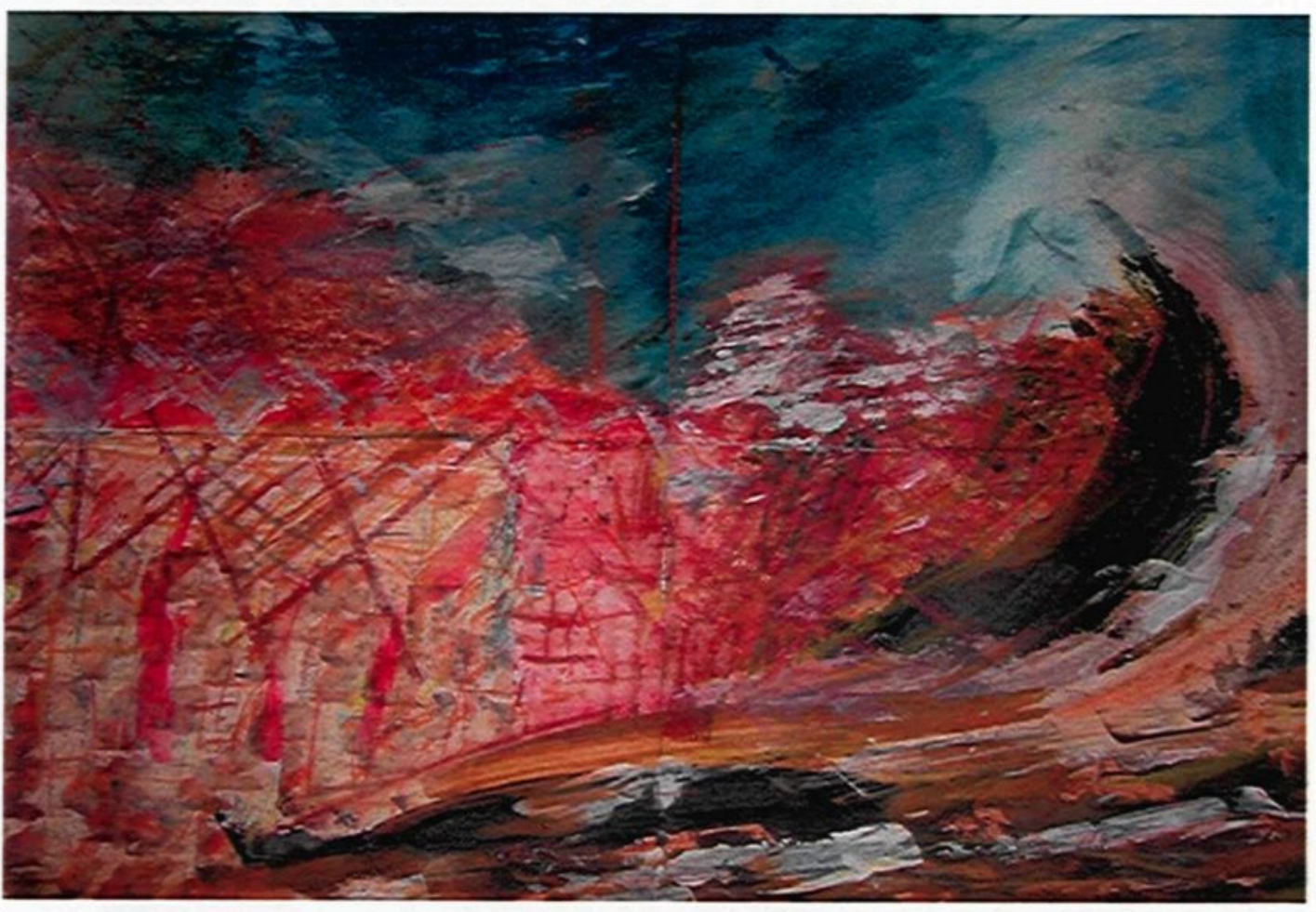

Fig. 8 : Réalisation, Nadine 


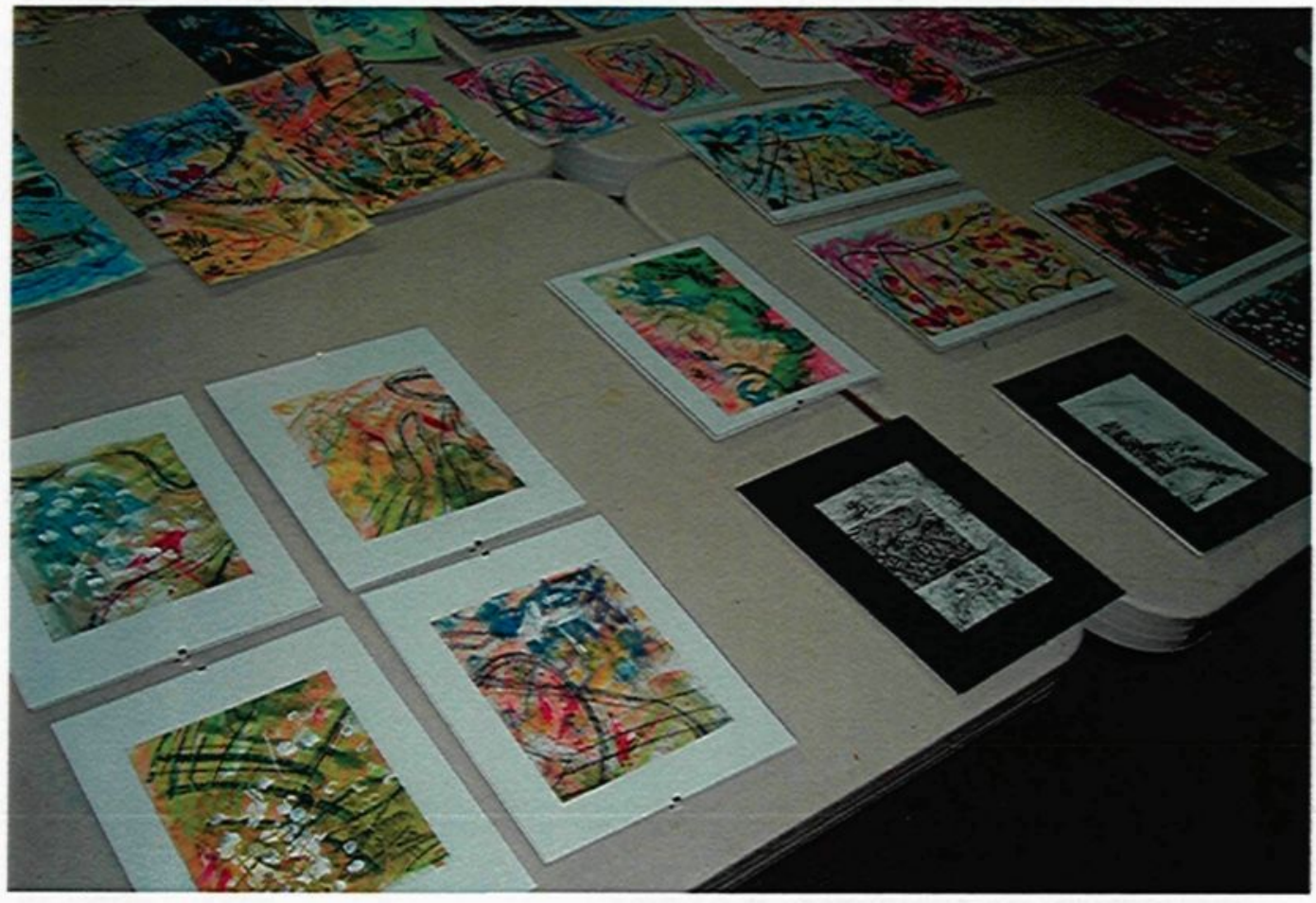

Fig. 9 : Synthèse, Émilie

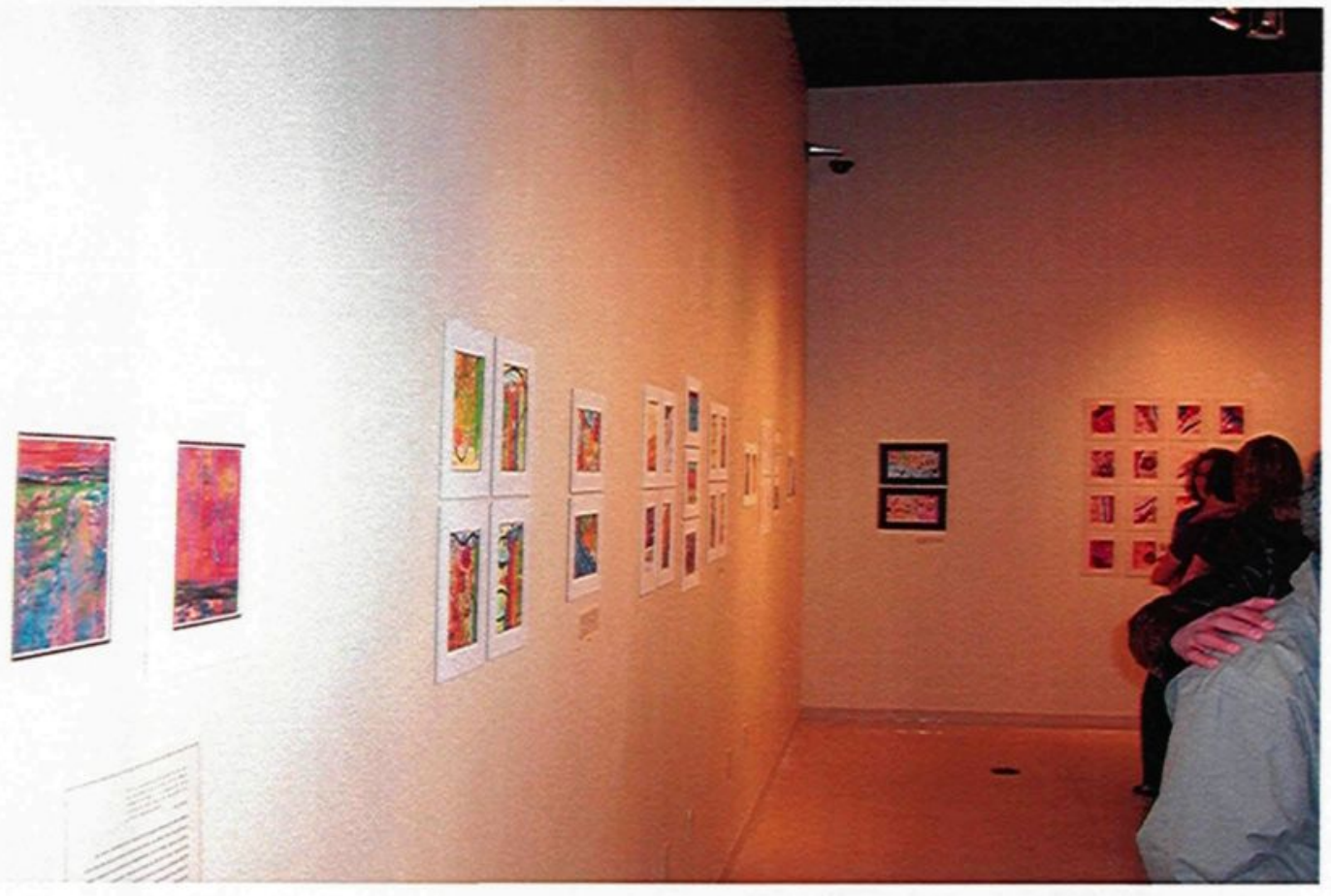

Fig. 10 : Vernissage, Centre des Arts et de la Culture de Chicoutimi, mai 2010 


\subsubsection{Expérience esthétique conscientisée}

Cette section-ci mettra en relief l'expérience esthétique vécue dans la convivialité créatrice. On pourra y constater comment cette manière particulière de s'aborder soi et d'aborder l'autre par la médiation artistique est à même d'induire un mouvement émancipateur.

\subsubsection{Advenir à soi}

À l'heure actuelle, l'art, tel que médiatisé, me semble tout à la fois attrayant mais fort inaccessible pour la moyenne des gens. Cet aspect me questionne : pourquoi cette apparence d'inaccessibilité alors que, selon John Dewey (2010) et d'autres auteurs tels Shusterman (2007) et Robillard (1998), l'art serait partie prenante des fondements ontologiques de l'humain? Le message que je perçois dans la pensée de ces auteurs est que l'art est fondamental pour l'être en recherche de complétude. Il se présenterait comme une dimension de l'être et une voie d'accomplissement. Je retrouve ici des références théoriques pour appuyer les convictions personnelles qui fondent ma pratique d'atelier, à savoir que l'expérience esthétique conscientisée est une voie royale pour «advenir à soi », créer, se créer, s'unifier, se transformer, s'émanciper. 


\subsubsection{Restaurer la continuité}

Dès 1934, Dewey semble déplorer le fait que l'on

identifie généralement l'œuvre d'art à l'édifice, au livre, au tableau ou à la statue dont l'existence se situe en marge de l'expérience humaine. Puisque la véritable œuvre d'art se compose en fait des actions et des effets de ce produit sur l'expérience, cette identification ne favorise pas sa compréhension. » (Dewey, 2010, p. 29)

Pour lui, il s'agit de « restaurer cette continuité entre ces formes raffinées et plus intenses de l'expérience que sont les œuvres d'art, et les actions, souffrances et événements quotidiens universellement reconnus comme des éléments constitutifs de l'expérience » (Dewey, 2010, p. 30). À cet égard, je suis d'avis que l'expérience esthétique conscientisée, entre autres, favorise la restauration de cette continuité, parce que nous n'y rencontrons que ce que nous sommes vraiment, et, dans le meilleur des cas, le nommons, l'accueillons, le réintégrons, participant ainsi à la fluidité de notre être au monde.

\subsubsection{Conscientiser l'expérience}

Lorsque Dewey veut rendre compte de l'expérience esthétique, il prend comme point d'appui l'expérience sous sa forme la plus élémentaire. Il met en évidence les phases de cette expérience et les raisons, en termes de complétude et d'évolution, qui lui confèreront éventuellement une qualité esthétique. De plus, comme il est mentionné plus haut, selon lui, l'œuvre devrait aussi se rapporter de façon inclusive à l'expérience, qui conscientisée et intégrée, devient dès lors complète et évolutive, portant ainsi «la promesse de cette 
perception exquise qu'est l'expérience esthétique. » (Dewey, 2010, p. 55). De fait, l'œuvre devrait s'identifier aussi à l'expérience du créateur et à son ouvrer plutôt qu'au seul objet, c'est-à-dire également au processus plutôt qu'au résultat uniquement. C'est ce qui se passe dans mes ateliers, là où l'œuvrer s'envisage comme le lieu expérientiel de la continuité, là où l'expérience esthétique conscientisée, laquelle constituée et de l'œuvrant, et de l'œuvre et de l'œuvrer, y est considérée comme la référence première, ce par quoi tout découle, et aussi ce par quoi se dynamise la continuité dont parle Dewey plus haut. Continuité dans laquelle se crée à la fois l'œuvre et l'humain.

\subsubsection{S'unifier}

De fait, cette continuité qui participe de l'expérience esthétique se manifeste à travers une qualité de rapports conscientisés que l'œuvrant établit avec son œuvrer. Cette qualité de rapport relève du fait de prendre conscience de son soi œuvrant, de son œuvre et de son œuvrer, cela, tout en développant des attitudes spécifiques telles le lâcher prise, l'accueil, l'auto-curiosité, la simplicité, la suspension du jugement, l'ouverture, etc. Cette conscientisation place l'œuvrant dans un contexte artistique signifiant et évolutif. C'est pourquoi, indépendamment du fait qu'un atelier s'inscrit dans un ensemble sériel plus vaste, chacun d'eux est conçu expressément de manière à stimuler un sentiment d'unification de sorte que les convives créateurs puissent vivre, à chaque fois, une expérience esthétique singulière, signifiante, évolutive et complète en elle-même. C'est pourquoi il m'importe entre autre qu'ils puissent repartir avec une réflexion nourrie et des réalisations achevées. 
C'est à mon sens ce qui favorise et fortifie en eux, atelier après atelier, un sentiment cumulatif d'accomplissement personnel par le biais de l'art.

À cet égard, le rapport unifiant que l'œuvrant établit avec son œuvre, avec son œuvrer, et même avec son « œuvré », c'est-à-dire cet espace où il fait place au regard seul pour éprouver son ouvre, est primordial dans un contexte artistique évolutif axé sur l'expérience esthétique conscientisée. Dewey stipule que «c'est l'expérience esthétique qui donc permet au philosophe de comprendre ce qu'est l'expérience ». Il soutient aussi que

la forme la plus élémentaire de l'expérience esthétique - l'unité immédiatement saisie qui relie les uns aux autres les éléments d'une expérience - est une condition nécessaire qui seule permet de faire d'une situation ou d'un état de choses une expérience cohérente et identifiable » (Shusterman, in Dewey, 2010, p. 18-19)

Il ressort de tout ceci que la qualité esthétique ne se définirait pas qu'en regard d'un concept, formel ou philosophique, qui plus est, ni à partir d'un objet à investiguer, ni à partir d'un sujet à analyser, mais plutôt par le biais, avant tout, d'interactions organiques évolutives et conscientisées entre objet/sujet, intériorité/extériorité, conscient/inconscient, action/réflexion, pulsion/intention, exploration/expression, etc. : il se passe quelque chose en moi quand je crée, un rythme, une pulsation, une dynamique... des sensations, des émotions, des sentiments, etc. En tant qu'artiste accompagnatrice je dois tenir compte de tous ces aspects. Ainsi, dans mes ateliers, l'art n'est pas séparé du sujet en tant que concept, plutôt, il s'intègre à son être au monde à travers le percept ${ }^{27}$. La procédure d'atelier tend à stimuler

\footnotetext{
${ }^{27}$ Percept, utilisé ici en tant que synonyme de perception : prise de connaissance sensorielle du monde extérieur effectuée en relation avec l'expérience et la pensée, et s'accompagnant d'un
} 
cet aspect. Vue sous cet angle, l'expérience, «à son plus haut degré », est « synonyme d'interpénétration totale du soi avec le monde des objets et des événements » (Dewey, 2010, p. 55), et a ainsi toutes les chances de devenir par le fait même esthétique en raison de sa complétude et de son impact évolutif. À cet égard, Dewey note encore que

[C]'est l'ignorance pure et simple qui conduit à la supposition que le lien de l'art et de la perception esthétique avec l'expérience signifie un affaiblissement de leur signification et de leur dignité. L'expérience, lorsqu'elle atteint le degré auquel elle est véritablement expérience, est une forme de vitalité plus intense. Au lieu de signifier l'enfermement dans nos propres sentiments et sensations, elle signifie un commerce actif et alerte avec le monde. [...] Au lieu de signifier l'abandon au caprice et au désordre, elle fournit l'unique manifestation d'une stabilité qui n'est pas stagnation mais mouvement rythmé et évolution. Parce que l'expérience est l'accomplissement d'un organisme dans ses luttes et ses réalisations dans un monde d'objets, elle est la forme embryonnaire de l'art. Même dans ses formes rudimentaires, elle contient la promesse de cette perception exquise qu'est l'expérience esthétique. (Dewey, 2010, p. 54-55)

\subsubsection{Aspect formel}

Dans mes ateliers, j'avais toujours cette pressante intuition que l'aspect formel avait un impact puissant dans le vécu de cette « forme de vitalité plus intense » et dans cette «manifestation d'une stabilité qui n'est pas stagnation mais mouvement rythmé et évolution $»$. La recherche me permet de rationaliser cette intuition, de lui donner forme et résonance dans la matière.

processus d'intégration émotionnelle et d'interprétation des informations sensorielles recueillies. (Source: http://www.granddictionnaire.com, recherche perception, par définition, sous l'onglet psychologie. 
À cet effet, je me souviens que lorsque j'ai commencé à offrir mes ateliers, les réalisations des convives créateurs m'ont beaucoup intriguée. J'étais agréablement surprise et profondément touchée. Je ressentais une joie particulière en voyant leurs œuvres. Puis, je me suis demandé pourquoi je ressentais une telle intensité? Ça me questionnait. Effectivement, je trouvais cela pour le moins étrange car, alors que les tableaux de peintres affirmés me laissaient un peu sur ma faim, pour différentes raisons, je me sentais réellement transportée par les propositions picturales des participants. J'ai pensé que c'était probablement parce que j'accédais en quelque sorte à une nouvelle façon de vivre mon humanité, et d'accueillir celle de l'autre aussi, par le biais de l'art. Par la suite, j'ai réalisé que ces propositions picturales portaient réellement des vibrations particulières, de la vitalité : elles étaient vivantes. Non pas que le tableau d'un peintre n'est pas vivant, cela est tout à fait autre chose, mais là, dans mes ateliers, le grouillant rapport à la vie créative « ordinaire » était très présent, palpable même. À cet égard, je crois que c'est cet aspect «sur le vif», si près de moi et si humain, qui faisait une réelle différence. C'est que j'assistais, en temps réel, à l'émotion et au surcroit de vie qui avait porté l'acte créateur. Mais le plus important, j'assistais à cela avec les participants, qui eux aussi, à leur manière, étaient à la fois générateurs et récepteurs, dans l'immédiateté, de ce grouillant rapport à la création. Donc, avec eux, j'avais été témoin de vie : témoin du doute, des hésitations, de l'autocritique néfaste, des revirements, de la joie soudaine. Témoin du chagrin parfois, de l'ouverture de conscience, de la confiance en soi, en l'autre, au processus. Témoin aussi de l'audace que cela demande, et souvent du courage inouï pour certains, de rencontrer ses désirs d'art. Mais aussi, j'avais été témoin de la satisfaction des convives créateurs. Cette 
satisfaction qu'ils avaient d'avoir accompli ce qu'ils ne croyaient pas être capables d'accomplir, c'est-à-dire une œuvre esthétique, et d'aimer ce qu'ils ne croyaient pas être capables d'aimer, ou d'apprécier, c'est-à-dire leurs propres œuvres.

À cet égard, fait important, ces ateliers m'auront permis de réaliser que chez beaucoup de gens c'est l'idée de l'art qui empêche l'art, en quelque sorte. Pour la moyenne des gens effectivement, il semble que l'art soit intimidant. Et moi, en tant qu'humaine, je ne peux cohabiter avec l'idée que l'art intimide, puisque je crois que c'est une dimension fondamentale en chacun de nous et que, de quelque manière, nous pouvons tous y accéder. C'est pourquoi, dans les ateliers, cette idée de l'art comme objet extérieur à soi est prise à bras le corps: on ne se laisse pas impressionner et on récupère en conscience, pour soi, l'énergie artistique. C'est à travers l'exploration, sans prétention, qu'on accède à cette dimension de soi. À cette dimension artistique que nous portons tous, chacun à notre manière. À mon sens, le fait d'explorer le langage plastique non figuratif peut faire une différence intéressante dans le phénomène de la convivialité créatrice. Avec le non figuratif, bien entendu il n'est pas question de performance et d'habileté particulière, mais de liberté d'expression dans la spontanéité. On peut donc dire que tout le monde est au même niveau, mêmes médiums, mêmes inducteurs, mêmes supports, etc. Toutefois, ce qui ressort de l'acte créatif est de l'ordre d'une singularité qui s'affirme, ou en voie d'affirmation. Cette singularité, elle s'affirme organiquement, émotionnellement, spirituellement et visuellement dans ce que je nomme le koan pictural ${ }^{28}$.

${ }^{28}$ Koan : courte phrase ou une brève anecdote absurde, énigmatique ou paradoxale, ne sollicitant pas la logique ordinaire. (Source : http://fr.wikipedia.org) 


\subsubsection{Koan pictural}

Le koan pictural est un terme que j'ai créé à partir de la définition du koan. Je m'en sers pour désigner les productions qui sont réalisées dans mes ateliers (voir fig. 6, 7,8, 9 et10). Il s'agit de propositions plastiques de petits formats qui contiennent une grande dose de vitalité et de spontanéité. Ces propositions sont ouvertes, multiples et parentes. Elles se présentent en polyptiques la plupart du temps. Elles sont formellement non résolues, interchangeables: on peut en rajouter, en enlever, on peut les disposer de multiples façons, les faire pivoter, etc. Ces propositions conduisent au-delà de la représentation habituelle. On se retrouve ainsi sans référents intellectuels stables. On est déstabilisé! À mon sens, telle que mentionné plus haut, c'est cette déstabilisation même, qui sans cesse dépassée, fait en sorte que le créateur est sollicité dans son intégralité organique et que l'expérience de l'art devient évolutive et émancipatrice. Ainsi, dans ce tous capable, dans ce dépassement de soi dans l'acte créatif, avec l'autre, cette expérience de l'art, « au lieu de signifier l'enfermement dans nos propres sentiments et sensations, [elle] signifie un commerce actif et alerte avec le monde ». (Dewey, 2010, p. 54-55)

\subsubsection{Mise en œuvre de l'œuvrer de groupe}

Ma praxis créative est inspirée de trois motifs qui me tiennent particulièrement à cœur pour leurs qualités transformatrices et évolutives, soit, enrichir la sensibilité artistique, favoriser la conscientisation de l'expérience esthétique et stimuler les rapports 
intersubjectifs. Quoique chacun des participants ait un rapport singulier et personnel à la création à travers ces trois aspects, n'en demeure que je les envisage dans un contexte d'accompagnement de groupe au sens où il m'importe que l'expérience esthétique de l'un enrichisse celle de l'autre.

\subsubsection{Enrichir la sensibilité artistique}

Dans mes ateliers, je conçois que la sensibilité artistique s'accroit avec l'attention, comme le fait d'être attentif à ses propres ressentis et sensations face à l'art, aux manières de le faire, de le voir, de le recevoir et de le partager. Cette sensibilité s'enrichit graduellement à travers l'exploration artistique, à la condition toutefois que celle-ci soit sans cesse permise et promue.

En ce sens, j'ai conçu les différents exercices de sorte que chacun puisse pénétrer toujours plus profondément dans son intériorité. Ainsi, tel que je l'ai abordé en détail à la section 3.1, l'atelier débute avec l'écriture conventionnelle (moment 1) pour se poursuivre dans une écriture pulsionnelle (moment 2) et s'acheminer graduellement vers la scription (moment 3). Ces différentes inscriptions de soi amènent à l'étape exploratoire suivante, celle de la picturalité (moment 4). Finalement, la phase poïétique (moment 5) quant à elle permet de réfléchir et de se réfléchir à travers cette connaissance sensible nouvelle, de la rencontrer, de la nommer, de se l'approprier et de la partager. Cette plongée toute particulière dans l'intériorité est à même d'enrichir la sensibilité artistique de façon significative. 


\subsubsection{Conscientiser l'expérience esthétique}

Abordée par le retour de nature poïétique, la conscientisation de l'expérience esthétique tend à valoriser le phénomène de l'exploration pour ce qu'il est, c'est-à-dire une voie d'avancement, de découverte et de connaissance sensible. Explorer, c'est aussi chercher dans le but de trouver quelque chose d'inconnu. Ainsi, le convive créateur ne rencontre pas ce qu'il connait, mais plutôt, dans le meilleur des cas, ce qu'il ne connait pas encore. Toutefois, paradoxalement, il peut s'y reconnaître. Partant, puisque mes ateliers sont axés sur l'exploration du langage plastique non figuratif, je considère évidemment qu'une trace n'est jamais rien qu'une trace, mais qu'elle est avant tout une inscription de soi dans un espace et un temps délimité par un cadre esthétique. Cette trace, elle est nôtre, elle naît de soi et n'est là que par soi. Il est certain qu'en tant qu'inscription ponctuelle singulière, cette trace participe avec des milliers d'autres à l'aspect formel d'une œuvre esthétique, mais ce n'est pas que ça. Car effectivement, dans mes ateliers l'œuvre esthétique formelle ne prend sa valeur véritable que dans le rapport existentiel qu'elle est à même d'aviver, c'est-à-dire dans ce qu'elle est apte à déployer en termes d'émois, de pensées, de valeurs, de sensations, de sentiments et aussi d'interrogations. Et tout cela il nous faut le conscientiser pour qu'il puisse y avoir une autoréflexion, une réappropriation et une affirmation de sa singularité. C'est ce dont il est question dans mes ateliers: il importe de cesser de projeter une idée de l'art provenant d'informations de seconde main, aussi valables soient-elles. L'attention doit être ramenée avant tout à soi, dans la valorisation toute simple de son être au monde en activité dans l'acte artistique et poétique. C'est le phénomène de la conscientisation qui fait une différence à savoir si oui ou non l'acte artistique s'avérera transformateur et évolutif. Et, 
s'il l'est pour un seul convive créateur, il y a de fortes chances qu'il le soit aussi pour d'autres convives, par résonance. Cet aspect a d'ailleurs été vérifié à de multiples reprises en cours d'atelier.

\subsubsection{Stimuler les rapports intersubjectifs autour de l'ceuvrer}

La convivialité créatrice est un phénomène qui favorise la création de sens aussi par le biais des rapports intersubjectifs d'œuvrant à œuvrant. Mais pour accéder à ce sens nouveau, avant la prise de parole bien sûr, il est nécessaire d'œuvrer. Toutefois, cet œuvrer est parfois déstabilisant, lieu d'interrogation, de déphasages, de surprises, d'autocritique et de découvertes inattendues. À cet égard, j'ai remarqué combien les échanges sincères et transparents lors des retours parlés ont un effet rassurant. Aussi, pour le convive créateur aux prises avec son désir d'art et ses insécurités artistiques, être reçu et rassuré est indispensable. J'ai constaté maintes et maintes fois que les échanges avec les autres participants sont à même de proposer de nouveaux paramètres de réception, pour tous. De fait, l'autocritique néfaste et le jugement sévère se diluent graduellement pour faire place à l'accueil de son expression propre et celle de l'autre, ce qui entraine une vision artistique plus libérée. Ces échanges sensibles participent ainsi d'un enrichissement de l'expérience esthétique de chacun. 
Au regard de tout ceci Dewey stipule que

Les ennemis de l'esthétique ne sont ni la nature intellectuelle ni la nature pratique de l'expérience. Ce sont la routine, le flou quant aux orientations, l'acceptation docile de la convention dans les domaines pratique et intellectuel. L'abstinence rigide, la soumission imposée et la rigueur, tout comme à l'opposé la dissipation, l'incohérence et la complaisance sans but, sont autant de déviations qui font obstacle à l'unité de l'expérience. (Dewey, 2010, p. 89)

Conséquemment, les moments-clés des ateliers, tout le contraire du flou et loin d'être routiniers, sont parties prenantes d'une structure conçue expressément dans le but d'orienter l'exploration artistique de groupe et de stimuler la liberté d'expression individuelle. C'est un lieu de découverte où il est permis et même requis d'être soi. Ces moments d'atelier se veulent un espace neuf, privilégié, c'est pourquoi dans la mesure du possible on tente de ne pas y transposer nos manières habituelles de faire et de penser. En ce sens, au risque de paraître stricte parfois, je tente d'éviter toute forme de dissipation qui pourrait nous éloigner de la sensibilité de l'expérience exploratoire. La visualisation en début d'atelier invite d'ailleurs à une qualité particulière de présence à soi et à l'autre, de même à ce respect mutuel de la bulle créative de chacun. Par exemple, lorsqu'une conversation s'engage hors propos entre deux personnes en cours d'atelier, c'est d'une certaine manière l'expérience de chaque membre du groupe qui s'en trouve contaminée. En tant qu'accompagnatrice, et en regard de la qualité de l'œuvrer de groupe, j'ai la responsabilité de rediriger les énergies créatrices adéquatement afin de ne pas mettre en péril la cohérence et l'efficience du processus d'atelier. C'est dire que, pour ne pas faire «obstacle à l'unité de l'expérience », mon rôle d'accompagnatrice implique aussi une vigilance particulière. Je me dois de teinter 
mon accompagnement artistique d'une sensibilité à la fois ouverte sur soi, sur l'autre, sur le groupe et sur l'Art.

Pour conclure sur la mise en œuvre de l'œuvrer de groupe, c'est donc une praxis créative axée à la fois sur l'enrichissement de la sensibilité artistique, l'expérience esthétique conscientisée et la stimulation des rapports intersubjectifs autour de l'œuvrer qui en est aux fondements. Selon l'expérience que j'en ai, cette praxis ne devient véritablement fonctionnelle que si elle est guidée et orientée de façon adéquate et qu'elle s'adresse à un groupe d'au moins quatre participants, huit au maximum. De plus, étant donné que ce processus est basé sur le déphasage et le renouvellement de certaines habitudes de faire et de penser, il importe qu'un climat de confiance et de transparence soit généré de quelque façon que ce soit. D'ailleurs, là se situe aussi une de mes responsabilités d'accompagnatrice : mettre en cuvre l'œuvrer de groupe de sorte que le processus d'atelier avance dans la confiance et la fluidité, pour tous.

L'élaboration de cette section sur l'ordre acté a mis à jour les faits importants du processus d'atelier, tels ses bases structurelles et fonctionnelles, et l'expérience esthétique conscientisée sur laquelle ce processus s'actualise. De même, j'y ai apporté un éclairage sur ma praxis créative. En référence à mon schéma-itinéraire, cette plongée dans l'écriture réflexive m'a amenée vers un ordre dévoilé. Conséquemment, le point suivant traitera ces données de manière à articuler et conceptualiser le sens du processus d'atelier. 


\subsection{Ordre dévoilé : articuler et conceptualiser le sens du processus d'atelier}

À la lumière de tout ceci, il apparaît évident que mon processus d'atelier est tributaire d'un accompagnement particulier. C'est cet aspect que je tenterai d'éclairer dans cette section-ci.

\subsubsection{Accompagnement artistique}

Extrait de la trame narrative 9 : Un pinceau inadéquat

[...] vers l'âge de 13 ans, à mon retour du pensionnat (là où ma mère m'avait placée pour me discipliner et là où je ne voulais plus être), je découvre sur mon bureau un petit chevalet de fer blanc, une minuscule toile vierge, quelques couleurs et un énorme pinceau. On voulait m'encourager, me stimuler, faire en sorte que je crée, mais je suis seule devant ce matériel d'artiste ne sachant trop qu'en faire. Évidemment, le pinceau est beaucoup trop gros pour peindre quoi que ce soit sur une si petite toile. Et je n'ai pas de palette. Étrange. Alors, terriblement impressionnée, je ne fais que quelques traces, assez difficilement d'ailleurs, pour réaliser finalement qu'il m'est impossible de peindre quoi que ce soit. Je suis dans l'impossibilité de poursuivre et je me sens affreusement découragée. Je croyais vraiment que ce serait facile pour moi de peindre, que j'en serais naturellement capable, mais je réalise que ce n'est pas le cas. J'ai besoin qu'on m'aide, qu'on m'appuie, qu'on me guide et qu'on me donne confiance. Je suis frustrée et je me dévalorise affreusement. Et puis, je me sens terriblement seule, isolée et ridicule. Blessée, je pense que je suis une incapable et que je n'ai pas de talent, moi qui pourtant ressentais un intense désir d'art. [...]

Ce préambule tiré d'un extrait d'une trame narrative m'a fait réaliser que l'importance que j'accorde à l'accompagnement artistique remonte à loin dans ma vie. Cet aspect participait jusqu'ici d'un ordre caché. 
À ce point-ci, je formulerai donc ma propre conception de l'accompagnement. Cette formulation prend sa source dans une trame narrative sur l'accompagnement qui fait partie de ma banque de données de l'écriture descriptive. Mais avant de la présenter, j'aimerais tout d'abord mettre en relief l'auto accompagnement, aspect qui me tient tout particulièrement à cœur.

\subsubsection{Autoaccompagnement formateur}

De mon point de vue, la notion d'accompagnement implique aussi et avant tout celle de l'autoaccompagnement. Car je suis d'avis que bien accompagner l'autre nécessite de savoir s'accompagner soi. Conséquemment, avant de formuler ma conception personnelle de l'accompagnement, il aura fallu que je porte une attention particulière à ma façon de m'autoaccompagner. J'ai alors réalisé que le fait de m'autoaccompagner était devenu une sorte de réflexe écologique personnel tout à fait naturel et intégré à mon vivre. Toutefois, dans le cadre de cette recherche, j'ai senti que cet aspect devait amorcer une transition harmonieuse à partir du ressenti que j'en avais, organique et intuitif, jusqu'à un acte d'accueil conscient, cognitif et rationnel. De fait, cette transition s'est effectuée par le biais de l'écriture, de la réflexion et du dialogue. Ainsi, cette manière devenue naturelle de m'autoaccompagner (écriture, méditation, art, marche, lecture, autoanalyse, etc.) a été mise à jour, identifiée, nommée, et réintégrée en conscience. C'est un acte de réappropriation qui fait en sorte que mon énergie vitale, en constante voie de clarification, devient plus transparente, donc plus aisément accessible à l'autre, ceux et celles que j'accompagne en 
fait. De plus, fait important, je m'assure ainsi d'agir et d'interagir à partir de ma perspective personnelle. Le résultat de cette introspection, même s'il ne figure pas dans ce mémoire, me permet tout de même d'avancer que la qualité de l'accompagnement en va de celle de l'autoaccompagnement: d'une certaine manière, on ne donne ou ne transmet réellement que ce que l'on possède soi, en propre et profondément. Ce point sur l'autoaccompagnement souligné, je reviendrai maintenant sur le thème de l'accompagnement.

\subsubsection{Accompagnement intuitif}

Jusqu'ici mon accompagnement était intuitif et naturel, un aspect que j'avais peu nommé en fait. Toutefois, à la lumière du traitement des données d'une trame narrative écrite en juin 2010 intitulée En marche avec l'autre, j'ai constaté que mon accompagnement se dynamise dans l'optique d'une avancée commune, d'une «marche avec, à coté et vers » dans un «silence sensible ${ }^{29}$. J'ai constaté aussi que pour moi l'accompagnement doit impliquer une «invitation» ou une demande plus ou moins formulée. En quelque sorte, l'accompagné invite l'accompagnant, en l'occurrence moi, à l'accompagner dans son incursion artistique. C'est dans cet esprit que je vis mon accompagnement: je tiens à savoir ce que je peux apporter à l'autre et dans quel but, et je lui en fais part. La demande ou le besoin se précise lors des premières conversations avant l'inscription. Un convive par exemple me fait savoir qu'il aimerait être appuyé dans sa démarche artistique personnelle, ou qu'il vise tel objectif, ou qu'il veut dépasser telle contrainte, ou simplement qu'il est

\footnotetext{
${ }^{29}$ Les termes entre guillemets sont tirés de ma trame narrative.
} 
curieux, qu'il veut se laisser guider dans l'exploration, partir à l'aventure, etc. Je tiens compte de ces informations et il m'est arrivé de les prendre en note dans mon journal d'atelier.

\subsubsection{Accompagnement artistique}

Ma conception de l'accompagnement artistique concerne avant tout l'écoute, écoute de soi, écoute de l'autre, écoute de l'environnement immédiat. Cette écoute, plus organique que cognitive, est habitée de conscience et traversée de silence sensible. Elle se rapporte à tous les sens, qui éveillés, disponibles, concentrés, ouvrent sur une perception nouvelle, allégée et fertile, relevant d'une sensibilité intuitive et ouverte. Cet accent, mis sur l'écoute sensible, et sur l'écoute du sensible, aurait pour effet de dépolariser l'attention dont l'accent est trop souvent porté sur l'intellect seul, lequel, dès lors, aurait tendance à être envisagé comme unique filtre du réel. Cette forme d'écoute sensible favorise l'accompagnement en libérant la situation des a priori inhibiteurs de créativité.

\subsubsection{Chemin partagé}

Un autre aspect essentiel de ma conception de l'accompagnement artistique est la conscience réciproque d'un chemin partagé : nous serons là l'un pour l'autre et nous nous rendrons, ensemble, à destination. Donc, dans un certain laps de temps, en coordonnant nos rythmes, nous avancerons dans la même direction, vers un but commun. De plus, même si la 
plupart du temps nous vivons le quotidien dans nos espaces respectifs, nous habitons tout de même, en conscience, une période identique et déterminée, celle de l'accompagnement artistique, qui en l'occurrence dans mes ateliers s'étale sur douze semaines, parfois plus lors d'exposition.

Voilà donc formulé l'essentiel de ma conception de l'accompagnement artistique. Un peu plus loin, je préciserai quels sont pour moi les aspects significatifs du processus d'atelier. Mais auparavant, puisque, en tant qu'accompagnatrice, cela est intrinsèquement lié au sens que je donne aux ateliers, il importe que soit quelque peu démystifié aussi le sens du processus d'atelier pour les convives créateurs. Le point suivant traitera de cet aspect.

\subsubsection{Sens du processus d'atelier pour les convives créateurs}

Je tenais donc à enrichir à la fois mon expérience d'atelier et mon expérience de recherche de celles des participants. Bien entendu, au cours des différents ateliers que j'ai offerts, j'ai eu certains témoignages verbaux et écrits me rassurant sur le bien-fondé et l'efficience de ma démarche d'accompagnatrice, mais ce sont en fait des témoignages et des écrits qui ne prennent leur valeur véritable que dans un rapport contextuel ou ponctuel. Toutefois, dans le cadre de ma recherche, il m'importait d'avoir un retour global sur leur expérience d'atelier. C'est pourquoi, de façon informelle, j'ai demandé à quelques-uns d'entre eux de me faire part de l'impact que le processus d'atelier a eu sur eux. On peut retrouver à l'annexe B quelques témoignages. 


\subsubsection{Sens du processus d'atelier pour moi}

Ces ateliers m'auront initiée à la découverte d'un espace neuf qui s'est fondé à la fois sur l'art et sur l'Autre. J'ai offert chacun de ces ateliers comme autant d'invitation au partage et à l'exploration conviviale de cet espace. C'est donc ensemble que nous avons exploré, que nous avons appris un nouveau langage. Nous nous sommes ainsi initiés à une façon novatrice de s'inscrire dans le monde qui rend compte d'une liberté innée en soi. De cette liberté qui par le regard poétique «déstabilise tout ce qui est fixe, dématérialise les formes, décloisonne la vision sociale du réel et sa vision de propriétaire.»(Fintz, 1996, p. 51)

Comme le souligne encore Fintz (1996, p. 52), « la puissance de l'art réside dans le transfert de l'énergie contenue dans la trace qui vibre jusqu'à notre œil ». Ainsi, de l'énergie il en faut! En produire, en dépenser, en recevoir, en partager, en exprimer. Les ateliers sont conçus pour ça. Expression de soi, vibration de l'être, tel est en fait le mouvement spirituel qui les sous-tend, de là leur intitulé, car mon atelier d'exploration du langage plastique non figuratif s'intitule effectivement « Expression de soi - Vibration de l'Être ». Ainsi, restaurer les liens avec son unicité propre, sa singularité, la ressentir, l'exalter, la propulser même, la mirer hors de soi. En regard de tous ces aspects, l'exploration picturale consiste en une expérience dynamique, intensive et exigeante, profondément intime, bouleversante parfois, mais évolutive. Telle que nous la vivons, elle est aussi résistance. Résistance aux formes établies, convenues, sécurisantes. De ces formes trop stables, statiques, figées et stériles. Mais encore, résistance au conforme, à l'attendu et au déjà trop vu. C'est pourquoi l'objet est aboli, et l'image tout autant. Abolie aussi l'idée même de valeur esthétique proposée par d'autres afin de parcourir pour soi seul les sentiers 
de la joie picturale, sans souci de plaire à qui que ce soit ou de répondre à quelque impératif extérieur. Nous sommes dans le lieu infini de la sensibilité esthétique et nous y laissons nos traces, nos traits et nos taches avec cœur et aplomb.

Ce que donne à saisir l'art, c'est le mouvement interne de ce qui est contemplé, c'est de saisir ce qui sous-tend, c'est s'avancer vers plus d'insignifiance, vers l'indifférenciation du sens. Un mouvement spirituel traverse la signification artistique et mène aux limites du sens. (Fintz, 1996, p. 5)

Ce «mouvement spirituel » et cet avancement «vers plus d'insignifiance » sont vécus pleinement dans mes ateliers. Ainsi, se détourner du moi appris et se disposer à désapprendre. Se diriger vers l'aurore de l'être. C'est d'ailleurs ce qui toujours est recherché, partout dans ma vie, et dans le penser qui cherche la non-pensée, et dans le faire qui cherche à ne pas faire. De même dans mes ateliers : on se saisit de l'art en s'en dessaisissant, comme on se réapproprie soi-même en s'abandonnant. Ainsi, participer de ce mouvement : ne pas peindre ce que l'on voudrait, mais plutôt cela même qui se veut peint. Alors, peindre cela qui se veut être peint, pas écrit, pas parlé, pas chanté, pas dansé, mais peint, juste peint par le geste-peintre, sans plus et tout simplement. Peindre, agir le questionnement en même temps qu'il a lieu. Peindre, agir la joie en temps réel. Peindre, agir la frustration à l'instant ressentie, agir l'hésitation quand elle est là. Peindre et être présent en même temps que soi. Dans le mouvement exploratoire que je propose, peindre c'est agir vrai, autrement et maintenant. C'est vivre l'instant en énergie pulsive, rythmique, colorée, vibrante et ondulatoire, tout à la fois. C'est tracer une voie nouvelle qui s'effondre sans cesse sur elle-même dans les sables terriblement mouvants du vivant en soi. Dans 
mon approche artistique, l'énergie de la spontanéité est aussi le nom de l'art. L'énergie du lâcher prise, de l'abandon, de l'accueil, de l'humilité est aussi le nom de l'art. La vibration avant le son, l'art. Le mouvement avant la danse, l'amour avant le geste, le silence avant la parole, l'art. Tout ce qui fait sens, parce que en deçà et au-delà du « sens », ouvre sur l'art. De même, perdre le fil attendu de la ligne droite fait art, comme perdre le sens attendu des mots fait poésie. Tout inconnu qu'on reconnait pourtant, c'est art. Tout ce qu'on ne peut nommer, mais qui pourtant nous nomme, c'est art. Étrange équilibre de l'entre-deux, mouvement incessant de recherche vibrante, comme un point de rencontre évanescent entre le langage pictural spontané et la vibration de l'Être. Le tableau matérialise ce passage insaisissable de ceci à cela qui n'est ni ceci ni cela. Créer les conditions de ce passage, proposer l'ouverture à l'insensé, un chemin vers l'intensité, stimuler le désir de la rencontre inusitée, du faire l'art ensemble, voilà le sens premier de mes ateliers. 


\subsection{Ordre communiqué : synthétiser et formaliser le sens renouvelé de ma démarche d'artiste accompagnatrice}

L'écriture de ce mémoire s'est vécue telle une quête de sens. Une quête qui m'a amenée à me réapproprier en conscience une phase de ma vie totalement dédiée à l'exploration de ma sensibilité artistique. Cette phase aura duré sept ans. Période riche, intense et transformatrice, mais sans contredit éprouvante, bouleversante et déstabilisante. $\mathrm{Au}$ début de mes études, j'entrevoyais l'art comme extérieur à moi. L'art était effectivement quelque chose d'impressionnant vers lequel je devais avancer, d'une façon ou d'une autre je m'y sentais poussée, inspirée, aspirée même. Du plus profond de moi, je tenais à comprendre l'art, son sens historique et sa portée humaine, surtout. C'était grandiose, mais à ce moment-là, l'art me provenait de l'extérieur, de l'histoire, du monde objectif en fait. Puis, le début des ateliers m'aura éclairée sur le fait que l'art ne provient pas de l'extériorité mais plutôt de l'Intériorité. À ce titre, beaucoup plus qu'un courant, qu'un concept, qu'une théorie ou qu'une technique, l'art devenait une dimension de l'Etre. Dès lors, je l'entrevoyais comme un langage transcendant auquel nous avons tous accès, une force multidimensionnelle qui nous habite, une énergie fabuleuse et disponible qui, telle une racine spirituelle, naturelle, innée et vivace, est à même de nous ancrer toujours plus profondément dans notre propre humanité en constant devenir.

Au début des ateliers, et même de ce mémoire, je n'avais pas vraiment les ressources nécessaires pour formaliser cette poétique existentielle qui me traversait de part en part, mais encore, cela se pouvait-il sans risquer d'en altérer l'essence me demandais-je? Je craignais 
en effet que l'intuition poétique ne se trouve amoindrie par une volonté de rationalisation. C'est pourquoi j'étais toujours hésitante et fort ennuyée à la seule pensée de faire transiter mon expérience artistique, organique et intuitive, vers les domaines du cognitif et du rationnel. En fait, je ne savais pas vraiment comment m'y prendre. C'est au cours de l'écriture de ce mémoire, et surtout à son terme, alors que je prenais connaissance des concepts d'autotélisme et d'expérience optimale, dont je parlerai plus loin, que j'ai compris et intégré réellement le fait que l'action et la réflexion (qui implique ici la rationalisation) représentent deux aspects essentiels dans un processus créatif évolutif. Aspects différents, mais tout à fait complémentaires dans leur fonction d'ordonnancement de la conscience. L'un ne nuisant à l'autre d'aucune façon, au contraire, car l'un et l'autre s'harmonisent dans la découverte et l'intégration d'un ordre immanent : l'un, l'ordre acté, le vivre poétique, l'action spontanée, et l'autre, l'ordre dévoilé, l'intégration cognitive, la réflexion. Dans ce processus de recherche, ces deux ordres trouvent conjointement une voie d'intégration à travers l'ordre communiqué. De même, dans mon processus d'atelier, ces deux ordres s'intègrent harmonieusement dans l'esthétisation des œuvres, c'est-à-dire, l'encadrement et l'exposition (formalisation et communication). ${ }^{30}$

${ }^{30}$ Dans l'optique d'établir un parallèle intéressant entre mon schéma ordonné et les fondements structurels des ateliers, l'ordre acté s'apparente donc à l'intervention picturale et l'ordre dévoilé aux moments poïétiques. 


\subsubsection{Expérience autotélique}

Au terme du mémoire, j'ai dédié quelques jours à la lecture de Csikszentmihalyi (2004). Bienheureuse intuition, car c'est en rencontrant la pensée de cet auteur que j'ai été à même d'appréhender toute la teneur de ma démarche artistique des sept dernières années. De même concernant la portée plus spécifique de ce travail de recherche en termes d'ordre et de sens, alors que j'ai réalisé que ces notions s'étaient toujours transposées de façon intuitive dans tous les domaines de ma vie. Je réalisais ainsi que ma démarche artistique de conceptrice et d'accompagnatrice, de même que l'écriture de ce mémoire, entre autres, participaient d'une expérience optimale et autotélique ${ }^{31}$. Ainsi, selon Csikszentmihalyi (2004, p. 79),

La phénoménologie de l'expérience optimale comporte huit caractéristiques majeures: 1) la tâche entreprise est réalisable mais constitue un défi et exige une aptitude particulière; 2) l'individu se concentre sur ce qu'il fait; 3) la cible visée est claire; 4) l'activité en cours fournit une rétroaction immédiate; 5) l'engagement de l'individu est profond et fait disparaitre toute distraction; 6) la personne exerce le contrôle sur ses actions; 7) la préoccupation de soi disparait, mais, paradoxalement, le sens du soi est renforcé à la suite de l'expérience optimale; 8) la perception de la durée est altérée.

À cela, je me permets d'ajouter que, de mon point de vue, j'ai vécu l'expérience optimale aussi comme un phénomène d'intégration qui a concerné tous les aspects de mon

${ }^{31}$ Danielle Boutet a publié un texte éclairant sur le concept d' « autotélisme ». Elle y souligne entre autres que «autotélique vient du grec «autos» (soi-même) et «telos » (but), et se dit d'une chose qui est sa propre raison d'être, son propre but». Re: BOUTET, D. Récits d'artistes, site de recherche sur l'expérience artistique [en ligne] disponible sur: http://www.recitsdartistes.org/carnet/8_autotelisme-autotelique-une-definition, (consulté le 12.08. 2011) 
être, physique, psychique, émotionnel et spirituel. Cette expérience déterminante - étude, atelier, mémoire - m'aura permis en quelque sorte de m'intégrer. De plus, la façon dont culmine mon expérience autotélique contient aussi la notion d'ouverture sur l'altérité. Ces deux aspects d'intégration et d'ouverture sur l'altérité participent donc pleinement de ma définition personnelle de l'expérience autotélique et de ma façon de la vivre. Bref, c'est pour moi une expérience mère qui contient en elle-même de nombreuses autres ramifications, comme autant de branches et de racines qui viennent s'ajouter à un arbre au cours des ans, lui octroyant son ancrage, sa force et son panache.

Ainsi, reprenant les critères de l'expérience optimale ci-haut mentionnés, je dois dire que même si au tout début de mon cheminement artistique j'agissais de façon spontanée, sans plan précis, mue par une étrange pulsion, je n'avais aucun doute que la «tâche entreprise » était réalisable et que j'avais les aptitudes appropriées (même si rationnellement je ne savais pas quelles étaient ces aptitudes, je les pressentais intuitivement). Je demeurais centrée et ma «cible visée », laquelle, quoique vaste et indéterminée dans ses multiples ramifications, était tout de même claire : en savoir davantage sur l'art, sa teneur et sa portée dans l'expérience humaine. À cet égard, j'avais continuellement des réponses, des pistes à suivre. Et même si parfois je croyais m'être égarée, le chemin que je retrouvais était enrichi de tous ces éblouissements spontanés. Je vivais ma vie comme une suite de synchronicités étonnantes. J'expérimentais la "rétroaction immédiate », mais aussi à moyen et long termes. Mon « engagement » était total. Je me sentais profondément concernée dans le fait de me réapproprier, de façon personnelle et originale, ma propre dimension artistique. À cet égard, j'ai toujours travaillé avec assiduité, sans trop me laisser «distraire » de mon but en 
vain, sacrifiant un emploi plus lucratif, et le plus souvent des activités familiales, amicales, sociales et culturelles. Finalement, mon «sens du soi » s'est extraordinairement renforcé à travers chacune des étapes de cette expérience autotélique des sept dernières années, d'autant plus au cours de cette recherche. Et à cet égard, l'itinéraire d'écriture que j'ai créé m'a permis d'ordonnancer un nouveau savoir et de me réapproprier le sens de l'art dans ma vie. Sur ce point, Servan-Schreiber, dans la préface de Csikszentmihalyi, souligne que la conscience de chacun est « la bataille essentielle de ce début de XXIème siècle. » (2005, p. 13). De son coté, Csikszentmihalyi en définit le champ à travers la psychologie de l'expérience optimale qui «porte sur le processus de la recherche du bonheur par la maîtrise de sa vie intérieure. » (Csikszentmihalyi, 2005, p. 13)

Avec l'expérience autotélique (l'expérience optimale), la vie passe à un autre niveau. L'aliénation fait place à l'engagement, l'enchantement remplace l'ennui; le sentiment de résignation est chassé par le sentiment de contrôle. L'énergie psychique n'est pas orientée vers la poursuite de récompenses externes mais est utilisée de façon à favoriser l'épanouissement du soi. (Csikszentmihalyi, 2004, p. 110)

À n'en point douter, des premières traces du portrait de Mickaël aux derniers mots de ce mémoire, ma vie est passée à « un autre niveau ». Ainsi, au terme de cette recherche, à la lumière des propos de Csikszentmihalyi, je peux comprendre que si mes études et mes ateliers me procuraient un tel sentiment de vérité personnelle, c'est parce qu'ils s'actualisaient dans le cadre élargi d'une expérience autotélique et optimale à même d'induire un ordre dans ma conscience. Aujourd'hui, je réalise que c'est avant tout cet 
ordre qui prime dans mon expérience existentielle et que c'est avant tout l'art qui pour moi a fait ordre.

C'est avec Csikszentmihalyi (2004, p. 29) que je conclurai ce point sur le sens renouvelé de ma démarche d'artiste accompagnatrice, qui note encore que

[L]'expérience optimale comporte un certain nombre de composantes dont la présence crée l'ordre dans la conscience et produit ces moments de vie intense que l'individu veut retrouver par la suite.

En ce qui me concerne, mes «moments de vie intense », non seulement veux-je les revivre, mais je veux aussi les partager. C'est d'ailleurs dans cette optique que le mémoire prend tout son sens, c'est-à-dire en me permettant d'accéder aux ressources intérieures qui me rendent apte à créer des dispositifs de rencontre dédiés à l'enrichissement des rapports humains par le biais de l'activité artistique transformatrice (l'expérience de l'art). Déjà, à travers mes ateliers, j'ai expérimenté à quel point la rencontre avec l'autre dans la convivialité créatrice permet à la fois de créer et de se créer. $\grave{A}$ présent, je comprends mieux pourquoi, puisque

[L]'expérience optimale rend le soi plus complexe, et c'est alors qu'il se développe. La complexité résulte de deux processus psychiques: la différenciation, qui implique un mouvement vers l'unicité en se distinguant d'autrui, et l'intégration, son opposé, qui implique l'union à d'autres gens, à d'autres idées et à d'autres entités au-delà du soi. Un soi complexe réussit à combiner ces deux tendances opposées. (Csikszentmihalyi, 2004, p. 71)

À la lumière de ces propos, je peux comprendre que, dans ma pratique intuitive d'atelier, je me suis « différenciée » en découvrant un espace d'accompagnement qui m'est 
devenu propre, mais que j'ai exploré toutefois en m'unissant à «d'autres gens, à d'autres idées et à d'autres entités au-delà du soi ». C'est ainsi que dans l'accompagnement artistique, j'ai été à même de proposer aux convives créateurs l'opportunité de se différencier eux aussi et de s'unifier également à travers le phénomène de la convivialité créatrice et de l'expérience esthétique conscientisée, qui selon moi sont aussi parties prenantes d'une expérience autotélique. 


\section{CONCLUSION}

Pour conclure ma recherche, $\mathrm{j}$ 'ai choisis dans un premier temps de revisiter mes ateliers à la lumière de ce nouveau savoir et de redéfinir succinctement les étapes méthodologiques qui m'y ont conduite.

Expression de soi-vibration de l'Etre

Telle qu'il a été démontré dans la recherche, la convivialité créatrice se présente comme une dynamique de création de groupe. Cette dynamique requiert un accompagnement artistique structuré, sensible et vigilant. Pour mieux vivre la convivialité créatrice, certains aspects sont importants. On y retrouve, dans un premier temps, la procédure d'atelier (les moments clés) qui fait en sorte qu'on plonge d'une manière progressive dans notre intériorité. Vient ensuite la procédure de création, différente de la procédure d'atelier. La procédure de création c'est la manière dont on s'y prend pour créer dans la spontanéité, à l'aide d'inducteurs créatifs que sont entre autres les contraintes et consignes intempestives et l'écoute flottante. Comme troisième aspect générateur de convivialité créatrice, je soulignerai les rapports intersubjectifs, lesquels s'opèrent principalement par le biais du retour parlé de nature poïétique, tant sur les écrits que sur le processus vécu et les œuvres. Quatrièmement, un autre point capital pour mieux vivre la convivialité créatrice est un état d'esprit porteur d'attitudes créatives : le lâcher prise; l'ouverture; l'accueil; la suspension du jugement; la non-comparaison, le partage, etc. Le cinquième point consiste en l'aspect formel, c'est-à-dire comment se présentent les œuvres. 
À et égard, on a pu constater à quel point et dans quelle mesure le koan pictural (voir sections 3.2.2.5 et 3.2.2.6) est partie prenante de l'expérience esthétique vécue en atelier.

Ainsi, la procédure d'atelier, la procédure de création, les rapports intersubjectifs, les attitudes créatives et l'aspect formel sont essentiels dans le phénomène de la convivialité créatrice. La recherche m'aura permis entre autre de définir ces notions fondamentales. En cela, je retrouve ce qui favorise mon travail d'artiste accompagnatrice dans la convivialité créatrice dans le fait d'amener l'autre, le convive, à vivre des expériences esthétiques évolutives et à les conscientiser.

\section{Une méthodologie ordonnée}

Dans cette deuxième partie de ma conclusion, je synthétiserai ici la voie épistémologique, sous tendue par les notions d'ordre et de sens, qui m'a conduite à une meilleure compréhension de ma démarche artistique.

L'autoaccompagnement et l'accompagnement se présentent pour moi en parcours qui s'entrecroisent et s'interpénètrent continuellement. L'autoaccompagnement, c'est un acte vers soi. Cet acte je l'ai accompli à travers mes ateliers et mon projet de maîtrise. Tandis que l'accompagnement, c'est un acte vers l'autre. Cet acte vers l'autre, c'est au travers mes ateliers que je l'ai accompli. Dans l'autoaccompagnement, par mes ateliers et mon projet de maîtrise, j'ai eu la possibilité, de m'accueillir, de m'explorer, de mieux me comprendre, de m'unifier et de me créer. C'est ce qui m'a rendue apte à accompagner 
l'autre, par le fait même à le sensibiliser également à s'autoaccompagner, c'est-à-dire à s'accueillir, à s'explorer, à se comprendre, à s'unifier, à se créer en fait.

Il y a donc là, processus d'intégration et d'unification. Ainsi, la conception et l'animation d'ateliers d'exploration picturale m'aura permis d'intégrer ma dimension artistique, ajoutant en cela à ma sensibilité organique et esthétique. De même, l'écriture de mon mémoire, en revisitant mon vécu et en lui donnant sens, m'aura permis d'unifier mon Être, c'est à dire de faire cö̈ncider mes dimensions physique, émotionnelle, mentale et spirituelle dans une œuvre de sens. C'est au regard de cela que l'art et la création sont devenus pour moi une forme d'entendement du monde. C'est d'ailleurs dans l'optique de projeter cet entendement à l'extérieur de moi, faire sens et le communiquer, que j'ai créé un itinéraire d'écriture ordonné. Dans mon esprit, il ne fait aucun doute que c'est à travers ma méthodologie scripturale que j'en suis arrivée à une meilleure compréhension de moi, de mon cheminement artistique et finalement de l'artiste accompagnatrice que je suis.

Ainsi, lorsqu'il est question d'ordre caché et d'origine dans mon mémoire, il y a référence à la fois, à l'origine de mon cheminement artistique, par le récit; à l'origine de la création des ateliers, par le récit de création; et à l'origine de la recherche, par ma problématique. Il s'opère donc une transposition de la notion de l'ordre : dans mon vécu, dans les ateliers et dans la recherche.

L'ordre acté répond à une impulsion vers le sens, un «mouvement vers». Ce mouvement concerne à la fois l'exploration sur le vif et la réflexion a postériori. C'est dire que, lorsque j'agis et que je réfléchis sur ces mêmes actes posés, je suis dans l'ordre acté. 
Ici aussi l'ordre se transpose : dans les ateliers, l'ordre acté c'est la phase exploratoire et réflexive et, dans mon mémoire, c'est le chapitre 2: De l'exploration à la mise en ordre.

L'ordre dévoilé est une phase d'intégration qui s'opère par la prise de parole écrite ou parlée. Il y a là articulation et conceptualisation. Dans les ateliers, cette phase a lieu à la fin de chaque atelier, mais aussi cette phase d'intégration a lieu après le cycle d'atelier des 11 rencontres hebdomadaires, lors de la synthèse esthétique. Dans le mémoire, c'est le point 3.3 : Ordre dévoilé: articuler et conceptualiser le sens du processus d'atelier.

L'ordre communiqué représente l'étape finale. C'est alors que le sens qui a été formulé à l'étape précédente prend maintenant forme : il sera formalisé. Il s'agit de « faire sens », de créer du sens en fait, et de le rendre dans une forme communicable. Dans les ateliers, cette étape se vit à chaque rencontre : les convives créateurs repartent avec des productions achevées, porteuses de sens, mais aussi avec ce surplus d'Être engendré par l'expérience esthétique conscientisée et le partage convivial. Cette étape du sens formalisé se vit aussi à la fin du cycle d'atelier et également lors de l'exposition publique. Dans mon mémoire, l'ordre communiqué se trouve au point 3.4 : Ordre communiqué: synthétiser et formaliser le sens renouvelé de ma démarche d'artiste accompagnatrice. Cet ordre communiqué consiste également au dépôt final du mémoire et à la communication verbale.

C'est donc en me laissant guider par mon schéma-itinéraire que j'ai été amenée vers une meilleure compréhension de mon parcours artistique. L'écriture du mémoire a fait en sorte que je puisse mettre en sens, conjointement, de un, des pans entiers de ma vie, de deux, mon parcours universitaire en art, et, de trois, ma passion pour l'humain. C'est ce qui 
fait que maintenant, c'est avec davantage de confiance et de conscience que je peux envisager d'apporter, à ma manière propre, ma contribution sociale.

Ce travail de recherche inaugure finalement un nouvel ordre dans ma conscience. Un ordre que l'art a rendu manifeste. Un ordre qui fait sens. Je peux maintenant m'actualiser à partir d'un registre cognitif et sensible beaucoup plus vaste. À cet égard, l'écriture de ce mémoire m'aura aussi permis de me réapproprier, de façon personnelle et originale, ma propre dimension artistique, ce qui logiquement me rend apte à aider l'autre à faire de même. C'est à cet égard un acte de transmission. Cet aspect qualitatif vient conséquemment enrichir ma démarche d'artiste accompagnatrice. Ainsi, une vision nouvelle et un défi stimulant imprègnent maintenant mon advenir : il s'agira de voir comment, à la lumière de l'ordre et de l'expérience autotélique, je peux mettre mon énergie physique, psychique, émotive et spirituelle au diapason de l'autre dans l'optique de lui permettre d'entrer en résonance avec sa propre dimension artistique. Au regard de ceci, j'envisage l'intégralité de ce mémoire comme participant d'un ordre caché qu'il me reviendra de déployer dans l'attention et le respect de tout ce que je pressens, mais que je ne comprends pas encore. 


\section{ANNEXE A \\ ÉTAT DE LA SITUATION}

J'ai effectué une recherche sur Internet afin de m'enquérir de l'offre en termes d'ateliers artistiques au Québec, et qui se rapproche le plus de mes ateliers. Parmi la panoplie de propositions offertes, la plupart se présentent dans une formule formation/expérimentation; expression/découverte de soi; exploration/recherche créative; initiation/perfectionnement. Toutefois, je n'en ai trouvé aucune qui mette l'accent sur un processus artistique exploratoire de groupe dans une optique conviviale tel qu'il se vit dans mes ateliers.

J'ai dénombré les quatre propositions suivantes, assez différentes les unes des autres. Je les ai retenues à la fois pour leur approche exploratoire axée sur le développement de l'Être et pour leur caractère humaniste. J'ai noté succinctement leurs caractéristiques tout en respectant les termes utilisés dans leur approche promotionnelle.

\section{1) LES ATELIERS SPONTANÉS (Québec)}

Ateliers d'expression artistique offerts en contexte communautaire et corporatif. Cadre ludique mais structuré. Approche semi-dirigée, dynamique et intuitive. Ses objectifs : bien-être, développement personnel et ressourcement. www.lesateliersspontanes.com (consulté en avril 2011)

\section{2) LES ATELIERS INFUSARTS (Montréal)}

Ateliers d'expression artistique spontanée par la peinture, le théâtre et l'écriture. Favorise le lien intergénérationnel et l'interaction. L'accent est mis sur le processus de 
création plutôt que le résultat. Des présentations publiques sont organisées. Se donne comme «double mission d'offrir des ateliers d'expression artistique spontanée pour les bienfaits thérapeutiques intrinsèques sur le développement individuel et celui de la collectivité et de faire rayonner le travail créatif des participants hors les murs. » www.linfusart.com (consulté en avril 2011)

\section{3) LES ATELIERS ART NEUF (Montréal)}

Art Neuf, organisme sans but lucratif, partenaire de la direction de la culture, des sports, des loisirs et du développement social de l'arrondissement du Plateau Mont-Royal à Montréal. Son mandat est d'offrir à la population des services de formation, de diffusion et de faire la promotion de la pratique artistique amateur. Plus d'une vingtaine d'ateliers artistiques sont offerts, allant de la danse au théâtre en passant par la peinture, le dessin, le chant et le modelage.

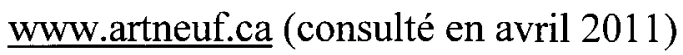

\section{4) LE STUDIO DE CRÉATIVITÉ (Montréal)}

Ateliers d'expression de soi axés sur la (re)découverte de son potentiel créateur par la stimulation de l'imaginaire et l'exploration créative. Les ateliers ont comme objectif de favoriser l'expression de soi, de conscientiser sa richesse intérieure, d'expérimenter la diversité des médiums d'expression, de développer ses habiletés artistiques, de partager son expérience et d'accueillir celle des autres, et, finalement, de se libérer de l'autocensure.

NB : ce site Internet et peut-être même cet atelier semblent temporairement fermés (février 2011), mais je tenais tout de même à le souligner dans cette recension car ce sont ses visées artistiques et humanitaires conjuguées qui se rapprochent le plus des miennes. creativite-montreal.bravehost.com (consulté en avril 2011) 


\section{ANNEXE B}

\section{RETOUR DES PARTICIPANTS}

\section{1) Retour de Normand}

Ce processus d'atelier a été transformateur pour moi dans le sens qu'il a permis de découvrir que je pouvais créer en laissant aller mon imagination avec confiance. J'ai dû apprendre à sortir des sentiers battus, à faire confiance et à me faire confiance. Te faire confiance d'abord, puis faire confiance au groupe dans lequel je participais. Ne pas craindre le jugement des autres et recevoir leurs opinions avec ouverture. Ce fut une expérience riche, intense et étonnante qui m'a permis de m'éloigner des structures rigides et conventionnelles dans lesquelles j'étais à l'aise, pour m'en aller hors de ma zone de confort, vers des espaces totalement inconnus. Cette découverte, importante pour moi, m'a permis de comprendre davantage mon fonctionnement personnel en territoire inconnu. Tout cela, je crois, fut le résultat de la façon dont l'accompagnement (sic) fut réalisé, entre autres dans mon rapport au groupe qui fut bénéfique pour moi car c'est ce rapport qui m'a donné une bonne part de confiance et d'estime personnelle. L'accompagnement reçu lors de ces ateliers fut assez particulier. Encouragements à l'exploration et à la découverte, incitations à l'expérimentation, sécurisation face aux résultats obtenus, mises en situation diverses et variées. Bref je me suis senti stimulé, tout en étant soutenu et écouté dans ce que je vivais.

J'avais suivi quelques cours de peinture à l'huile consistant essentiellement à reproduire un modèle, surtout des paysages. Ce fut l'occasion d'apprendre le mélange des couleurs et différentes techniques de peinture à l'huile. Le résultat visé : une toile représentant de façon assez exacte le modèle choisi. C'était une sorte de démarche artistique pour moi, très satisfaisante pendant une certaine période. Mais le processus 
d'atelier m'a fait découvrir autre chose : exprimer un ressenti face à une photo par exemple, saisir le mouvement, l'intensité, exprimer l'effet d'un sujet sur moi-même, découvrir...Laisser aller mon imagination et produire des formes colorées, quelquefois énigmatiques, parfois en résonance avec mon état d'âme, mais toujours accompagnées d'un grand étonnement et d'une satisfaction imprévue.

Je crois que ce processus artistique m'a permis une plus grande ouverture sur ce qu'est l'art. Un tableau pour moi ne s'est plus jamais regardé de la même façon. Et je crois maintenant qu'une production peut être très significative pour quelqu'un, très intense, alors que pour d'autres, elle les laisse froid. Et c'est correct ainsi. Je serais beaucoup moins enclin à dévaloriser telle ou telle production ou à la juger.

Normand

\section{2) Retour de Nadine}

Bonjour Andrée,

Je n'ai pas vraiment de temps pour élaborer un beau grand texte de mon expérience, mais je veux quand même prendre quelques minutes pour toi et le beau travail que tu fais!

Alors en gros :

Cette expérience a été très certainement transformatrice, mais difficile de cibler précisément en quoi. Cela se passe à un niveau subtil, difficilement palpable puisque c'est au niveau de l'inconscient.

Je la définirais comme étant un processus qui m'a permis de renouer un contact intime avec ma créativité plastique et l'inspiration spontanée de l'écriture. Je dis bien processus puisque j'ai senti à la suite des ateliers un appel à rester ouverte à moi-même, à mon instinct créateur. 
J'ai utilisé cette approche pour moi et mes enfants, pour nous permettre de laisser libre cours à notre inconscient sans barrière ni retenue, pour nous permettre d'exprimer des non-dits par la créativité plastique, de partager et d'être séduit ensemble par la magie de l'art, les mêmes effets que le groupe produisait lors des ateliers.

Le fait d'être bien guidée, bien accompagnée, me permettait d'être dans un total abandon, une confiance sans équivoque, qui me donnait accès à mon pouvoir créateur sans que mon mental modérateur ne vienne faire abstraction.

Bref, une belle expérience enrichissante tant au point de vue humain qu'artistique qui permet de se découvrir et de découvrir l'autre sous un angle pictural, intemporel et puissant.

Nadine

\section{3) Retour de Martine}

Je dis Oui à la Terre tremblante que je sentais sous moi lors de mes premiers cours. Cette terre qui me forgeait dans ses mêmes labours depuis tant de décennies. Mouvement interne qui permute le changement.

Je regarde, étrangetés qui vont sortir de moi, oui ce que j'ai mis tant de temps à bâtir dans des mondes connus. Construire, élaborer, vivre selon un prisme audacieusement façonné par mes expériences, mes certitudes rassurantes, mes peurs précieusement écoutées, mes scénarios logiquement mis en scène par des émotions rêvées...Je l'ai été, mais entrer dans ce « miroir de papier » m'a doucement transportée et amenée à dépasser la fine pellicule du connu. Entrer dans l'autre partie du décor de moi-même, couper le ruban, inaugurer une nouvelle partie de moi longtemps cachée dans l'ombre. L'ombre sera toujours là car comment être dans la Lumière s'il n'y a pas d'ombre. Voir cette ombre, l'aimer, la désirer pour ne faire qu'un avec la Lumière. Enfin, une union amoureuse de ses parties. 
La joie de découvrir la plupart du temps les yeux fermés, les lignes qui naissent joyeusement sous le geste. Où était-elle cachée pour n'en avoir si peu tenu compte ? Elle vivait dans l'admiration chez les autres.

L'atelier a été un véritable plaisir de plénitude : je me remplis enfin de moi-même. $\mathrm{Nul}$ besoin des autres car je sors moins, peu de contacts superficiels ou pour combler un vide. L'échange naît d'un véritable désir de rencontre, non pour tuer l'ennui et le vide.

Une douceur face à moi-même, un nouvel accueil de ce qui est là. Un geste qui naît et qui vit, grâce à la VIE (sic). Nulle angoisse de l'avenir, juste la continuité de l'instant.

Je me perçois plus comme une entité : les « amoureux » ont fait le lien entre eux. Ce geste continu se pose partout dans mes rapports, dans ma vie en général comme si ce que je bloquais avec tant d'ardeur m'était disponible peu importe ce que les gens en diront.

Texte tel que lu lors du dernier atelier de Andrée Forget du 22 avril 2010 Martine

4) Retour de Rébecca

Une grande part de mon cheminement est due à ta présence et à ton accompagnement dans cette démarche. Je suis privilégiée d'avoir fait cette belle rencontre, tu es une de ces personnes qui a fait une différence dans ma vie! Merci très sincèrement Andrée!

Rébecca 


\section{BIBLIOGRAPHIE}

André, A. Cifali, M. (2007). Écrire l'expérience : vers la reconnaissance des pratiques professionnelles. Paris : PUF.

Bruneau, M. Villeneuve, A. (2007). Traiter de recherche création en art. Québec: PUQ.

Cameron, J. (2004). L'art pratique de la créativité: le pèlerinage de l'être créateur. Montréal : Éditions du Roseau.

Cifali, M. Théberge, M. Bourassa, M. (dir.) (2010). Cliniques actuelles de l'accompagnement. Paris : L'Harmattan.

Csikszentmihalyi, M. (2005). Vivre : la psychologie du bonheur. Paris : Robert Laffont. ( $1^{\text {iere }}$ édition 1990).

Delamotte, R. Gippet, F. Jorro, A. Penloup, M-C. (2000). Passages à l'écriture: un défi pour les apprenants et les formateurs. Paris : PUF.

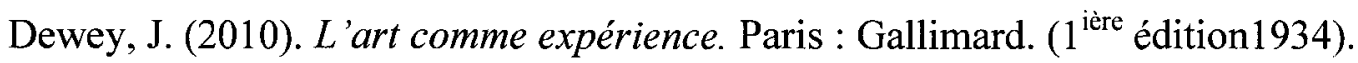

Edwards. B. (1979). Dessiner grâce au cerveau droit. Bruxelles: Pierre Mardaga éditeur.

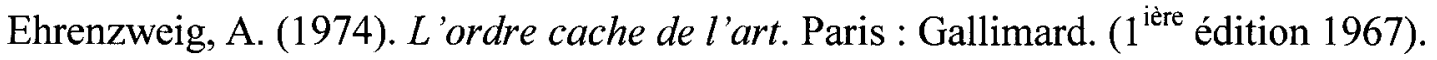

Fintz, C. (1996). Expérience esthétique et spirituelle chez Henri Michaux. Paris: L'Harmattan.

Levine, S.K. (1992). Poiesis: the language of psychology and the speech of the soul. London and Philadelphia: Jessica Kingsley.

Nolin, D. (2008). L'art comme processus de formation de soi. Paris: L'Harmattan. 
Pineau, G. Legrand, J.-L. (2007). Les histoires de vie. Paris : PUF (1 ${ }^{\mathrm{ière}}$ édition 1993).

Rivard, Y. (2010). Une idée simple. Montréal : Boréal.

Robillard, Y. (1998). Vous êtes tous des créateurs ou le mythe de l'art. Montréal : Lanctôt.

Shusterman, R. (2007). Conscience du corps : pour une soma-esthétique. Paris-Tel Aviv : Éditions de L'Éclat.

Souriau, É. (2010). Vocabulaire d'esthétique. Paris : PUF.

Thérien C. Valéry et le statut "poïétique » des sollicitations formelles de la sensibilité, Les études philosophiques 2002\3, $\mathrm{n}^{\circ} 62$, p. 353-369.

Vézina, J.-F. (2001) Les hasards nécessaires. Montréal : Les Éditions de l'Homme.

\section{Sites Internet consultés :}

BOUTET, D., http://www.recitsdartistes.org/

http://www.larousse.fr

http://www.granddictionnaire.com

http://dictionnaire.reverso.net 